\title{
CATALYSIS AND INHIBITION OF MYCOBACTERIUM TUBERCULOSIS METHIONINE AMINOPEPTIDASE
}

\author{
BY \\ (C)2010 \\ Jingping Lu \\ B.S., East China Normal University, 1998 \\ Submitted to the graduate de gree program in Molecular Biosciences \\ and the Graduate Faculty of the University of Kansas \\ in partial fulfillment of the requirements for the degree of \\ Doctor of Philosophy
}

Committee members:

Chairperson - Mark L. Richter

$\overline{\text { Chairperson - Qi-Zhuang Ye }}$

Roberto N. De Guzman

Krzysztof Kuczera

Emily E. Scott

Date defended 5/24/2010 
The Dissertation Committee for Jingping Lu certifies

that this is the approved version of the following dissertation:

\title{
CATALYSIS AND INHIBITION OF MYCOBACTERIUM TUBERCULOSIS METHIONINE AMINOPEPTIDASE
}

Committee members:

\author{
Chairperson - Mark L. Richter \\ $\overline{\text { Chairperson - Qi-Zhuang. Ye }}$ \\ Roberto N. De Guzman \\ Krzysztof Kuczera \\ Emily E. Scott
}

Date approved:

$05 / 25 / 2010$ 


\begin{abstract}
Tuberculosis, caused by Mycobacterium tuberculosis, is the leading cause of death due to infectious disease. Now, the prevalence of multidrug-resistant and extensively drug-resistant $\mathrm{TB}$, and the emergence of co-infection of TB and HIV have highlighted the need for new antibiotics with novel mechanisms of action.

Methionine aminopeptidase (MetAP) is a ubiquitous enzyme found in both prokaryotic and eukaryotic cells and carries out an important cotranslational modification of newly synthesized proteins. The MetAPs can be divided into type I and type II based on the existence of an insert in the catalytic domain. Prokaryotic cells have only one type of MetAP, either type I or type II; encoded by a single gene. MetAP is essential for cell viability, which is demonstrated by gene deletion experiment in E.coli and Salmonella typhimurium. Therefore, MetAP is a promising target for developing novel drugs against bacterial infection, including TB-causing drug resistance bacteria.

Two genes, mapA and mapB, were found in Mycobacterium tuberculosis H37Rv. They encode two type I MetAP enzymes, MtMetAP Ia and MtMetAP Ic, respectively. Both MtMetAP proteins were over-expressed and purified in homoge neity as apoenzyme. Biochemical characterization using a fluorogenic substrate (Met-AMC) was carried out with bo th MtMetAP Ia and MtMetAP Ic.

Both MtMetAPs can be activated by divalent metals, including Ni(II), Co(II), Mn(II) and Fe(II). Ni(II) is the best activator for both MtMetAPs, followed by Co(II) . $\mathrm{Mn}(\mathrm{II})$ and $\mathrm{Fe}(\mathrm{II})$ are the least efficient to activate MtMetAP Ia and MtMetAP Ic, respectively. Metal titration assays were used to determine the metal binding affinity to each MtMetAP. In both MtMetAP Ia and MtMetAP Ic, Co(II) and Fe(II) are the tightest
\end{abstract}


binding metals, as indicated by their smallest $K_{d}$ values. $\mathrm{Mn}$ (II) gives the weakest binding in MtMetAP Ia and Ni(II) shows a weakest binding to MtMetAP Ic.

Grow th complementation experiments were employed to evaluate the cellular function of MtMetAP in the E. coli that had an amber mutation in the chromosomal EcMetAP gene, and a pBAD plasmid, which encod ed a suppressor tRNA to suppress the lethal effect of the amber mutation. The existence of glucose or arabinose in the culture medium could suppress or express the tRNA respectively, therefore result the death or survival of the E. coli, respectively. The plasmid-expressed MtMetAP Ic in the amber mutant rescued the $E$ coli from death and supported cell growth.

A set of inhibitors with selectivity for different metalated MetAPs were tested on both MtMetAPs. For MtMetAP Ib, all tested compounds retained their inhibitory activities and metal selectivity. However, in MtMetAP Ia, the Co(II)-, Mn(II)- and Fe(II)selective inhibitors did not show inhibition. Only Fe(II)-selective inhibitors retained their inhibition, whereas they lost their metal selectivity.

An amino acid sequence alignment suggested some differences in the active sites between MtMetAP 1a and MtMetAP Ic. A homology model of MtMetAP Ia based on MtMetAP Ic structure was generated. A similar active site is observed in this virtual structure of MtMetAP Ia. Given the size of the tested compound library, the failure to find an inhibitor specific for MtMetAP Ia may be due to the limited number of compounds in the library. Screening of a compound library consisting of a larger number of molecules with more structural diversity will possibly identify inhibitors for MtMetAP Ia. 
The inhibitors of MtMetAP Ic were further tested for their inhibition on cellular growth. The fact that only the Fe(II)-form selective inhibitors inhibited the cellular MtMetAP Ic activity and inhibited the MtMetAP Ic-complemented cell growth, suggested that $\mathrm{Fe}(\mathrm{II})$ was the native metal used by MtMetAP1c in an E. coli cellular environment. X-ray structures of MtMetAP Ic in complex with three metalloform-selective inhibitors were analyzed. The results demonstrated different binding modes and different interactions with metal ions and active site residues for these inhibitors. The MtMetAP1c inhibitors with metalloform selectivity are potential leads for antitubercular drugs.

Understanding the catalytic mechanism and inhibition of the mycobacterial MetAP is an essential step towards discovering and developing effective MetAP inhibitors as therapeutics. The compounds with potent inhibition and high metal selectivity toward MtMetAP may be therapeutically useful for improved TB treatment. 


\section{ACKNOWLEDGEMENTS}

First and foremost, I would like to express my deepest gratitude and acknowledge my advisors, Dr. Ye and Dr. Richter, for giving me the opportunity and freedom to do research and pursue my degree.

I do not know how I can possibly express my appreciation for Dr. Ye. I am extremely fortune to be offered the opportunity to work with him. In the past three years, Dr. Ye has given me invaluable support, encouragement, and guidance. This research would not have proceeded this far without his expertise. He has offered me the great privilege to learn and to interact with multi-disciplinary groups, which indeed made my graduate study a very precious experience.

I also would like to acknowledge Dr. Richter for his continuous support and encouragement. He has been very supportive all the time. His support helped my move to Dr. Ye’s lab to continue my study. He has provided suggestions and advice for my research. He has always helped me out whenever I was required to comply with a miscellaneous policy set for international students. If not for his help, I would never be able to finish my degree.

I am very grateful to all my current and previous committee members, Dr. De Guzman, Dr. Kuczera, Dr. Scott, Dr. Picking and Dr. Lamb. I am not a good student; thank you all for your patience and commitment to my development to become a qualified Ph.D. I am very for tune to have known you in my life when I was seeking training in Biochemistry and Biophysics. I would like to specially thank Dr. Scott for her continued kindly guidance and mentoring. She is a constant source of inspiration. 
I also want to thank all the colleagues in Dr Ye’s lab. They are Hai Yuan, Sergio Chai, Sarah Hudon, Xiuhua Yuan, Wenlong Wang, Hongzhen He, and Qi Zhang. I would like to thank my friends Yang Wang, Qianyi Luo, Xingxian Gu, and Daniel Zhang for their help over my graduate school career.

Last, I would like to thank my parents for their support and consideration. They have always been the source of motivation and courage for me in my life. Without their encouragement and firm belief in me, I would never have achieved this. I thank them for giving me the freedom to pursue my goal. I thank them for their uns elfish love and their strong suppo rt that I can always lean on. 


\section{Table of Contents}

CHAPTER 1 INTRODUCTION:METHIONINE AMINOPEPTIDASES IN ANTI-

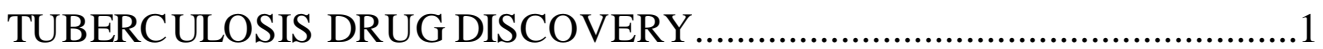

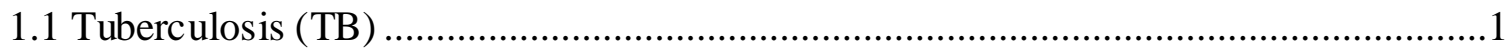

1.1.1 History of tuberculosis .....................................................................................

1.1.2 Pathogen of tuberculosis ...................................................................................

1.1.3 Pathogenesis and transmission of tuberculosis .................................................

1.1.4 Drugs used in chemotherapy of tuberculosis .......................................................6

1.1.5 The challenge encountered in anti- TB drug discovery .......................................

1.2 Methionine aminopeptidase .....................................................................................10

1.2.1 Methionine aminopeptidase family ………………........................................10

1.2.2 Structure of methionine aminopeptidase ............................................................11

1.2.3 Catalys is of methionine aminopeptidase ......................................................... 13

1.2.4 Metal activation of methionine aminopeptidase.................................................18

1.3 Methionine aminopeptidase implication in anti-TB drug discovery ...........................21

1.3.1 Methionine aminopeptidase in Mycobacterium tuberculosis ..............................21

1.3.2 MtMetAPs as the potential targets for anti-TB drug ..........................................21

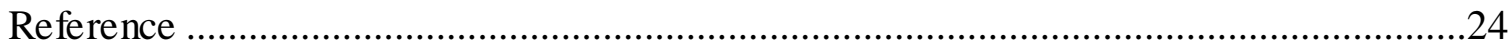

CHAPTER 2 BIOCHEMICAL CHARACTERIAZATION OF METHIONINE AMINOPEPTIDASE Ia IN MYCOBACTERIA TUBERCULOSIS ............26

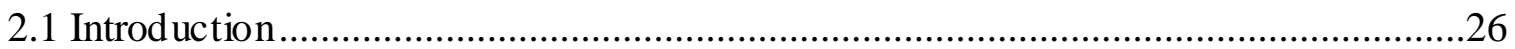

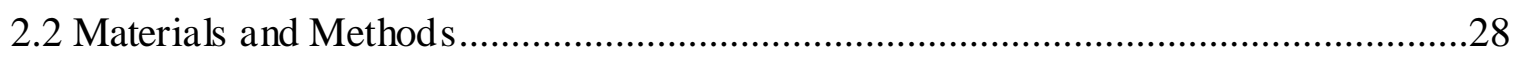

2.2.1 Cloning of MtMetAP Ia into p GEMEX-1 plasmid ..............................................28

2.2.2 Re-cloning of the mapA gene into pET28a plasmid ............................................29

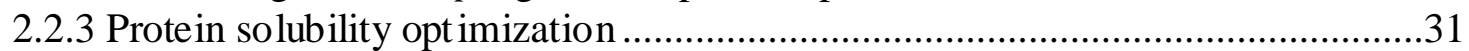

2.2.4 Over-expression and p urification of His MtMetAP Ia ............................................33

2.2.5 Untagged MtMetAP Ia prepareation and confirmation of removal of His-tag ....34

2.2.6 Metal activation of HisMtMetAP Ia ...................................................................35

2.2.7 Kinetic measurement of different metallo form His MtMetAP Ia ...........................36

2.2.8 IC $_{50}$ determination with different metallo form of HisMtMetAP Ia .......................38

2.2.9 Co-crystallization of His MtMetAP Ia and MtMetAP Ia with inhibitors ..............38

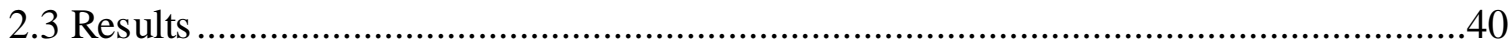

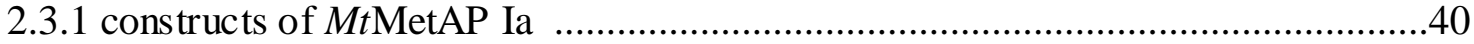

2.3.2 Expression and purification of HisMtMetAP Ia protein..........................................42

2.3.3 Activation of HisMtMetAP Ia apoe nzyme by divalent metals................................42

2.3.4 K inetic measurement of different metalloform His MtMetAP Ia ...........................48

2.3.5 IC50 determination with different metallo form MtMetAP .....................................50

2.3.6 Co-crystallization of MtMetAP Ia with inhibitors...................................................52

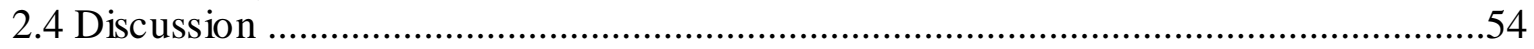

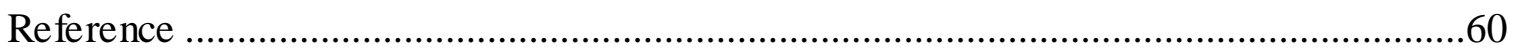


3.1 Introduction

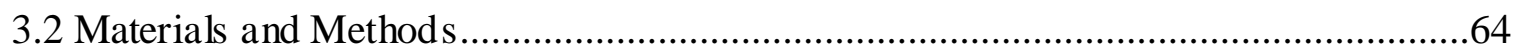

3.2.1 Cloning of MtMetAP Ic into p GEMEX-1 plasmid ......................................64

3.2.2 Over-expression and purification of MtMetAP Ic ...........................................64

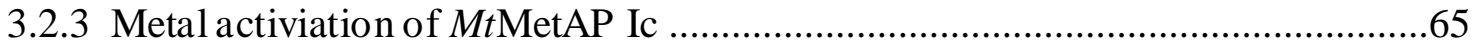

3.2.4 Kinetics measurement of different metalloform MtMetAP Ic .........................66

3.2.5 $\mathrm{IC}_{50}$ determination with different metalloform of MtMetAP Ic ........................67

3.2.6 Complementation of the essential function of EcMetAP with MtMetAP Ic in E.coli

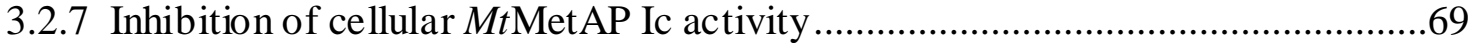

3.2.8 Inhibition of MtMetAP Ic-complemented E.coli growth .................................... 70

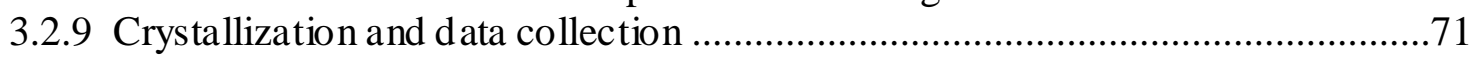

3.2.10 Structure solution and refinement ........................................................... 71

3.2.11 Identification of quaternary structure of MtMetAP Ic using s ize exclusion

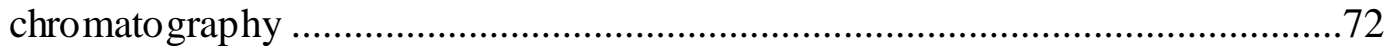

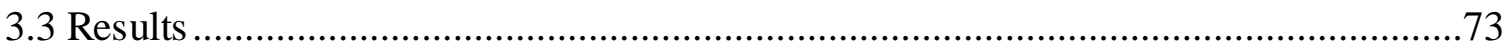

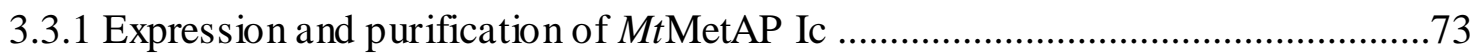

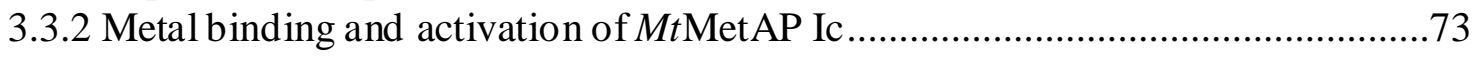

3.3.3 Kinetic characterization of purified MtMetAP Ic ............................................77

3.3.4.Functional complementation of EcMetAP I in E.coli growth by MtMetAP Ic.....77

3.3.5 Metalloform-selective inhibition of purified MtMetAP Ic and the enzyem in an

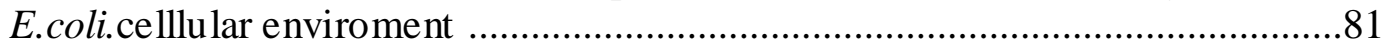

3.3.6 Growth inhibition of MtMetAP Ic-complemented E.coli cells ............................83

3.3.7 Co-crystallization of MtMetAP Ic with inhibitors .............................................84

3.3.8 Identification of quaternary structure of MtMetAP IC using size exclusion

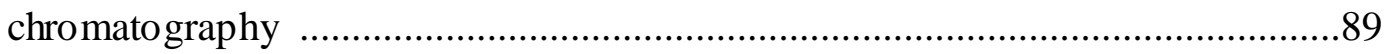

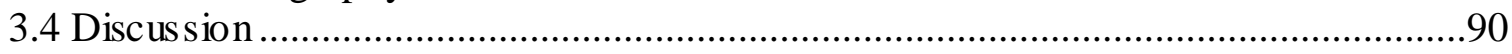

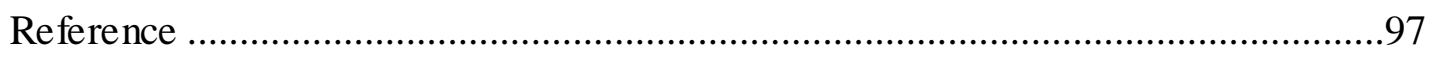

CHAPTER 4 CONCLUSIONS AND FUTURE PLANS ..........................................100

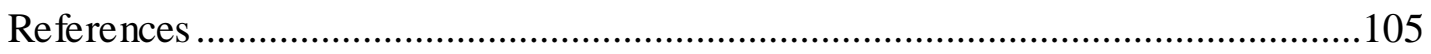




\section{List of Figures}

Figure 1-1 Mycobacterium tuberculosis .................................................................2

Figure 1-2 Cell wall of Mycobacterium tuberculosis .....................................................4

Figure 1-3 Domain architechture of Methionine Aminopeptidase..................................12

Figure 1-4 Crystal structures of EcMetAP I,PfMetAP IIa and HsMetAP IIb ..................12

Figure 1-5 The dinuc lear metal centers and the amino acid residues in EcMetAP I, PfMetAP IIa and HsMetAP IIb................................................................14

Figure 1-6 Proposed reaction mechanism of dimetalated EcMetAP I ...........................16

Figure 1-7 Proposed reaction mechanism of monometalated EcMetAP I .......................17

Figure 1-8 Crystal structure of MtMetAP Ic (PDB ID: 1 YJ3) .....................................22

Figure 2-1 Calculation of $K_{m}$ and $K_{c a t}$ values using non linear regression curve fitting based on Michaelis-Menten equation ...........................................................37

Figure 2-2 Calculation of $\mathrm{IC}_{50}$ using non-linear curve fitting ........................................39

Figure 2-3A Overexpression of HisMtMetAP upo n IPTG ind uction ..............................41

Figure 2-3B Optimization of over-expression of MtMetAP Ia by changing the composition

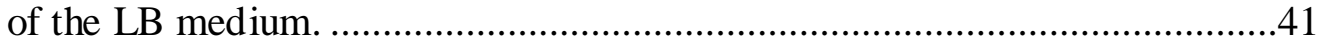

Figure 2-4 The purification of His MtMetAP Ia ......................................................43

Figure 2-5 Metal activation of (A)HisMtMetAP Ia and (B) untagged MtMetAP Ia ........45

Figure 2-6 Calculation of the apparent $K_{d}$ of different metalloforms of MtMetAP Ia ....46

Figure 2-7 Removal of His-tag from HisMtMetAP Ia confirmed by Western blot .........47

Figure 2-8 Calculation of the $K_{m}$ of different metalloforms of MtMetAP Ia by using no linear regression curve fitting ba sed on Michaelis-Menten equation .............49

Figure 2-9 Structure-based sequence alignment of EcMetAP, MtMetAP Ia and MtMetAP EcMetAP I, MtMetAP Ic and virtual MtMetAP Ia

Figure 2-10 Ribbon drawing of the 'pita-bread' domain fold existing in EcMetAP, MtMetAP Ic, and homology model of MtMetAP Ia based on MtMetAP Ic structure.

Figure 3-1 Conditional control of growth of E.coli amer mutant...................................68

Figure 3-2 The purification of MtMetAP Ic ...............................................................74

Figure 3-3 Activation of MtMetAP Ic apoenzyme by divalent metals ...........................75

Figure 3-4 Calculation of the apparent $K_{d}$ of different metalloforms of MtMetAP Ic by using a MIBS model ............................................................................77

Figure 3-5 Calculation of the $K_{m}$ values of different metallo forms of MtMetAP Ic .........78

Figure 3-6 Complementation of EcMetAP I by MtMetAP Ic .....................................80

Figure 3-7 Structure of MtMetAP Ic in the Mn(II)- for m in complex with the $\mathrm{Mn}(\mathrm{II})$ form selective inhibitor 4.

Figure 3-8 Structures of MtMetAP Ic in the Ni(II)- form in complex with the Co(II)- and $\mathrm{Ni}(\mathrm{II})$ - form selective inhibitors $\mathbf{7}$ and $\mathbf{8}$

Figure 3-9 Identification of quaternary structure of MtMetAP Ic using Superdex 75 ......91

Figure 4.1 Complementation of EcMetAP function by MtMetAP1a ... ..............102 


\section{List of Tables}

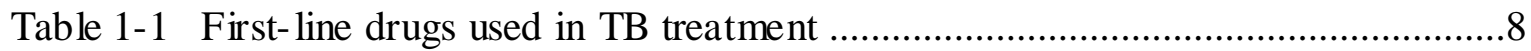

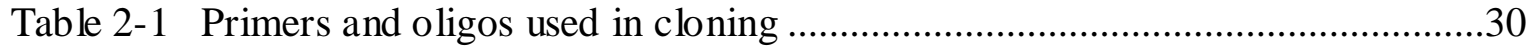

Table 2-2 Medium recipes used in HisMtMetAP Ia solubility optimization test..............32

Table 2-3 Comparison of metal activation of HisMtMetAP Ia and MtMetAP Ia .............46

Table 2-4 Kinetic measurement of HisMtMetAP Ia.....................................................49

Table 2-5 Inhibition of enzymatic activities of purified MtMetAP Ia............................51

Table 2-6 Summary of MtMetAP Ia initial crystallization screens ...............................53

Table 3-1 Activation of MtMetAP Ic by different metals ............................................76

Table 3-2 Kinetic measurement of MtMetAP Ic .........................................................78

Table 3-3 Inhibition of enzymatic activities of purified and cellular MtMetAP Ic and inhibition of cell growth of MtMetAP Ic-complemented E.coli by metalloform-selective inhibitors ...............................................................82

Table 3-4 X-ray data collection and refinement statistics ............................................85

Table 4.1 Comparison of Kinetic measurement of HisMtMetA Ia and MtMetAP Ic ......102 
Page left intentionally blank 
Page left intentionally blank 


\section{CHAPTER 1}

\section{INTRODUCTION: METHIONINE AMINOPEPTIDASES IN ANTI-TUBERCULOSIS DRUG DISCOVERY}

\subsection{Tuberculos is (TB)}

\subsubsection{History of tuberculosis}

Tuberculosis (TB) is a deadly pulmonary disease caused by Mycobacterium tuberculosis in humans. The history of TB can be backdated to ancient Egypt since the sign of TB infection was found in the fragments of spinal columns in mummies from $2400 \mathrm{BC}$. The terms of consumptions, phthisis, scrofula, Pott's disease, and the White Plague had been used to refer to tuberculosis throughout history without knowing the exact cause of the disease. In 1882, Dr. Robert Koch revealed the bacterium that caused TB, which advanced the understanding of TB. The chest X-ray enabled physicians to diagnose and track the disease. In the following years until the twentieth century, the sanatorium movement, a medical program that involved diet, rest and medical treatment, began in Europe and spread to the U.S, and greatly contributed to the decline of the incidence and fatality of TB. As the century progressed, the BCG vaccines from Mycobacterium bovine and new antibiotics were used for TB treatment. Particularly, the discovery of streptomycin, the first antibiotic effective against $M$. tuberculosis, was considered as the beginning of the modern era of TB treatment. Combination therapy with isoniazid and rafampcin has significantly reduced the incidence of TB.

However, the steady decline of TB incidence began to stop and even started to reverse since the middle of the 1980s. It was mainly due to the rise of multidrug-resistant (MDR) $M$. tuberculosis strains, and the emergence of co-infection with HIV. According to the data released from WHO in March 2010, in some areas of the world, one in four people with TB have MDR 

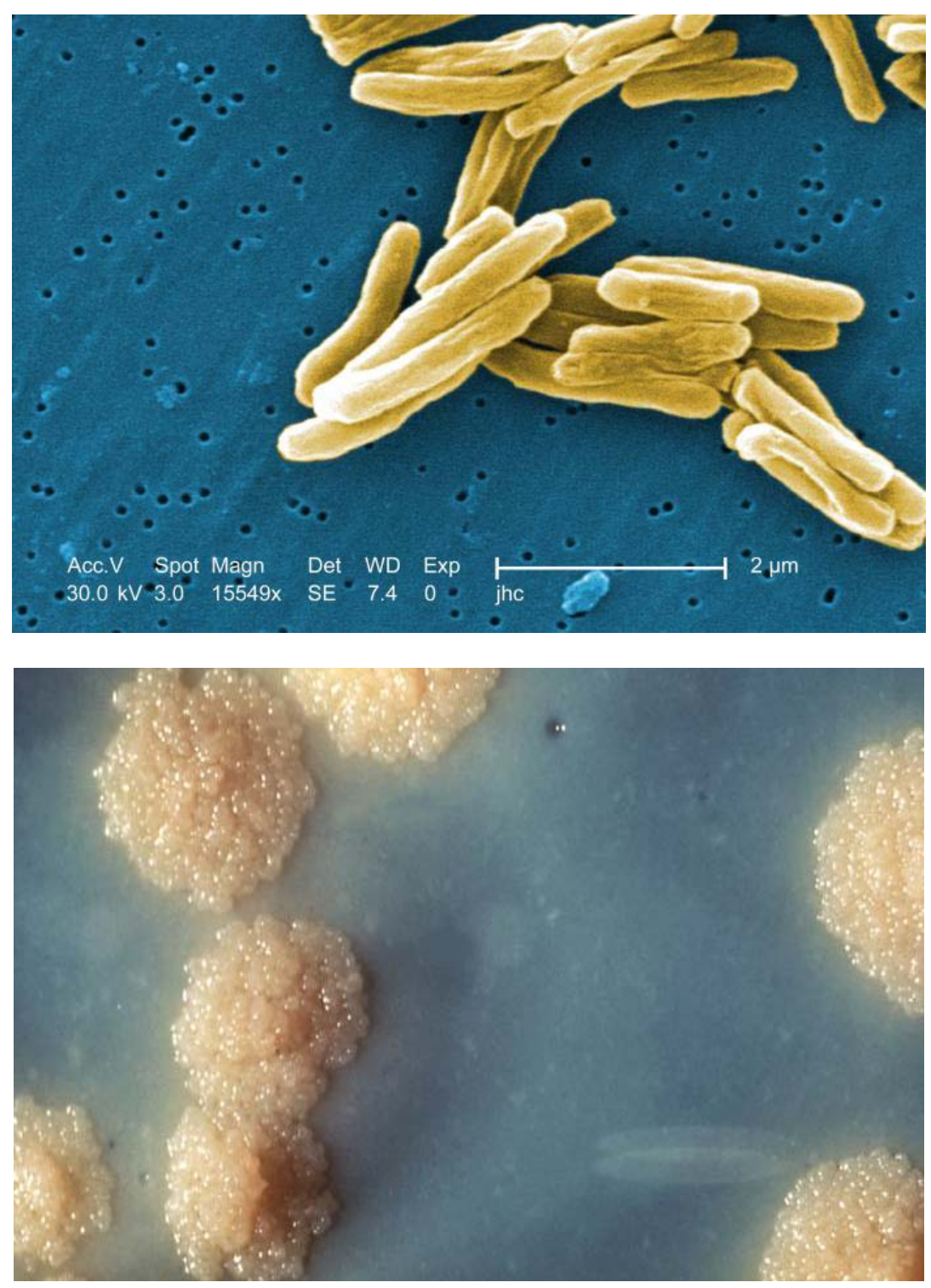

Figure 1-1 Mycobacterium tuberculosis

A) Mycobacterium tuberculosis under scanning electron microscopy. Magnification $15549 \times$, M. tuberculosis is rodshaped, 2-4 $\mu \mathrm{m}$ in length and 0.2-0.5 $\mu \mathrm{m}$ in width.

B) Mycobacterium tuberculosis colonies formed in the Middlebrook's medium.

Both pictures are from the website of Center for Disease Control 
TB. This poses a tremendous challenge for TB treatment as the standard drugs currently being used show much less effect on the disease. Therefore, developing new and highly effective antiTB medicines with novel mechanisms is essential to address the emergence of MDR TB.

\subsubsection{Pathogen of tuberculos is}

The etiologic agent of TB in humans is Mycobacterium tuberculosis. It is a Gramresistant, non-motile, and rod-shaped bacterium. It is a relatively large bacterium as the rods are 2-4 micrometers in length and 0.2-0.5 micrometers in width. Other than in humans with TB infection, M. tuberculosis is usually found in water and soil, and grows under anaerobic conditions with a slow generation time of 15-17 hours. When it is cultured in a Midd lebrook's medium [1], it forms visible white or light yellow colonies after 4-6 weeks (Figure 1-1). The distinctive serpentine cords can be observed in the laboratory grown colonies because of the tendency of colonies to aggregate. M. tuberculosis is an obligate aerobe. For this reason, the invading M. tuberculosis in hos ts is always found in the upp er bronchiole. The bacterium can also survive inside cells with slow growth rates, such as macrophages, which contributes to their virulence.

M. tuberculosis has a special cell wall with a high content of lipids. It is composed of mycolic acid/mycolate, and a peptidoglycan_layer connected by polysaccharide (Figure 1-2). The extreme hydrophobic cell wall contributes to the impermeability and resistance to antimicrobial agents, the resistance of killing by acidic or alkaline agents in an intercellular or extracellular environment, and the resistance to lysosomal delivery after being taken into macrop hages. Therefore, disruption of the M. tuberculosis cell wall, particularly interfering with the synthesis 


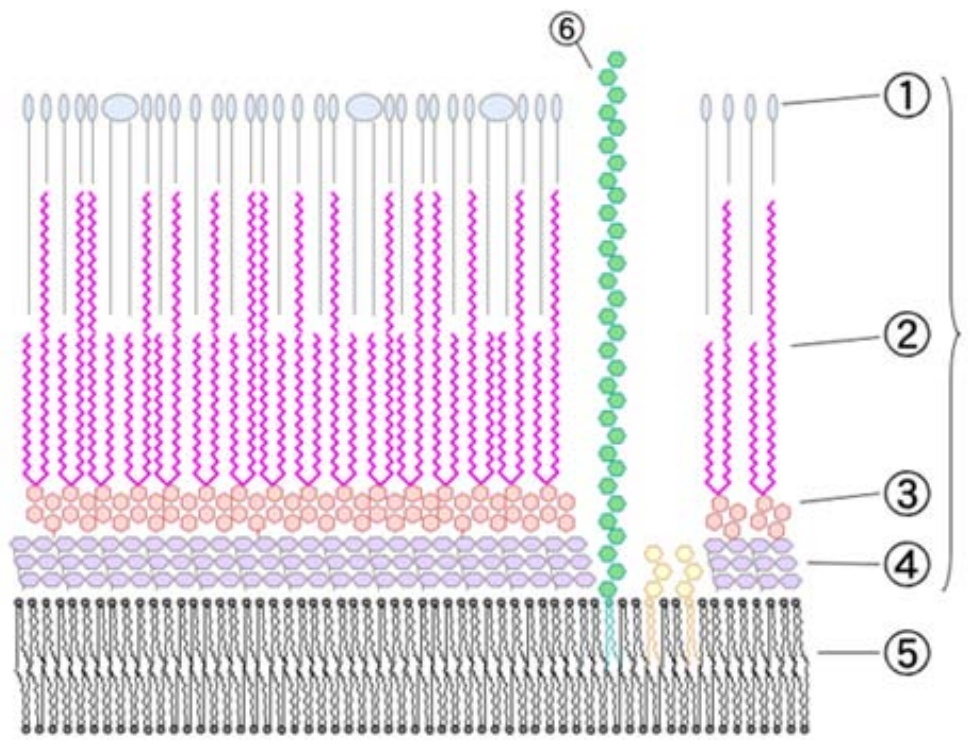

Figure 1-2 Cell wall of Mycobacterium tuberculosis.

M. tuberculosis has a cell wall with high lipid content above $60 \%$. It is made of mycolic acid/ mycolate, and a peptidoglycan layer, connected by polysaccharide and arabnogalactan. (1) outer lipid (2) mycolic acid/ mycolate (3) polysaccharide (4) peptidoglycan (5) plasma membrane (6) lipoarabinomannan (LAM). 
of virulent factors in cell membrane components, is the main strategy of the drugs currently used for TB treatment.

\subsubsection{Pat hoge nesis and trans mission of tube rculos is}

Four stages are involved in pathogenesis of pulmonary tuberculosis [2]. The nuclei droplets with mycobacteria exhaled from TB patients can spread from one to another. At the first stage, the alveolar macrophages in the host can take up the inhaled drop lets nonspecifically and destroy them. But this destruction of $M$. tuberculosis depends on the intrinsic capacity of host phagocytes and virulence factors of the ingested pathogen. If the macrop hages cannot de stroy the inhaled mycobacteria, the mycobacteria will multiply in macrophage until the macrop hage burst. Upon the destruction of macrophages, which starts the second stage, blood monocytes are attracted to the place and develop into new macrop hages in order to engulf $M$. tuberculosis without destroying them. Hence, the engulfed bacteria grow logarithmically inside macrophages and the macrophages accumulate within the first to the third weeks of the initial infection. No tissue damage occurs. In the third stage, when T-cell immunity develops, the lymphocytes are able to recognize the pathogen, $M$. tuberculosis, and trigger the release of interferon. The interferon leads to the activation of macrophages to kill the mycobacteria. The intracellular logarithmical growth of bacteria is halted and the extracellular growth of bacteria is inhibited because of the solid center of necrosis in the primary infection. Therefore, the bacteria become latent and may be disseminated to other organs through blood circulation.

In the last stage, which may be after months or even years later, under the circumstance of a weakening immune system, the latent pathogens could be reactivated in hosts. Because of an unknown mechanism, the centers of caseation necros is liquefy, which provides a perfect 
circumstance for extracellular multiplication of mycobacteria. Cavity formation may disrupt the nearby bronchi so that the mycobacteria will spread to other parts of the lungs and the outside environment. In summary, after entering the host, $M$. tuberculosis encounters a series of barriers from the host with different defense mechanisms. The final outcome of infection with $M$. tuberculosis depends on the ba lance be tween the outgrowth and killing of mycobacteria and the defense capability of the host's immune system.

A critical step in the pathogenesis of TB is the survival of $M$. tuberculosis in the host's macrophages. Normally, the engulfed bacteria are transferred to the lysosome and degraded. But in case of TB, mycobacterium is resistant to this transfer. A protein kinase $\mathrm{G}$ (PknG) from $M$. tuberculosis is suggested to relate to resistance. The PknG mediates intracellular survival of bacteria and is identified as a target for the control of mycobacteria infections [3]. More study is needed to illuminate the inactivation mechanism of macrophage and will shed light on the discovery of new agents for TB treatment.

\subsubsection{Drugs used in che motherapy of TB}

The funda mental purpos e of chemotherapy of TB is to kill bacteria or inhibit growth. Currently, there are five first-line drugs used for TB treatment, including streptomycin, isoniazid, rifampicin, ethanmbutol and pyrazinamide (Table 1-1). These drugs act in cell wall synthesis, DNA replication, RNA transcription and protein synthesis, which are essential for cell viability or logarithmical growth.

Streptomycin (SM) was the first effective antibiotic used against TB, extracted from Streptomyces griseus. It targets the S12 protein of the 30S subunit of the ribosome in $M$. tuberculosis, therefore interfering with the binding of formyl-methionyl-tRNA to the 30s 
ribosome subunit [4]. This results in the failure of protein synthesis initiation and leads to cell death. This drug is given by intramuscular injection due to its poor absorbance in the gastrointestinal tract. Adverse effects include the toxicity to peripheral and central nervous systems. Drug-resistant bacteria strains exist.

Isoniazid (INH) is a pro-drug and requires the activation of catalase-peroxidase enzyme (kat G) from $M$.tuberculosis [5]. The kat G catalyzes the formation of isonicotinic acyl-NADH complex, which inhibits ketoenoylreductase (InhA) [6] and consequently blocks fatty acid synthesis. This process inhibits the synthesis of mycolic acid, a virulence factor required in cell walls. INH can be bactericidal to the M. tuberculosis in the log-phase, while it is bacteriostatic to the mycobacteria in the stationary-phase. The side effect includes hepetoxicity, and the toxicity to the peripheral and central nervous systems. However, hepetoxicity can be eliminated by the careful clinical monitoring of patients, while the toxicity to the nervous system can be avoided by the supplement of vitamin B6. The mutation in the inhA gene contributes to resistance to the INH in M. smegmatis[7].

Rifampicin (RIF) belongs to ansamycin antibiotics because its structure is similar to a basket. The aromatic moiety is the 'basket', and the long aliphatic chain that links both sides of the aromatic moiety is the 'handle'. It inhibits RNA polymerase and reduces protein synthesis in mycobacteria. The combination of isoniazid and rifampicin increases the risk of hepatoxicity.

Ethambutol (EMB) is bacteriostatic and usually given in combination with isoniazid, rifampicin, and pyrazinamide. It disrupts arabinogalactan synthesis by inhibiting arabinosyl transferase, therefore the complex of mycolyl-arabino galactan-peptidoglycocan in the cell wall cannot be formed, which leads to the increased permeability of the cell wall. 
Tabel 1-1 First-line drugs used in TB treatment

\begin{tabular}{|c|c|c|c|c|c|}
\hline Name & Structure & Mechanism & $\begin{array}{l}\text { Gene(s) invovled } \\
\text { in resistance }\end{array}$ & Gene function & $\begin{array}{l}\text { Mutantion } \\
\text { Frequency }\end{array}$ \\
\hline SM & & $\begin{array}{l}\text { Inhibition of protein } \\
\text { synthesis by targeting } \\
30 \mathrm{~S} \text { subunit of } \\
\text { ribosome }\end{array}$ & $\begin{array}{l}\text { rpsL } \\
\text { rrs } \\
\text { gidB }\end{array}$ & $\begin{array}{l}\text { S21 ribosomal protein } \\
16 \text { s rRNA } \\
\text { rRNA methyltransferase }\end{array}$ & $\begin{array}{l}52-59 \% \\
8-21 \%\end{array}$ \\
\hline INH & & $\begin{array}{l}\text { Inhibit fatty acid } \\
\text { synthesis by targeting } \\
\text { mycolate synthetase }\end{array}$ & $\begin{array}{l}\text { KcatG } \\
\operatorname{Inh} A\end{array}$ & $\begin{array}{l}\text { catalase-peroxidase } \\
\text { enoyl ACP reductase }\end{array}$ & $\begin{array}{c}50-95 \% \\
8-43 \%\end{array}$ \\
\hline RIF & & $\begin{array}{l}\text { Intefer with protein } \\
\text { systhesis by targeting } \\
\text { DNA-dependant RNA } \\
\text { polymerase }\end{array}$ & rров & ubunit of RNA polymerase & $95 \%$ \\
\hline EMB & & $\begin{array}{l}\text { Interfer with fatty acid } \\
\text { synthesis by targeting } \\
\text { arabinosyl transferase. }\end{array}$ & $e m b B$ & Arabinosyl transferase & $47-65 \%$ \\
\hline PZA & & $\begin{array}{l}\text { to reduce the duration } \\
\text { of treatment required }\end{array}$ & pncA & tinamidase/pyrazinamidase & $72-97 \%$ \\
\hline
\end{tabular}

Abbreviations: SM: streptomycin INH: isonizid RIF: rifampicin; EMB: ethambutol. PZA: pyrizinamide. Table modified from Yew et al 2009 [8] 
Pyrazinamide (PZA) does not have significant bactericidal effects. It is used with isoniazid and rifampicin to shorten the treatment course. This pre-drug is converted to pyrazinoic acid by mycobacterial amidase. The mutation in the pncA gene coding pyrazinamise confers resistance to this drug.

There are also second-line drugs for TB treatment. They are defined as such because they are unavailable in most developing countries, or they are less effective than the first-line drugs, or they have a higher toxicity or more side-effects. Aminoglycosides and fluoroquinolones are in this category and inhibit protein synthesis and membrane integrity in M. tuberculosis.

\subsubsection{The challenge encountered in anti-TB drug discovery}

All of the five first-line drugs listed above were discovered in the 1950s and have been extensively used. The high mutational frequency $\left(10^{-6} \sim 10^{-8}\right)$ in the chromosome DNA is the major cause of drug resistance observed in M. tuberculosis. Moreover, long treatment courses as well as the misuse and mismanagement of these drugs also contribute to resistance to the drugs. Novel antibiotics to combat drug-resistant TB strains with higher potency, less adverse effects, and that facilitate a shorter treatment course, are in critical need to address this challenge. Rather than focusing on modifying current antibiotics and optimizing current treatment regimens, exploring potential targets for drug design is likely to be the most promising app roach.

New antibiotics with novel mechanisms hold great promise to conquer drug-resistant TB. The completion of sequencing of the Mycobacterium tuberculosis $\mathrm{H} 37 \mathrm{Rv}$ genome led to identification of essential genes for cell viability and greatly expanded the target pools for drug development. As more details of tuberculosis pathoge nesis and mechan isms of drug-resistance 
have been uncovered, a new paradigm targeting the virulence factor has been suggested as a better alternative for drug development [9].

\subsection{Methionine aminopeptidase}

\subsubsection{Methionine aminopeotidase family}

The methioine aminopeptidases (MetAPs) are a family of enzymes that are found in Bacteria, Archaea, and Eukarya. The enzymes cleave the $\mathrm{N}$-terminal methionines from methionine-peptides in the presence of divalent metals. All protein translations begin at the $\mathrm{N}$ terminus with a methionine (or N-methylmethionine), corresponding to the start codon AUG. However, 50-70\% proteins have this initial methionine removed by MetAPs. This process, which variously correlates with protein stability, function and degradation, plays an essential role in almost every aspect of cellular biology.

MetAPs can be divided into two groups, type I and type II, based on the existence of the insert in the catalytic domains (Figure 1-3). Type I has no insert while type II has a 60 amino acid long insert. Eukaryotic cells have bo th type I and type II MetAPs, such as Saccharomyces cerevisiae [10] and humans [11]. In contrast, single MetAP is common in proeukaryotic cells. For instance, Eubacteria only has a type I MetAP, while Archaea only has one type II MetAP. Multiple MetAPs are rare in bacteria, but with more genomic sequences reported, two or more putative MetAP genes have been identified in a small number of bacteria [12-13].

The presence of an $\mathrm{N}$-terminal extension can subdivide MetAP into three groups. MetAPa doe s not have the extension, while MetAP b and MetAP c have the extension. MetAP b and MetAP c are differentiated by the length of the N-terminal extension. Therefore, type Ia enzyme has neither an insert in the catalytic domain nor an $\mathrm{N}$-terminal extension, and 
MetAP from E.coli [14] is in this category. The Type Ib enzyme contains no insert in the catalytic domain, while it has an N-terminal extension, such as human MetAP Ib (HsMetAP Ib) and Saccharomyces cerevisiae MetAP Ib (ScMetAP Ib). Both of them have an extension of approximately 120 amino acids at the $\mathrm{N}$-terminus, which includes two zinc-fingers and a linker of 50 amino acids. The proteolysis of the ScMetAP Ib by trypsin releases a fragment whose Nterminal sequence starts at Asp-70 with an immediately following Lys-69, indicating that ScMetAP Ib has an N-terminal zinc finger domain, and a C-terminal catalytic domain [15]. Metal titration experiments with wild-type ScMetAP Ib and the deletion mutant ScMetAP $\Delta 2-69$ indicated that the native ScMetAP Ib had two zinc fingers and the zinc fingers were essential for MetAP normal function in vivo [16]. The type Ic MetAP has no insert in the catalytic domain and has a shorter $\mathrm{N}$-terminal extension of 50 a mino acid residues without a zinc finger. Type Ic MetAP was first described in Mycobacterium tuberculosis [17] and it was named as such in order to be differentiated from type Ib MetAP.

The alignment of MetAPs from E.coli, yeast and humans shows a high sequence similarity, indicating the evolutionary conservation of this type of enzyme.

\subsubsection{Structure of methionine aminopeptidase}

Crystal structures of EcMetAPs [18] reveal a pita-bread fold in the active sites. This unique fold consists of a central antiparallel $\beta$-sheet flanked by two pairs of $\alpha$-helices, which have been observed in most MetAPs including EcMetAP, ScMetAP, and HsMetAP. Similar pitabread folds are also found in aminopeptidase P (AMPP) and creatine amidinohydrolase (creatinase) even though these two enzymes have different activities and substrate specificities. 


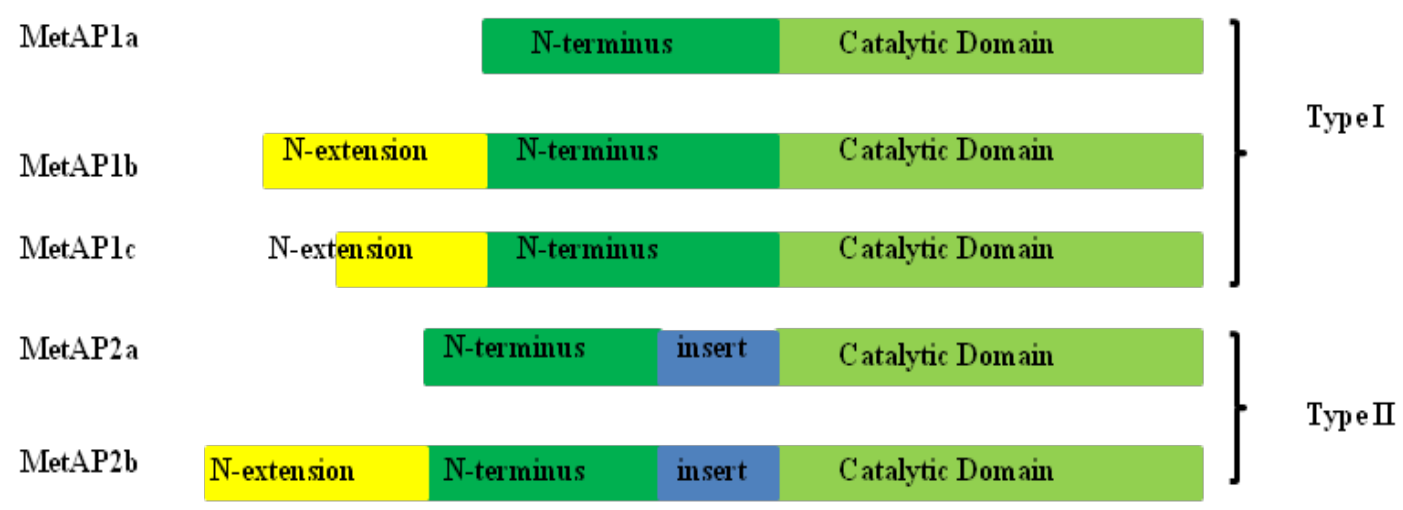

Figure 1-3 Domain architecture of methionine aminopeptidase
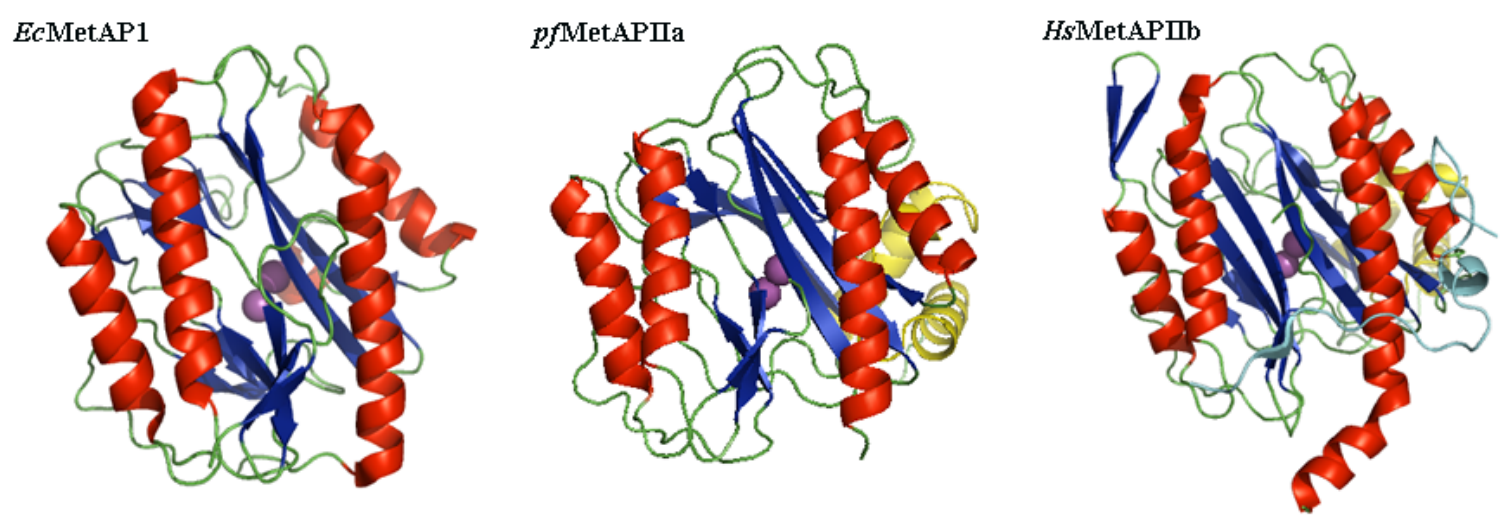

Figure 1-4 Crystal structures of EcMetAP I, pfMetAP IIa a nd HsMetAP IIb.

The pita-bread core domain is illustrated by red $\alpha$-helices and blue $\beta$-sheets. The $\alpha$-helical subdo main insertion in the type II enzymes is labeled in yellow. The $\mathrm{N}$-terminal domain extension in HsMetAP IIb is indicated in blue. Metal ions are shown in magenta; Mn(II) in EcMetAP I, and Co (II) in pfMetAP IIa and HsMetAP IIb. 
The pita-bread fold forms an internal pseudo 2-fold asymmetry. In EcMetAP I, which doe s not have the $\mathrm{N}$-terminal extension or the insert in the catalytic do main, this pseudo symmetric fold can be clearly visualized. The symmetric unit consists of a $\beta$-sheet and a helixbend-helix motif. The first half of the sequence residues from 11-116 comprises the $\mathrm{N}$-terminal domain and the residues from 120-241 make another domain located at the $\mathrm{N}$-terminus (EcMetAP I in Figure 1-4). The least squares transformation, which superimposed 64 selected $\alpha$-carbon atoms from the C-terminal part on those in the $\mathrm{N}$-terminal part, is equivalent to a rotation of $174^{\circ}$ and a translation of $0.6 \AA$ to the axis of rotation. In addition to EcMetAP, chyrotryps in- like serine proteases and the acid protease are also alike in structure within a single pol ypeptide. This phenomenon has been suggested as evidence of an ancestral gene duplication and fusion.

The dinuclear metal sites are located at the junction of two domains where two metal ions are clearly seen. These metals are in the center of the molecule, right between the $\beta$-sheets, and are bound through coordination with amino acids Asp-97, Asp-108, Glu-235, His-171 and Glu204 (Figure 1-5). The metal binding coordination is very similar to that is observed in PfMetAP IIa and HsMetAP IIb. Even though the numbering of the metal coordinating residues are different in these MetAPs, the binding modes in the active sites are very comparable.

\subsubsection{Catalysis of methionine aminopeptidase}

By analyzing crystal structures of MetAPs with or without substrate binding (or substrate analogues), catalytic models for dimetalated and monometalated MetAP have been proposed [19-21]. 


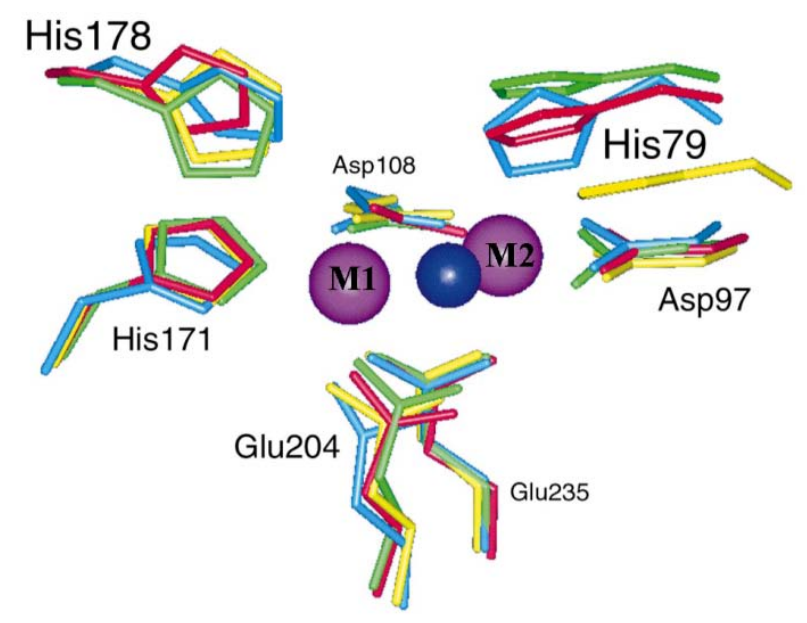

Figure 1-5 The dinuclear metal centers and the amino ac id residues in EcMetAP I, PfMetAP IIa and HsMetAP IIb

EcMetAP is colored in yellow, PfMetAP IIa is colored in green, and HsMetAP IIb is colored in red. The blue colored enzyme is AMPP that has a similar pita-bread fold in its active site. Two metal ions are colored in magenta. The water molecule that bridges the metal ions is colored in deep blue. Only numberings in EcMetAP are listed. Modified from ref [22] 
In dimetalated MetAP (Figure 1-6A), two metals (M1 and M2) and water molecules (A and $\mathrm{B}$ ) are involved. The model is constructed based on following assumptions:1) The Nterminus of the substrate binds to M2 at the cost of replacing water B; 2) A non-covalent tetrahedral gem-diolate intermediate is formed during catalys is; 3) The carboxyl oxygen from the scissile peptide bond interacts with Glu-204, and; 4) Water is the nucleophile during catalysis. In the resting MetAP, water A and B are clearly seen to coordinate to the metal center. Water A bridges the metal ions whereas water B behaves as the terminal ligand of M2. M1 is coordinated to Asp-108, His-171, Glu-204, Glu-235 and water A. The coordination geometry is a distorted trigonal bipyrimid. M2 is coordinated with Asp-97, Asp-108, Glu-235, water A and water B and the geometry is a distorted octahedron. Upon the substrate analog binding, water A, B and D in the active site are replaced by the $\mathrm{O} 2$ hydroxyl, the $\mathrm{N}$-terminal nitrogen and the $\mathrm{O} 1$ atom of the inhibitor (Figure 1-6B). The geometry of M1 for ms a distorted octahedron. The proposed reaction mechanism of dimetalated MetAP was illustrated in Figure 1-6C.

When the substrate approaches the active site, the carboxyl oxygen of the scissile bond (Oc) has been rotated so that it can interact with M1. Meanwhile, the hydroxide moiety from water A attacks the carbonyl carbon of the scissile bond. The Oc also interacts with His-178 and possibly forms a hydrogen bond to stabilize the transition state. Glu-204 is proposed to interact with the P'1 part of the substrate and shuttle a proton from the attacking hydroxide to the new Nterminus, facilitating its leaving. Mutation experiment and the binding mode adopted from substrate-alike inhibitors support this model [19].

In monometalated MetAP (Figure 1-7), only o ne metal (M1) and one water (A) are involved. M1 is coordinated with residues of His-171, Glu-204, Glu-235 and water A. When the 
A

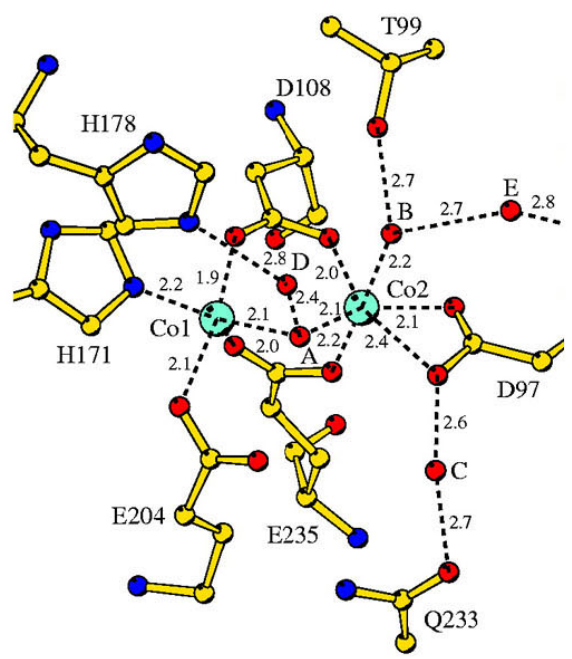

B

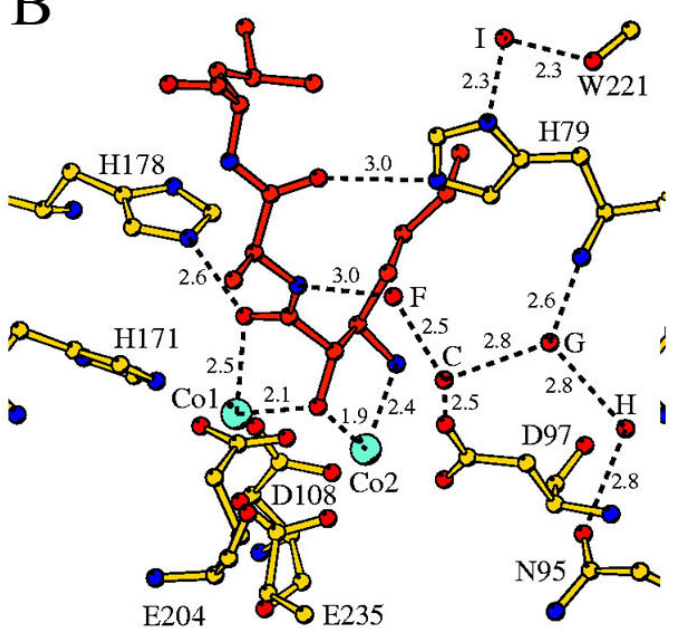

C.

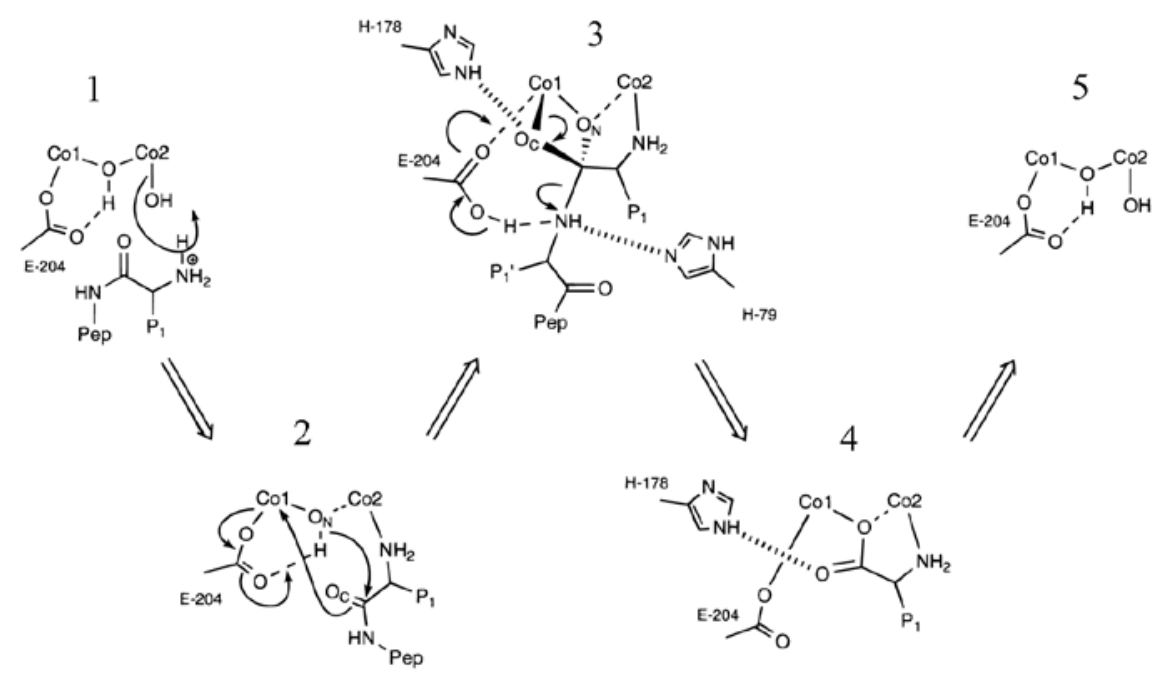

Figure 1-6 Proposed reaction mechanism of dimetalated EcMetAP I

A. Interactions in the metal center of EcMetAP.

B. Interactions in the metal center of $E c$ MetAP bo und with substrate- like inhibitor AHHрA. Color scheme for atoms: red, oxygen; blue, nitrogen; yellow, carbon; cyan, cobalt. Metals are labeled as Co1 and Co2; and water molecules are labeled as A to E.

C. Proposed reaction mechanism for dimetalated EcMetAP (Figure modified from reference [23] 


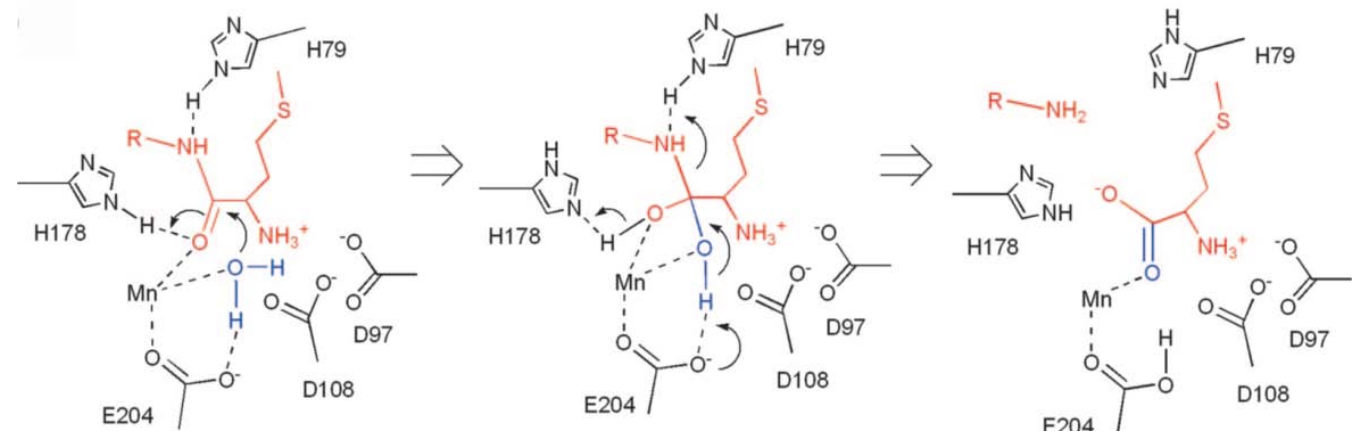

Figure 1-7 Proposed reaction mechanism of monometalated EcMetAP I

Substrate Met-Ala-Leu is colored red and its tetrahedral intermediate binds to the active site. The nucleophilic water molecule is colored blue. (Figure modified from ref [21] 
substrate binds to the enzyme, it likely approaches M1 with the scissile bond in a transconformation. The imidazole moiety from His-79 moves toward the substrate and forms a hydrogen bo nd to the nitrogen of the scissile amide. Residue His-178 forms a hydrogen bond to the oxygen of the scissile carbonyl group. The metal-coordinated water A attacks the scissile carbonyl-group and a tetrahedral intermediate is formed. It shuttles a proton from the carbonyl group to the leaving group. As no M2 exists, residue Asp-97 and Asp-108 are no longer coordinated with metal. However, both residues move closer toward the positively charged moiety of the N-terminus of the peptide to develop charge-to-charge interaction, which helps to orient the peptide substrate for productive binding[21].

This catalytic mechanism of monometalated MetAP suggests the possibility of using one metal for MetAP activity and modifies the prevailing catalytic mechanisms of dimetalated MetAP.

The affinity differences were observed between two metal binding sites in a metalloenzyme. For example, the dissociation constants of Co (II) to the first and second binding sites in DNA polymerase I are $2.5 \mu \mathrm{M}$ and $600 \mu \mathrm{M}$, respectively; and $\beta$-lactamase has $K_{d}$ value of $0.14 \mu \mathrm{M}$ and $2.52 \mathrm{mM}$ for its tight and weak binding sites, respectively. Considering there would be no such large variation under nor mal physiological conditons, it is possible that only one metal binding site is occupied and used for catalysis. Therefore, caution must be exercised when structures are generated to aid in drug design.

\subsubsection{Metal activation of methioinine aminopeptidase}


MetAP catalyzes the removal of the N-terminal methionine from nascent polypeptides. However, the loss of EcMetAP activity upon EDTA treatment suggested the MetAPs were metalloenzymes, which depend on metal binding for activities [14].

Purified apo-MetAP I can be activated by divalent metals in vitro, usually by more than just one type of metal. MetAP from E. coli (EcMetAP) can be activated by Co(II), Mn(II), Ni(II) and Zn(II); MetAP from Saccharomyces cerevisiae (ScMetAP Ib) can be activated by Co(II) [24], Zn(II), Mn(II) and Ni [25]. MetAP from humans (HsMetAP1b) can be activated by Co(II), Mn(II) and Zn(II). Similar metal activation was also reported for type II MetAP. HsMetAP IIb shows activity in the presence of Co(II), Mn(II) and Zn(II). ScMetAP IIb also showed metal activation by $\mathrm{Co}(\mathrm{II}), \mathrm{Mn}(\mathrm{II})$ and $\mathrm{Zn}(\mathrm{II})$. The diversity of activation by metals in vitro can be explained by the flexibility of the metal binding pocket. As long as the divalent metals can fit into the metal activity pocket consisting of Glu, Asp and His, it may promote necleophilic catalysis with the hydroxide ion (-OH) via water ionization.

Even though the apoenzyme of MetAP shows activity in the presence of various metals in vitro, the metals used by the cellular MetAPs remain controversial. The activating metals used by metalloenzymes under physiological conditions are affected by two factors: 1) The binding affinity of a metal. An enzyme tends to bind the metals that show high affinity if the abundances of the metals are assumed to be the same. Affinities for metals tend to follow the Irving-Williams series (Mg(II) or $\mathrm{Ca}($ II $)<\mathrm{Mn}(\mathrm{II})<\mathrm{Fe}(\mathrm{II})<\mathrm{Co}$ (II) $<\mathrm{Ni}$ (II) $<\mathrm{Cu}(\mathrm{II})>\mathrm{Zn}(\mathrm{II})$ ). For example, if all divalent metals are present and abundant, all proteins would bind $\mathrm{Cu}(\mathrm{II})$ as it has the highest binding a ffinity; and: 2) The available of metals for metalloprotein in vivo. This is determined by metal homeostasis, which is related to metal-specific importers and exporters in the membranes, and is tightly regulated by metal sensors through metal-responsive transcription [26]. 
Several candidates for the metals used by MetAP in vivo have been proposed, including Co (II) [18, 27], and Zn(II) [25], Mn(II) [28] and Fe (II) [29-30]. Co(II) is most often advocated as the metal used in vivo, because of its stable and repeatable activation of MetAPs [18, 24]. A low concentration of Zn(II) was observed to activate to the EDTA-pretreated ScMetAP Ib, which was comparable to the activation by Co(II). ScMetAP Ib activity was further tested using high concentration of $\mathrm{Zn}(\mathrm{II})$ and $\mathrm{Co}(\mathrm{II})$ in the presence of a physiological concentration of reduced glutathione. The fact that the Zn(II)-substituted ScMeAP Ib retained high activity whereas the $\mathrm{Co}(\mathrm{II})$ substituted $S c$ MetAP Ib lost activity suggested that $\mathrm{Zn}(\mathrm{II})$ could be the metal used under physiological circumstances [25]. Ec MetAP substituted by $\mathrm{Co}(\mathrm{II})$ and $\mathrm{Fe}(\mathrm{II})$ in the presence of reduced glutathione gave the highest activity, indicating both metals were relevant to physiological function of MetAP. However, in the same paper, the metal content of mycobacterial extracts was measured with the extracts from two types of $E$. coli cells; one had a plasmid to express EcMetAP and another did not have. The mycobacterial extract from the E.coli with plasmid-expressed EcMetAP gave an increased Fe(II) content, when compared with the Fe(II) content from E.coli without plasmid-expressed EcMetAP, suggesting Fe(II) was the metal used by E.coli in vivo [30]. The E.coli growth was inhibited by the compo unds that showed inhibition toward the Fe(II)-subs tituted EcMetAP, not by the compounds inhibiting Co(II) and Mn(II)-substituted EcMetAP. It also suggested that Fe(II) could be the metal used by E. coli. Chai et al. used metal-selective inhibitors to assign the metals used by E.coli in vivo. Only $\mathrm{Fe}(\mathrm{II})$-specific inhibitors prevented the removal of $\mathrm{N}$-terminal methionine in the recombinant glutathione S-transferanase, which confirmed the cellular target of these compounds was MetAP and $\mathrm{Fe}(\mathrm{II})$ was likely the metal used in E. coli [29]. At this time, more evidence is required to clarify the metal used by MetAP in vivo. 


\subsection{Methoinine aminopeptidase implication in anti-TB drug discovery}

\subsubsection{Methionine aminopeptidase in Mycobacterium tuberculosis}

Mycobaterium tuberculosis has two MetAP genes (mapA and mapB in H37 Rv genome and map_1 and map_2 in CDC1551 genome), and both belong to type 1 MetAP with high homology to E. coli MetAP (EcMetAP). Little is known about their biochemical properties other tha n their DNA sequences. Addlagatta et al. purified MtMetAP 1c, which is encoded by the mapB gene, and crystallized it in an apoform and in a complex with methionine. The structure analysis revealed an SH3 bind ing motif at its N-terminus (Figure 1-8), which could potentially interact with ribos omes through the SH3 motif to facilitate removal of methionine [17]. Zhang et al. cloned and purified both MetAPs (MtMetAP1a encoded by the mapA gene; and MtMetAP1c encoded by the mapB gene). Both enzymes were characterized with metal activation, substrate specificity and temperature optima. Both enzymes could be activated by Co(II), Mg (II) and Zn(II). While Cu(II), Fe(II), and Ni(II) showed strong inhibitions of enzyme activity.

Transcriptional levels of two map genes were analyzed by real-time quantitative PCR. Gene mapA showed a 2-fold higher expression level in the 14-day log phase culture. In contrast, gene map $B$ gave a higher expression level in the 60-day stationary phase, which was about 1.5 fold higher than in the log phase. This result suggested that MtMetAP Ia and MtMetAP Ic could perform important functions in different growth phases of M. tuberculosis [31].

\subsubsection{MtMetAPs as the potential targets for anti-TB drug}




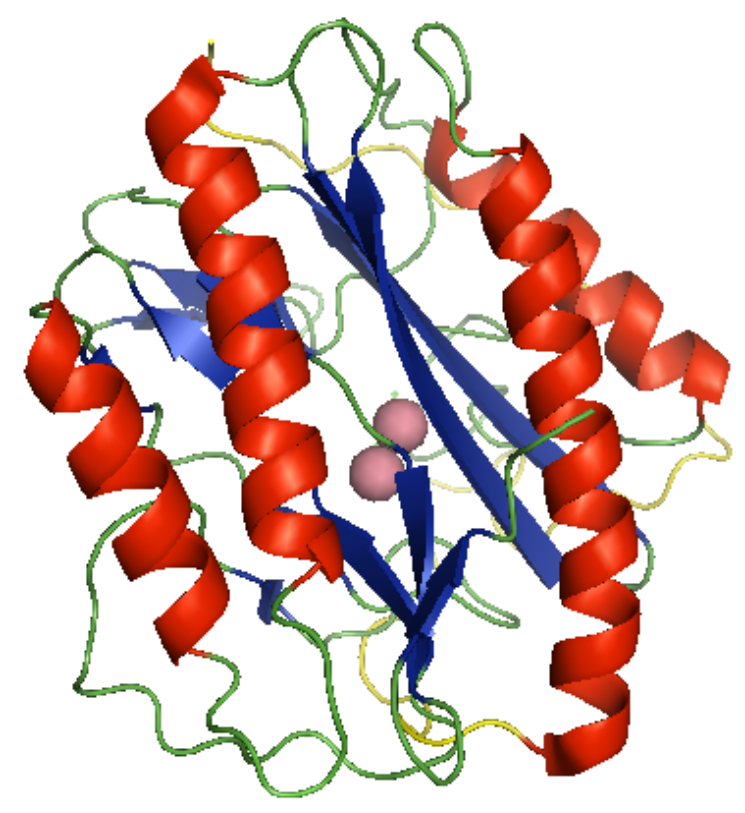

Figure 1-8 Crystal structure of MtMetAP Ic (PDB ID: 1YJ3) The $\alpha$-helices are colored red and $\beta$-sheets are colored blue. Two Co ions colored magenta are located in the active site. The $\mathrm{N}$-terminal extension is colored yellow. PDB ID: 1 YJ3 
MetAPs have gained much attention as drug targets in the past few years because of their essentiality in cellular function. MetAP inhibitors targeting cancer, rheumatoid arthritis, fungal and malarial infections have been reported.

There are two putative map genes in M. tuberculosis, which share abo ut $36.9 \%$ identity to each other. The different expression profiles of gene mapA and mapB in the $\log$ phase and the stationary phase indicate they may play different roles in M. tuberculosis pathogenesis [31]. The compounds that inhibit MetAP in M. tuberculosis hold the significant promise of effective TB therapy. However, it is important to determine if inhibition of either MetAP or both is sufficient for inhibition of mycobacterial growth.

The compounds that inhibit MetAP enzymatic activity could be used to co-crystallize with MtMetAPs. Once the structure of MetAPs in the complex with the inhibitors is identified, it will provide useful information for rational design of anti-TB drugs. The inhibitors with higher potency and selectivity can be developed for TB treatment. 


\section{References:}

1. Palomino, J.C., et al., Rapid culture-based methods for drug-resistance detection in Mycobacterium tuberculosis. J Microbiol Methods, 2008. 75(2): p. 161-6.

2. $\quad$ van Crevel, R., T.H. Ottenhoff, and J.W. van der Meer, Innate immunity to Mycobacterium tuberculosis. Clin Microbiol Rev, 2002. 15(2): p. 294-309.

3. Walburger, A., et al., Protein kinase $G$ from pathogenic mycobacteria promotes survival within macrophages. Science, 2004. 304(5678): p. 1800-4.

4. Sharma, D., et al., Mutational analys is of S12 protein and implications for the accuracy of decoding by the ribosome. J Mol Biol, 2007. 374(4): p. 1065-76.

5. Zhang, Y., et al., The catalase-peroxidase gene and isoniazid resistance of Mycobacterium tuberculosis. Nature, 1992. 358(6387): p. 591-3.

6. Suarez, J., et al., Antibiotic resistance in Mycobacterium tuberculosis: peroxidase intermediate bypass causes poor isoniazid activation by the S315G mutant of $M$. tuberculosis catalase-peroxidase (KatG). J Biol Chem, 2009. 284(24): p. 16146-55.

7. Ahmed Kamal, S.A., M. Shaheer Malik, Ahmad Ali Shaik, Maddamsetty V. Rao, Efforts Towards the Development of New Antitubercular Agents: Potential for Thiolactomycin Based Compounds. J Pharm Pharmaceut Sci, 2008. 11(2): p. 56s-80s.

8. Zhang, Y. and W.W. Yew, Mechanisms of drug resistance in Mycobacterium tuberculosis. Int J Tuberc Lung Dis, 2009. 13(11): p. 1320-30.

9. Clatworthy, A.E., E. Pierson, and D.T. Hung, Targeting virulence: a new paradigm for antimicrobial therapy. Nat Chem Biol, 2007. 3(9):p. 541-8.

10. $\mathrm{Li}, \mathrm{X}$. and Y.H. Chang, Amino-terminal protein processing in Saccharomyces cerevisiae is an essential function that requires two distinct methionine aminopeptidases. Proc Natl Acad Sci U S A, 1995. 92(26): p. 12357-61.

11. Arfin, S.M., et al., Eukaryotic methionyl aminopeptidases: two classes of cobaltdependent enzymes. Proc Natl Acad Sci U S A, 1995. 92(17): p. 7714-8.

12. You, C., et al., The two authentic methionine aminopeptidase genes are differentially expressed in Bacillus subtilis. BMC Microbiol, 2005. 5: p. 57.

13. Chen, X., et al., Inhibitors of Plasmodium falciparum methionine aminopeptidase $1 b$ possess antimalarial activity. Proc Natl Acad Sci U S A, 2006. 103(39): p. 14548-53.

14. Ben-Bassat, A., et al., Processing of the initiation methionine from proteins: properties of the Escherichia coli methionine aminopeptidase and its gene structure. J Bacteriol, 1987. 169(2): p. 751-7.

15. Zuo, S., et al., Evidence that two zinc fingers in the methionine aminopeptidase from Saccharomyces cerevisiae are important for normal growth. Mol Gen Genet, 1995. 246(2): p. 247-53.

16. Vetro, J.A. and Y.H. Chang, Yeast methionine aminopeptidase type 1 is ribosomeassociated and requires its $N$-terminal zinc finger domain for normal function in vivo. $\mathrm{J}$ Cell Biochem, 2002. 85(4): p. 678-88.

17. Add lagatta, A., et al., Identification of an SH3-binding motif in a new class of methionine aminopeptidases from Mycobacterium tuberculosis suggests a mode of interaction with the ribosome. Biochemistry, 2005. 44(19): p. 7166-74.

18. Roderick, S.L. and B.W. Matthews, Structure of the cobalt-dependent methionine aminopeptidase from Escherichia coli: a new type of proteolytic enzyme. Biochemistry, 1993. 32(15): p. 3907-12. 
19. Lowther, W.T., et al., Escherichia coli methionine aminopeptidase: implications of crystallographic analyses of the native, mutant, and inhibited enzymes for the mechanism of catalysis. Biochemistry, 1999. 38(24): p. 7678-88.

20. Lowther, W.T., et al., In sights into the mechanism of Escherichia coli methionine aminopeptidase from the structural analysis of reaction products and phosphorus-based transition-state analogues. Biochemistry, 1999. 38(45): p. 14810-9.

21. Ye, Q.Z., et al., Structural basis of catalysis by monometalated methionine aminopeptidase. Proc Natl Acad Sci U S A, 2006. 103(25): p. 9470-5.

22. Lowther, W.T. and B.W. Matthews, Structure and function of the methionine aminopeptidases. Biochim Biophys Acta, 2000. 1477(1-2): p. 157-67.

23. Lowther WT, Z.Y., Sampson PB, Honek JF, Matthews BW., Insights into the mechanism of Escherichia coli methionine aminopeptidase from the structural analysis of reaction products and phosphorus-based transition-state analogues. Biochemistry, 1999. 38(45): p. 14810-9.

24. Chang, Y.H., U. Teichert, and J.A. Smith, Purification and characterization of a methionine aminopeptidase from Saccharomyces cerevisiae. J Biol Chem, 1990. 265(32): p. $19892-7$.

25. Walker, K.W. and R.A. Bradshaw, Yeast methionine aminopeptidase I can utilize either Zn2+ or Co2+ as a cofactor: a case of mistaken identity? Protein Sci, 1998. 7(12):p. 2684-7.

26. Waldron, K.J. and N.J. Robinson, How do bacterial cells ensure that metalloproteins get the correct metal? Nat Rev Microbiol, 2009. 7(1): p. 25-35.

27. Ghosh, M., et al., Characterization of native and recombinant forms of an unusual cobalt-dependent proline dipeptidase (prolidase) from the hyperthermophilic archaeon Pyrococcus furiosus. J Bacteriol, 1998. 180(18): p. 4781-9.

28. Li, J.Y., et al., Mutations at the S1 sites of methionine aminopeptidases from Escherichia coli and Homo sapiens reveal the residues critical for substrate specificity. J Biol Chem, 2004. 279(20): p. 21128-34.

29. Chai, S.C., W.L. Wang, and Q.Z. Ye, FE(II) is the native cofactor for Escherichia coli methionine aminopeptidase. J Biol Chem, 2008. 283(40): p. 26879-85.

30. D'Souza V, M. and R.C. Holz, The methionyl aminopeptidase from Escherichia coli can function as an iron(II) enzyme. Biochemistry, 1999. 38(34): p. 11079-85.

31. Zhang, X., et al., Expression and characterization of two functional methionine aminopeptidases from Mycobacterium tuberculosis H37Rv. Curr Microbiol, 2009. 59(5): p. 520-5. 


\section{CHAPTER 2}

\section{BIOCHEMICAL CHARACTERIAZATION OF METHIONINE AMINOPEPTIDASE 1A IN MYCOBACTERIA TUBERCULOSIS}

The work described in this chapter was published in Bioor ganic \& Medicinal Chemistry Letters, entitled "Expression and characterization of Mycobacterium tuberculosis methionine aminopeptidase type $1 \mathrm{a}$ ”.

\subsection{Introduction}

Mycobaterium tuberculosis, the etiological factor of tuberculosis (TB), is one of the toughest microbe that humans have ever fought against [1]. According to the data released by WHO in 2010, about one third of the world's population are infected with TB Bacillus [2]. The emergence of multidrug- resistant $M$. tuberculosis strains and the co-infection of TB with HIV complicate the disease; and the long duration of the required treatment reduces the efficiency of the therapy. New antibiotics with novel mechanisms are urgently needed to solve the problem.

Methionine aminopeptidase (MetAP) is a promising target for anti-bacterial drug development, including anti-TB agents. It is widely distributed in prokaryotic and eukaryotic cells, catalyzing the removal of the $\mathrm{N}$-terminal methionine in the nascent peptides [3]. The essentiality of the enzyme was demonstrated in deletion mutants in Escherichia coli [4], Salmonella typhimurium [5], and Saccharomyces cerevisiae [6], which were lethal, suggesting it as a potential drug target for antibiotic development.

A critical step in discovering anti-TB agents is to characterize the MetAP of $M$. tuberculosis, and to find inhibitors targeting MetAP with strong potency and high selectivity. Determining the activation metal ions of MetAP is particularly important as MetAP is a 
metalloenzyme, for which divalent metal ions play a key role in the hydrolysis. It shows metaldependant activities in the presence of a series of divalent metals in vitro, such as Co(II) [7], Mn (II) [8], Fe(II) [9], and Zn(II) [10]. However, which metal is utilized by MetAP in vivo has remained contentious. Fe (II) [9, 11], Mn(II) [12], and Zn(II) [13] have all been suggested to be the metal used under physiological conditions. The fact that compo und showed potent inhibition of MetAP from in vitro screening, but failed to inhibit the enzyme in vivo ind icated the a discrepancy between the metals used in vitro and in vivo [14-15]. Therefore, in order to develop anti-TB drugs based on MetAP, the covalent metals used by MetAP in vivo should be taken into consideration. Thus, determining which metal is responsible for the activation of MetAP is a necessary step in anti-TB drug development.

There are two putative MetAP genes (mapA and mapB) found in the $M$. tuberculosis H37Rv strain [16] and bot h of them are type I MetAPs with high homology to E. coli MetAP (EcMetAP). Little is known about the biochemical properties of these putative MetAPs other than the DNA sequences. Recently, two MetAP proteins from $M$. tuberculosis were purified, and characterized for metal binding and activation [17]. However, the metal activation results from their experiment were not convincing. The MetAPs tested in their experiments showed activity in the absence of metal ions, indicating the enzymes were not apo form enzymes. Their result, therefore, be misleading.

In order to characterize MetAP in M. tuberculosis, particularly its metal activation, both MtMetAP genes were cloned and the enzymes were purified and characterized in our labor atory. In this chapter, characterization of MtMetAP Ia is described, including metal activation, kinetic measurements, metal-selective inhibition, and crystallization. The results offer further insight into discovering and developing MtMetAP Ia inhibitors for anti-TB treatment. 


\subsection{Materials and Methods}

\subsubsection{Cloning of MtMetAP Ia into pGEMEX-1 plas mid}

The DNA encod ing MtMetAP Ia (mapA, locus_tag Rv0734 ) from the genomic DNA of Mycobacterium tuberculosis H37Rv (a generous gift from Professor Scott G. Franzblau at the University of Illino is at Chicago) was amplified by PCR . The PCR fragments were digested by EcoRI and NheI (New England Biolabs, Ispwich, MA) and cloned into plasmid p GEMEX-1 (Promega, Madison, Wisconsin). The primers for PCR were synthesized by Enrofins MWG Operon (Enrofins MWG Operon Biotech, Huntsville, Alabama). All the sequences are listed in Table 2-1.

The construct pGEMEX1-MtMetAP Ia-1 was checked by DNA sequencing a nalys is. It showed that a shorter mapA gene was cloned into the pGEMEX-1 plasmid instead of the complete mapA gene. It was due to an EcoRI restriction site (G-AATTC) in the mapA gene. The DNA sequence at the end of the mapA gene is shown be low. The missing nucleotides are framed and the EcoRI restriction sites are underlined.

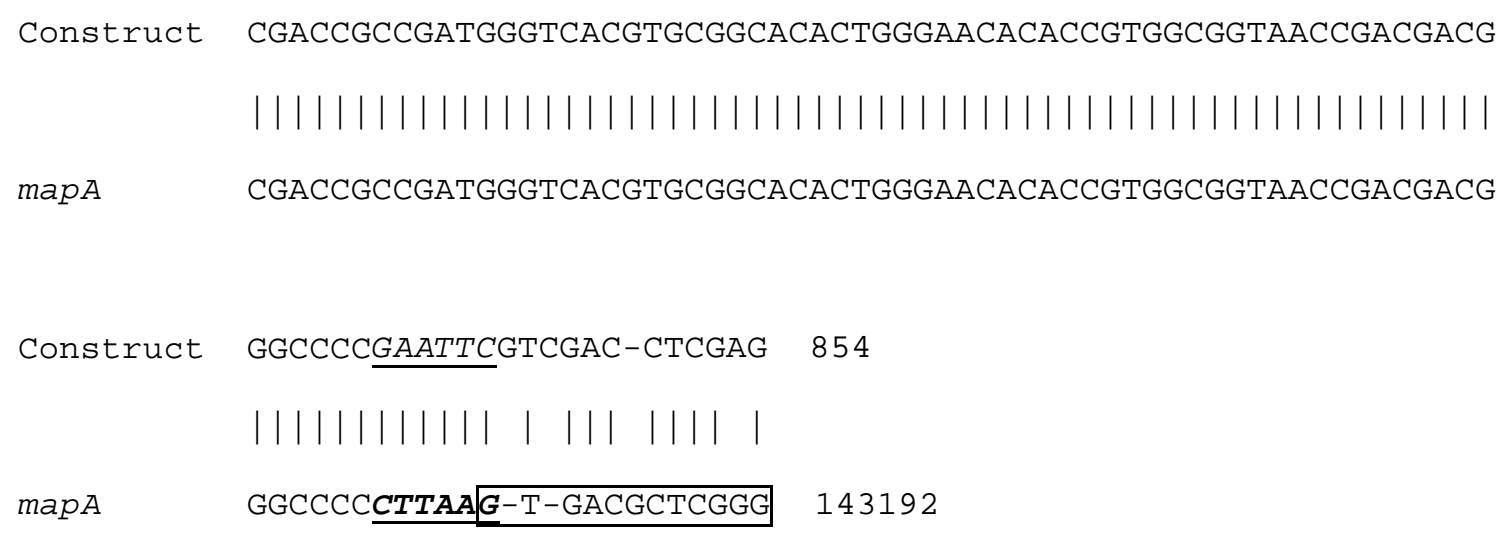


To fix this problem, two DNA oligonucleotide s were designed to change the EcoRI restriction site from GAATTC to GTATAC. Two ApaI digestion sites (G-GGCCC) and one AvrII digestion site (C-CTAGG) were introduced for easy confirmation of the new construct. Both DNA oligonucleotide s had the same sequences and were reverse-complement to one another. As shown be low, the ApaI restriction sites are framed, and the AvrII restriction site is underlined.

Oligonucleotides RF: TGCGACGAC GGGCCC CGTATACTGACCCTAGGTAGAATTCGGGCCCTCTAGATGC Oligonucleotides RR: GCATCTAGA_GGGCCC GAATTCTAACCTAGGGTCAGTATACGEGGCC]GTCGTCGCA

These two oligo nucleotides (100 $\mu \mathrm{M})$ were mixed together in the annealing buffer ( $1 \mathrm{mM}$ EDTA, $10 \mathrm{mM}$ Tris- $\mathrm{HClpH}$ 8.0, and $50 \mathrm{mM} \mathrm{NaCl}$ ) in a $1.5 \mathrm{~mL}$ centrifuge tube and heated both in a boiling water bath for 5 minutes. The mixture was left in the water and allowed to cool down to room temperature. The annealed oligonucleotides were kept at $-20{ }^{\circ} \mathrm{C}$, ready for use.

Both the annealed oligonucleotides and pGEMEX1-MtMetAP Ia were digested by ApaI at $37^{\circ} \mathrm{C}$ for 2 hours, followed by treatment with calf intestinal alkaline phosphatases (CIP) to remove the 5'- phosphates and prevent recircularization of the vector. The digested DNA oligonucleotides and pGEMEX1-MtMetAP Ia-1 were joined by T4 ligase. The fixed EcoRI restriction site in the resulting pGEMEX1-MtMetAP Ia-2 was confirmed by DNA sequencing.

\subsubsection{Re-cloning of the mapA gene into pET28a plas mid}

The mapA gene was cut from plasmid pGEMEX1-MtMetAP Ia by NheI and EcoRI and cloned into pET28a (EMD Biosciences, Gibbstown, NJ) to put a hexahistidine tag at its N- 
Table 2-1: Prime rs and oligonucleotides used in cloning

\begin{tabular}{|c|c|c|c|}
\hline Protein & Primer sequence & $\begin{array}{c}\text { Restriction } \\
\text { Enzy me }\end{array}$ & Plas mid \\
\hline \multirow[t]{2}{*}{$\begin{array}{l}\text { MtMetAP } \\
\text { Ia }\end{array}$} & forward 5'-GGATCA CCA GCTA GCATGCGCCCACTGGCACGG-3’ & NheI & \multirow[t]{2}{*}{$\begin{array}{c}\text { pGEME } \\
X-1\end{array}$} \\
\hline & Reverse 5'-A GCA CTCGAATTCTAACCGA GCGTCA GAAT-3' & Eco RI & \\
\hline \multirow{2}{*}{$\begin{array}{l}\text { Oligonucl } \\
\text { eotides to } \\
\text { fix } \\
\text { MtMetAP } \\
\text { Ia-Mutant }\end{array}$} & $\begin{array}{l}\text { Oligonucleotide RF: } \\
\text { 5'-TGCGACGA CGGGCCCCGTATACTGA CCCTAGGTTAGAATT } \\
\text { CGGGCCCTCTA GATGC-3' }\end{array}$ & $\underline{\text { AvrII }}$ & \multirow[t]{2}{*}{$\begin{array}{c}\text { pGEME } \\
\mathrm{X}-1\end{array}$} \\
\hline & $\begin{array}{l}\text { Oligonucleotide RR: } \\
\text { 5'-GCA TCTA GA GGGCCCGAATTCTAA CCTAGGGTCA GTATAC } \\
\text { GGGGCCCGTCGTCGCA-3' }\end{array}$ & ApaI & \\
\hline
\end{tabular}


terminus. The sequence of the plasmid pET28a-MtMetAP Ia was confirmed by DNA sequencing analysis.

\subsubsection{Protein solubility optimiza tion}

Due to the poor solubility of HisMtMetAP Ia, an optimization test was carried out based on Kim’s publication [18] to improve the solubility. Kim et. al indicated that protein solubility can be improved by changing the constitution of the LB medium. Adding salt, sorbitol, or betaine as well as exposing bacteria to a heat shock can increase the cellular concentration of osmolytes or of chaperones, thereby helping to express soluble target proteins. The medium recipes investigated in optimization tests are listed in Table 2-2.

Solubility op timization tests were carried out in $10 \mathrm{~mL}$ culture tubes. Cells were grown in $5 \mathrm{~mL}$ LB with ampicillin at $37{ }^{\circ} \mathrm{C}$ until an $\mathrm{OD}_{600}$ of $0.6 \sim 0.8$. Isopropyl- $\beta$-Dthiogalactopyranoside (IPTG) was added at a final concentration of $0.3 \mathrm{mM}$ to ind uce protein expression. All of the heat-shock tubes were incubated in a $47^{\circ} \mathrm{C}$ water bath for 10 minutes before they were put in a shaker and incubated at $20{ }^{\circ} \mathrm{C}$ for 20 hours.

The cells were harvested and cell densities were adjusted to the same level. One milliliter samples of cell culture grown in the different mediums were taken from each sample and centrifuged $\left(5000 \times \mathrm{g}, 5\right.$ minute, $\left.4^{\circ} \mathrm{C}\right)$, The pellets were resuspended with $100 \mu \mathrm{L} 50 \mathrm{mM}$ TrisHCl, pH 8.0 and $150 \mathrm{mM} \mathrm{NaCl}$ and sonicated for 10 x 10 sec (with 10 second rest between each sonication) at full power in an ice bath to avoid overheating of the samples. The cellular debris was removed by centrifugation at $16,873 \times \mathrm{g}$ for $10 \mathrm{~min}$ at $4{ }^{\circ} \mathrm{C}$. The whole cell sample, as well as the supernatant, was collected after centrifugation. All the samples were examined by SDSPAGE gel to check the expression level of soluble protein. 
Table 2-2 Medium used in HisMtMetAP Ia solubility optimization test

\begin{tabular}{cc}
\hline Medium ID & Ingredient \\
\hline LB & LB \\
LBS & LB + 0.5 M sorbitol \\
LBSB & LB + 0.5 M sorbitol + 1 mM betaine \\
LBSG & LB + 0.5 M sorbitol + 0.2\% glucose \\
LBSBG: & LB + 0.5 M Sorbitol+ 1 mM betaine + 0.2\% glucose \\
LBG & LB + 0.2\% glucose \\
LBN & LB + 0.5 M NaCl \\
LBNB & LB + 0.5 M NaCl + 1 mM betaine \\
LBNG & LB + 0.5 M NaCl + 0.2\% glucose \\
\hline
\end{tabular}




\subsubsection{Over-expression and purification of HisMtMetAP Ia}

The pET28 a-MtMetAP Ia plasmid was introduced into E.coli BL21(DE3) (Invitrogen, Carlsbad, CA) for protein expression. A single colony freshly transformed was cultured in LB medium with $50 \mathrm{ng} / \mathrm{mL}$ kanamycin at $37{ }^{\circ} \mathrm{C}$ overnight. The pre-culture was inoculated into 1 liter LB with kanamycin (50 ng/mL) and kept growing at $37^{\circ} \mathrm{C}$ until the optical cell density reached $0.6-0.8$ at $600 \mathrm{~nm}$. Protein production was induced by adding $0.4 \mathrm{mM}$ IPTG and the temperature was reduced to $16{ }^{\circ} \mathrm{C}$. After 20 hours, the cells were harvested by centrifugation at $4400 \times \mathrm{g}$ for 10 minutes and the pellets were resuspended with suspension buffer $(50 \mathrm{mM}$ Tris$\mathrm{HCl}$, pH 8, and $150 \mathrm{mM} \mathrm{NaCl})$. The pelleted cells were stored at $-20{ }^{\circ} \mathrm{C}$ until purification.

Frozen cells were disrupted by passing through French Press three times consecutively and the cellular debris was removed by centrifugation at $47,810 \times \mathrm{g}$ for 45 minutes at $4{ }^{\circ} \mathrm{C}$. Sodium chloride and imidazole were added to the supernatant to make their concentrations in the supernatant to be the same as in the elution buffer (50 mM Tris- $\mathrm{HCl}, \mathrm{pH}$ 8, $500 \mathrm{mM} \mathrm{NaCl,} 5 \mathrm{mM}$ imidazole). The supernatant was loaded onto a HiTrap FF His column (GE Healthcare Life Science, Piscataway, NJ) equilibrated with the elution buffer. A linear gradient of imidazole, from $10 \mathrm{mM}$ to $200 \mathrm{mM}$, was applied and the HisMtMetAP Ia was eluted at the approximately $150 \mathrm{mM}$ imidazole. Fractions containing the His-tagged MtMetAP Ia were examined by SDSPAGE be fore being poo led and concentrated with an Amicon stirred cell through a YM-10 membrane (Millipore, Billerica, MA). The concentrated protein was treated with 1,10phenathroline to remove the divalent metals. The treated protein, about $4-5 \mathrm{~mL}$, was loaded to a 5 mL HiTrap desalting column (GE Healthcare Life Science, Piscataway, NJ) to change the buffer to $50 \mathrm{mM}$ MOPS-NaOH, $\mathrm{pH}$ 7.5, and $150 \mathrm{mM} \mathrm{NaCl}$, which was pretreated with Chelex- 
100 resin (BioRad, Hercules, CA). The apoenzyme was aliquoted into $0.2 \mathrm{~mL}$ fractions and kept at $-20^{\circ} \mathrm{C}$.

\subsubsection{Untagged MtMetAP Ia preparat ion and confirmation of removal of His-tag}

A small amount of untagged MtMetAP Ia was prepared to compare the kinetic characteristic with His-tagged MtMetAP Ia. The purified HisMtMetAP Ia was treated with thrombin (1000 units /mg protein) (EMD, San Diego CA) at $4{ }^{\circ} \mathrm{C}$ for 48 hours in a buffer containing $50 \mathrm{mM}$ Tris-HClpH 8.0, and $1.5 \mathrm{mM} \mathrm{CaCl}_{2}$. The thromb in treated sample was loaded onto a HiTrap FF His tag column and the untagged MtMetAP Ia was recovered in the flowthrough. All fractions including the flow-through fractions and the eluted fractions were collected for Western blotting test.

Western blotting was carried out to check the removal of the His-tag from HisMtMetAP Ia by thrombin treatment. A horseradish peroxidase (HRP) conjugated His•Tag® antibody (EMD, San Diego, CA) was used to check for the existence of the consecutive His- tag in combination of luminescence detection. All the fractions mentioned above and the pre-treated fractions were adjusted to appropriate concentrations to make one microgram of each sample for SDS-PAGE. After electrop horesis, the separated protein bands in the polyacrylamide gel were transferred to a PVDF membrane (Pall Corp. Pensacola, FL) using Bio-Rad Semi-dry Transfer Cell (BioRad, Hercules, CA). The transfer was performed at $400 \mathrm{~mA}$ for 30 minutes. The PVDF membrane was washed with $1 \times$ TBS $(150 \mathrm{mM} \mathrm{NaCl}, 10 \mathrm{mM}$ Tris-HCl, $\mathrm{pH}$ 7.5) twice, 10 minutes for each wash and incubated with $5 \%$ non-fat milk at $4{ }^{\circ} \mathrm{C}$ overnight. The blocked membrane was washed with $1 \times$ TBSTT $(500 \mathrm{mM} \mathrm{NaCl}, 20 \mathrm{mM}$ Tris-HCl, $0.2 \%$ v/v Triton X-100, $0.05 \%$ v/v Tween20, $\mathrm{pH}$ 7.5) twice, 10 minutes for each time, and with $1 \times$ TBS for 10 minutes. Thereafter, it was 
incubated with HRP conjugated His-tag antibody $(1: 2000)$ at $4{ }^{\circ} \mathrm{C}$ for 1 hour, followed by membrane washing with $1 \times$ TBSTT twice, and with $1 \times$ TBS once, 10 minutes for each wash. The substrate for detection was made immediately prior to use by combining equal parts of $2 \times$ Luminol/Enhancer Solution and $2 \times$ WestPico Stable Peroxide Solution (ThermoF isher Scientific, Rockford, IL). They were mixed briefly and added to the membrane. The PVDF Membrane was ready for luminescent signal detection after being soaked in the substrate mix for 1 minute. Excess substrate was drained from the membrane by touching the membrane edge to a paper towel. The membrane was placed on a fresh sheet of plastic wrap. Bubbles between plastic and membrane were removed by folding plastic over the membrane. The liquid was gently removed from the exterior of the plastic and A gLOCATOR ${ }^{\mathrm{TM}}$ Luminescent Label was put into the plastic folder to record blot-identifying data for future reference. The image was taken in the chamber of the imaging system from UltraLum, (Claremont, CA).

\subsubsection{Metal activation of HisMtMetAP Ia}

Kinetic analysis with His MtMetAP Ia was carried out with a fluorescence based assay, using the fluorogenic substrate methionine-7-amido-4-methyl-courmarin (Met-AMC) (Bacham, Bioscience, King of Prussia, PA), which was hydrolyzed by MetAP in the presence of covalent metal .The released AMC emits fluorescence that can be detected at $460 \mathrm{~nm}$ with $\lambda_{\mathrm{ex}} 360 \mathrm{~nm}$ as an enzymatic activity monitor. All kinetic experiments were carried out in 384-well plates in a SpectraMax Gemini XPS plate reader (Molecular Devices, Sunnyvale, CA), at room temperature as described $[8,19]$.

For metal activation, each well contained 50 mM MOPS-NAOH, pH 7.5, $100 \mu \mathrm{M}$ MetAMC, $50 \mathrm{nM}$ apoenzyme and increasing amounts of metal ions $\left(\mathrm{NiCl}_{2}, \mathrm{CoCl}_{2}, \mathrm{MnCl}_{2}\right.$, or $\mathrm{FeCl}_{2}$ 
with twice the concentration of ascorbic acid). The total volume was $80 \mu \mathrm{L}$. The initial velocity values were converted to specific activity values and plotted against increasing concentrations of the metal.

In order to describe metal activation of MtMetAP Ia, we determined the metal concentration that gave $50 \%$ activity of the enzymes, and defined it as apparent $K_{\mathrm{d}}$ as it suggested the binding affinity. For determination for binding of the divalent metals to HisMtMetAP Ia, the titration curves were generated using different amounts of HisMtMetAP Ia (12.5 $\mathrm{nM}$ apoenzyme for $\mathrm{Ni}(\mathrm{II}), 25 \mathrm{nM}$ apoenzyme for $\mathrm{Co}(\mathrm{II})$ and $\mathrm{Fe}(\mathrm{II})$, and $50 \mathrm{nM}$ apoenzyme for $\mathrm{Mn}(\mathrm{II}))$ in $50 \mathrm{mM}$ MOPS-NAOH-NAOH, pH 7.5, $100 \mu \mathrm{M}$ Met-AMC and increasing concentrations of either $\mathrm{CoCl}_{2}, \mathrm{MnCl}_{2}, \mathrm{NiCl}_{2}$ or $\mathrm{FeCl}_{2}$. In the case of $\mathrm{FeCl}_{2}$, ascorbic acid was added at a two-fold concentration of $\mathrm{FeCl}_{2}$.

The metal activation was also carried out with untagged MtMetAP Ia for comparison with that of HisMtMetAP Ia.

\subsubsection{Kinetic meas ure ment of different metalloform HisMtMetAP Ia}

For determination of Michaelis-Menten kinetic parameters, enzyme activities were measured in the $80 \mu \mathrm{L}$ assay mixture containing $50 \mathrm{mM}$ MOPS-NAOH, pH 7.5, HisMtMetAP Ia (25 nM Co(II)- or Fe(II)- substituted enzyme, 50 nM Mn(II)-substituted enzyme, or 12.5 nM Ni(II)-substituted enzyme), covalent metals (10 $\mu \mathrm{M} \mathrm{FeCl}_{2}$ with $20 \mu \mathrm{M}$ ascorb ic acid, $20 \mu \mathrm{M}$ $\mathrm{CoCl}_{2}, 200 \mu \mathrm{M} \mathrm{MnCl}_{2}$, or $20 \mu \mathrm{M} \mathrm{NiCl}_{2}$ ), and substrate Met-AMC in a 2-fold dilution up to 2 $\mathrm{mM}$ at room temperature. The initial rates were plotted with the corresponding substrate concentrations, a nd the curve was fitted to the Michaelis-Menten equation to ob tain $\mathrm{Km}$ and $\mathrm{kcat}$ values (Figure 2-1). 


\begin{tabular}{|c|c|c|c|c|c|}
\hline [Substrate] & Va & $V_{c}$ & $(\mathrm{Va}-\mathrm{Vc})^{2}$ & STD & \\
\hline 2000 & 30.591 & 30 & 80294 & $2 \mathrm{Km}$ & 70.5 \\
\hline 1000 & 30.678 & 29 & 2667 & $2 V \max$ & 31.4 \\
\hline 500 & 29.242 & 27 & 380 & 1 Sum(Va-Vc)2 & 45 \\
\hline 250 & 24.964 & 24 & 331 & 1 & \\
\hline 125 & 19.253 & 20 & 465 & 0 & \\
\hline 62.5 & 12.420 & 15 & 78 & 0 & \\
\hline 31.25 & 7.655 & 10 & 391 & 0 & \\
\hline 15.625 & 3.919 & 6 & 65 & 0 & \\
\hline 7.8125 & 2.071 & 3 & 32 & 0 & \\
\hline 3.90625 & 1.034 & 2 & 5 & 0 & \\
\hline 1.953125 & 0.471 & 1 & 15 & 0 & \\
\hline 0.9765625 & 0.282 & 0 & 23 & 0 & \\
\hline
\end{tabular}

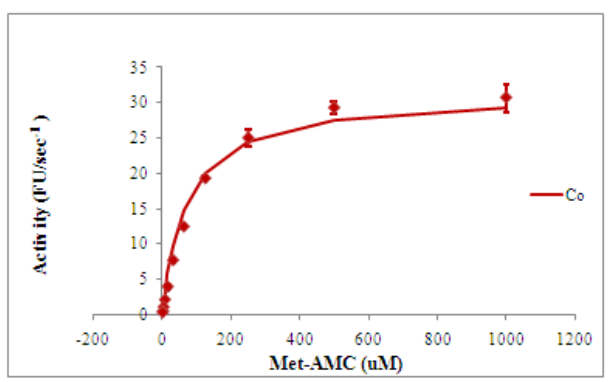

\begin{tabular}{|c|c|c|c|c|c|}
\hline [Substrate] & Va & $V_{c}$ & $(\mathrm{Va}-\mathrm{Vc})^{2}$ & STD & \\
\hline 2000 & 13.805 & 14 & 0 & $0 \mathrm{Km}$ & 169.9 \\
\hline 1000 & 12.939 & 13 & 0 & $0 V \max$ & 15.0 \\
\hline 500 & 11.092 & 11 & 0 & 0 Sum(Va-Vc)2 & 0 \\
\hline 250 & 9.124 & 9 & 0 & 1 & \\
\hline 125 & 6.664 & 6 & 0 & 1 & \\
\hline 62.5 & 4.365 & 4 & 0 & 0 & \\
\hline 31.25 & 2.556 & 2 & 0 & 1 & \\
\hline 15.625 & 1.395 & 1 & 0 & 0 & \\
\hline 7.8125 & 0.530 & 1 & 0 & 0 & \\
\hline 3.90625 & 0.353 & 0 & 0 & 0 & \\
\hline 1.953125 & 0.162 & 0 & 0 & 0 & \\
\hline 0.9765625 & 0.225 & 0 & 0 & 1 & \\
\hline
\end{tabular}

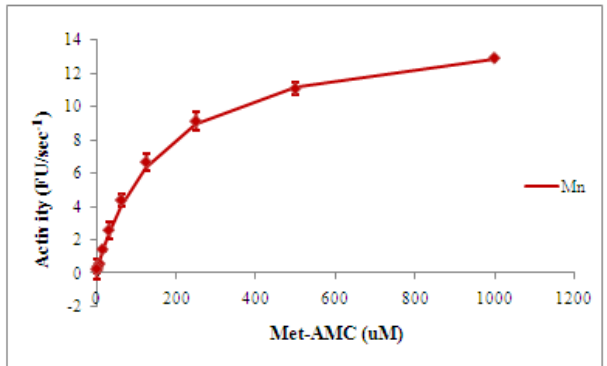

Figure 2-1 Calculation of $K_{m}$ and $K_{\text {cat }}$ values using non linear regression curve fitting bas ed on Michae lis-Menten equation. Va represents the measured enzyme activities. Vc represents the calculated activities based on Michaelis-Mention equation $(\mathrm{V}=\mathrm{Vmax} *[\mathrm{~S}] /(\mathrm{Km}+[\mathrm{S}]))$. 


\subsubsection{IC I $_{50}$ determination with different metalloform HisMtMetAP Ia}

The $\mathrm{IC}_{50}$ is the compo und concentration at which $50 \%$ of the enzyme activity is inhibited. For $\mathrm{IC}_{50}$ determination, enzyme activities were monitored in the presence of inhibitors at different concentrations and converted into percent inhibitions. The $\mathrm{IC}_{50}$ value was obtained from the non-linear curve fitting of percent inhibition (\% inhibition) vs. inhibitor concentration [I] using t he equation,

$$
\% \text { inhibition }=\frac{100}{1+\left(\frac{I C_{50}}{[\text { Inhibitor }]}\right)^{k}}
$$

where $k$ is the Hill coefficient, the [inhibitor] is the inhibitor concentration, and the \% inhibition is the percent of activity in the presence of inhibitor at the corresponding concentration.

The inhibitors were serially diluted with eight concentrations in total, and the maximal concentration of inhibitor was $1 \mathrm{mM}$. The $80 \mu \mathrm{L}$ assay mix included $50 \mathrm{mM}$ MOPS-NAOH, pH 7.5, $100 \mu \mathrm{M}$ Met-AMC, HisMtMetAP Ia (50 nM Co(II)- or Fe(II)- substituted enzyme, $200 \mathrm{nM}$ Mn(II)-substituted enzyme, or $12.5 \mathrm{nM} \mathrm{Ni(II)-substituted} \mathrm{enzyme),} \mathrm{and} \mathrm{metal} \mathrm{ions} \mathrm{at} \mathrm{the} \mathrm{optimal}$ concentrations for the activity of MtMetAP Ia (10 $\mu \mathrm{M} \mathrm{FeCl}_{2}$ with $20 \mu \mathrm{M}$ ascorbic acid, $20 \mu \mathrm{M}$ $\mathrm{CoCl}_{2}, 200 \mu \mathrm{M} \mathrm{MnCl}_{2}$, or $20 \mu \mathrm{M} \mathrm{NiCl}_{2}$ for the opt imal enzymatic activities). The percentages of inhibition converted from the activities were applied to calculate $\mathrm{IC}_{50}$ (Figure 2-2).

\subsubsection{Co-crystallization of His MtMetAP Ia and MtMetAP Ia with inhibitors}

Concentrated HisMtMetAP Ia samples were combined with $2 \mathrm{mM}$ covalent metals be fore mixing with inhibitors at a ratio of 1:5 or 1:10 (Table 2-5). The enzyme-compound complex was mixed up with well solution at a 1:1 ratio and used to set up crystal trays using a hanging drop vapor-diffusion method at room temperature. The screening kits from Hampton 


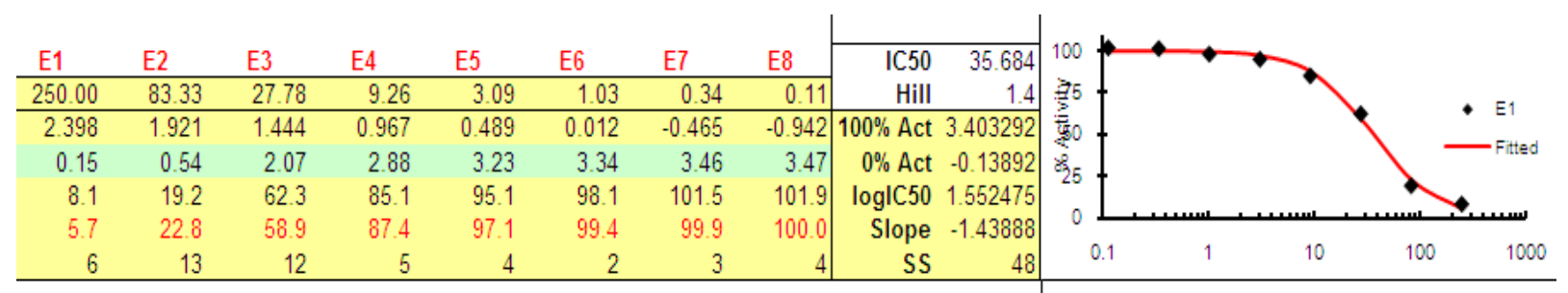

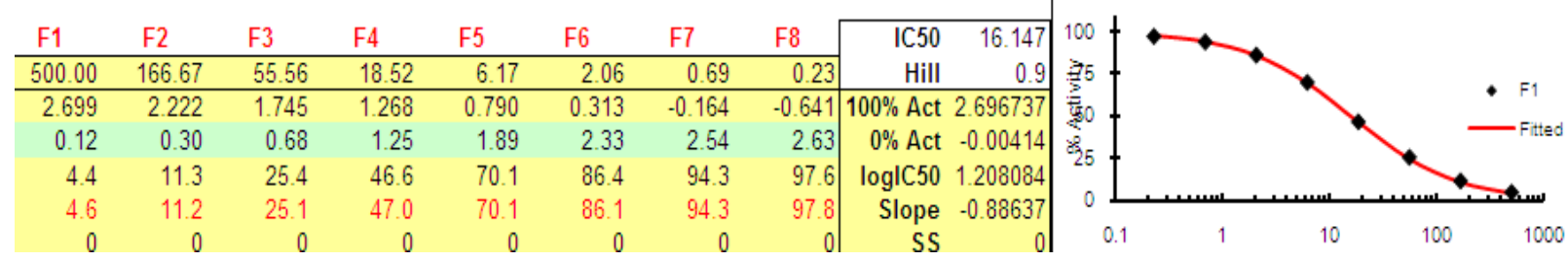

Figure 2-2 Calculation of $\mathbf{I C}_{50}$ using non-linear curve fitting. The percentage of inhibition (\% inhibition) was plotted against inhibitor concentration using the equation described in Method 2.2.8. 
Research (Aliso Viejo, CA) were tested, including Crystal Screening ${ }^{\mathrm{TM}}$, Crystal Screening $2^{\mathrm{TM}}$, Index ${ }^{\mathrm{TM}}$, and PEG/ION TM. A small amount of untagged MtMetAP Ia was also prepared and concentrated to $2.5 \mathrm{mg} / \mathrm{mL}$ to test using t ne PEG/ION.

\section{$2.3 \quad$ Results}

\subsubsection{Constructs of MtMetAP Ia}

The gene mapA was first cloned into the pGEMEX1 plasmid. The DNA sequence showed that the last 12 nucleotides at the end of the map A gene were missing in the constructed plasmid of pGEMEX1-MtMetAP Ia-1 due to an EcoRI restriction site (G-AATTC) in the mapA gene. Two DNA oligos (Table 2-1), oligonucleotide RF and oligonucleotide RR, were designed to mutate the EcoRI restriction site in the mapA gene. Meanwhile, a restriction site of AvrII was introduced to identify the mutant. The modified plasmid pGEMEX1-MtMetAP Ia-2 was confirmed with a corrected DNA insert and transformed into E.coli BL21(DE3) competent cells for protein expression.

MtMetAP Ia protein was overexpressed upon IPTG induction (Figure 2-3A), which was indicated by a single band observed in the post-induction sample but not in pre-induction sample. The observed molecular weight of MtMetAP Ia was around $37 \mathrm{Kd}$, which was larger than its theoretical molecular weight of $29.7 \mathrm{Kd}$. It might be due to the hydrodynamic radius of the protein which in turn affected the protein mobility on SDS-PAGE.

Due to the poor solubility of MtMetAP Ia, a n expression optimization test was carried out by changing the components of the culture medium [18]. The MtMetAP Ia proteins expressed in different kinds of media were examined by SDS-PAGE (Figure 2-3B). The MtMetAP Ia protein was expressed as it was observed in the whole cell lysate of IPTG-induced samples on the gel 


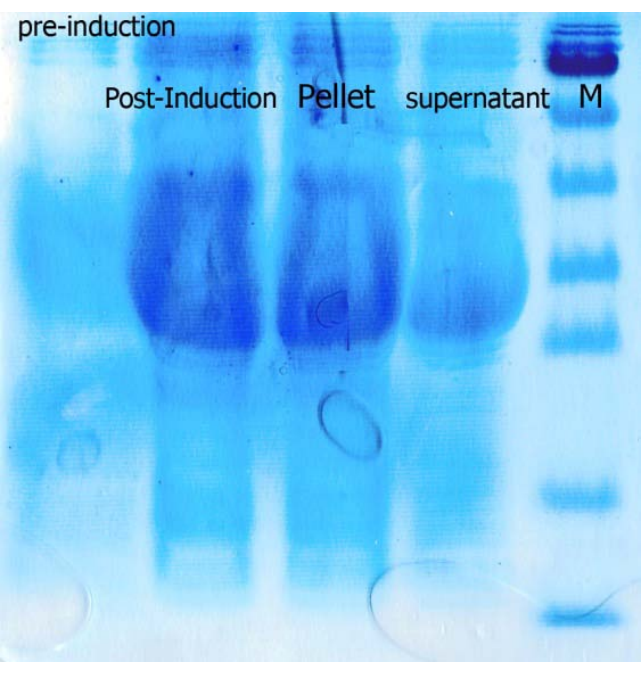

$100 \mathrm{kD}$

$72 \mathrm{kD}$

$55 \mathrm{kD}$

$40 \mathrm{kD}$

$35 \mathrm{kD}$

$25 \mathrm{kD}$

$15 \mathrm{kD}$
Figure 2-3A Overexpression of HisMtMetAP upon IPTG induction.

From left to right are whole cell lysate from pre-induction sample, whole cell lysate from post-induction sample, the pellet and the supernatant of postinduction sample separated by centrifugation at $16,873 \times \mathrm{g}$ for 10 minutes. $\mathrm{M}$ is the prestained protein ladder from Fermentas. The expressed MtMetAP Ia showed a Mw of $37 \mathrm{Kd}$, which was larger than its theoretical Mw of $29.7 \mathrm{Kd}$.
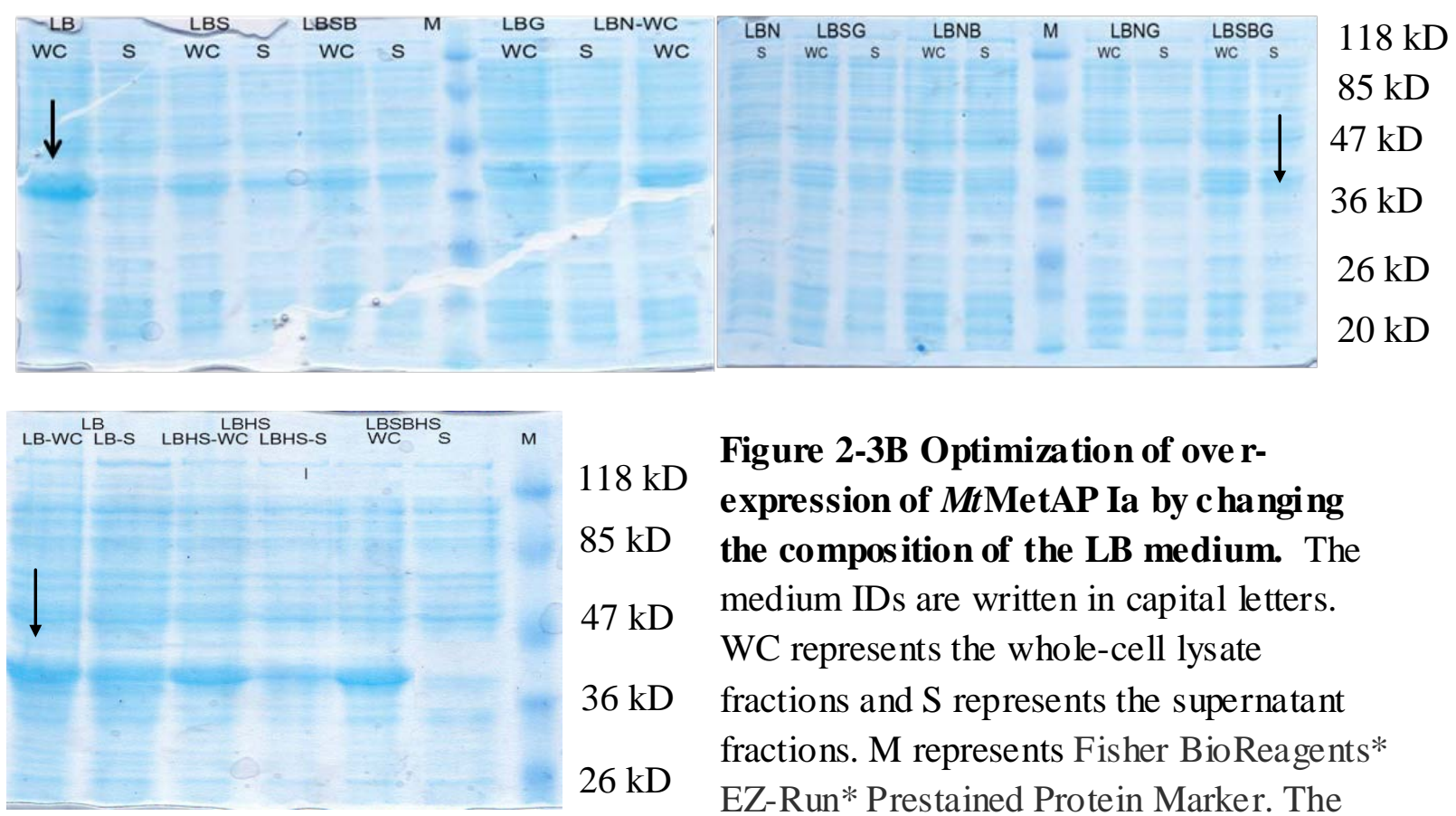

\section{$118 \mathrm{kD}$}

Figure 2-3B Optimization of ove $r$ -

$85 \mathrm{kD}$ expression of MtMetAP Ia by changing

\section{$47 \mathrm{kD}$} the composition of the LB medium. The

$47 \mathrm{kD}$

medium IDs are written in capital letters.

$36 \mathrm{kD}$ fractions and S represents the supernatant

$26 \mathrm{kD}$ fractions. M represents Fisher BioReagents* EZ-Run* Prestained Protein Marker. The observed Mw of HisMtMetAP Ia is $37 \mathrm{Kd}$. 
and it was not seen in the pre-induction samples. However, the molecular weight of the expressed protein was around $37 \mathrm{KD}$, which was larger than the theoretical molecular weight of MtMetAP Ia, 29.7 KD. However, it could barely be seen in the supernatant, indicating very little soluble proteins was expressed. The culture medium and the heat shock treatment seemed not to improve the solubility of MtMetAP Ia. Therefore, LB medium was subsequently used to grow E.coli cells for MtMetAP Ia expression.

\subsubsection{Expression and purification of HisMtMetAP Ia protein.}

MtMetAP Ia was first cloned into plasmid pGEMEX-1 as an untagged protein, because of the possible interference between the His-tag and divalent metals. However, the untagged MtMetAP Ia showed poor solubility and it was extremely hard to trace the enzyme during purification. Therefore, the gene mapA was cloned into pET28a to introduce a His-tag at the Nterminus. Even though HisMtMetAPa did not have a better solubility, the small amount of soluble protein with a His-tag was easily purified by metal-affinity chromatography (Figure 2-4). Purified HisMtMetAP Ia was treated with 1,10-phenathroline to remove metal ions, and the purified apoenzyme showed no activity in hydrolyzing the fluorogenic substrate Met-AMC unless metal was added in the assay mixture. The yield of HisMtMetAP Ia was around 2 mg per liter of E.coli cell culture.

\subsubsection{Activa tion of His MtMetAP Ia apoe nzy me by diva lent metals.}

Activity of MtMetAP Ia was monitored by detecting an increase of fluorescence of 7amido-4-methylcourmarin released from the hydrolysis of the non-fluorogenic substrate MetAMC. The metal activation was immediate, and the fluorescence increased linearly for at least 30 min once the apoenzyme was mixed with the metals (10 minutes for Fe (II) with 2-fold 


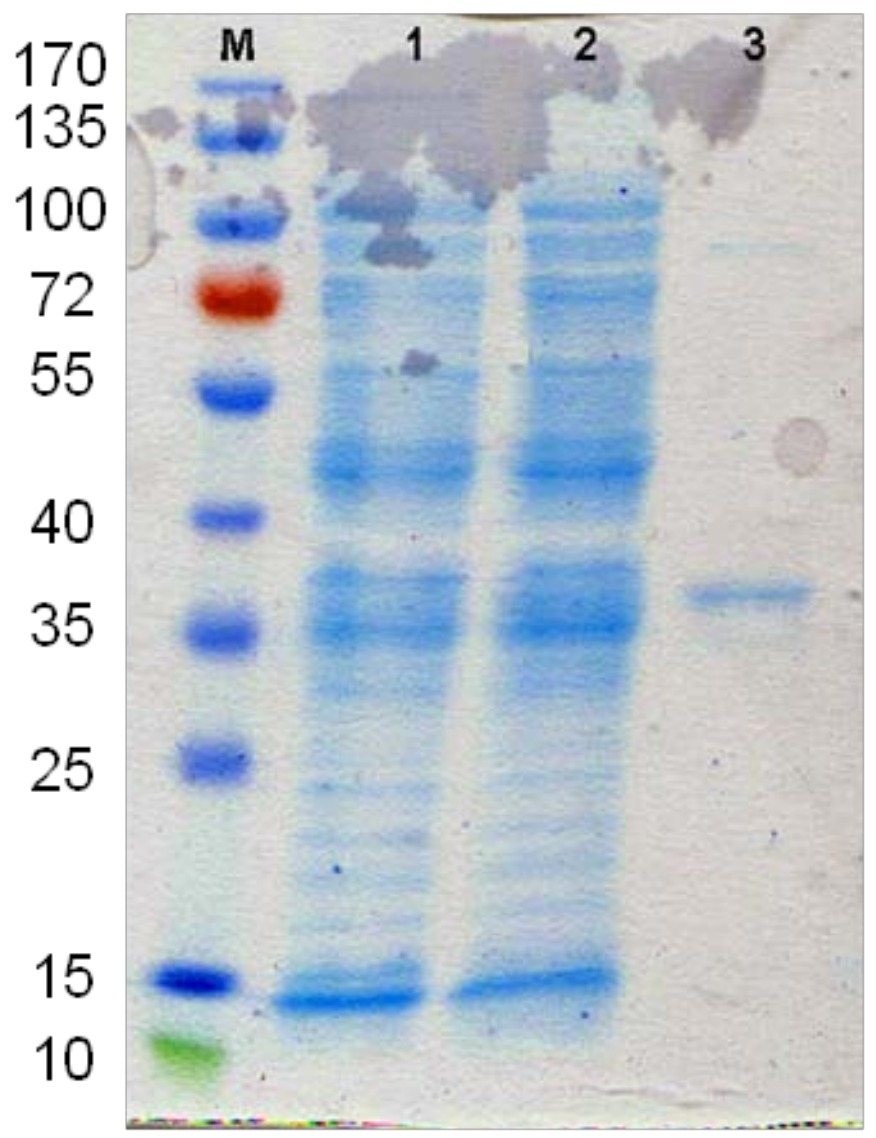

Figure 2-4 The purification of HisMtMetAP Ia

M: protein ladder from Fermantas

Lane1: flow-through

Lane2: supernatant

Lane3: eluted His-tagged MtMetAP Ia 
concentration of ascorbic acid). The apoenzyme concentration was held constant at $50 \mathrm{nM}$ and increasing concentrations of metal were added for activation. $\mathrm{Ni(II)}$ was the most efficient metal to activate MtMetAP Ia, followed by $\mathrm{Co}(\mathrm{II}), \mathrm{Mn}(\mathrm{II})$ and Fe(II) (Figure. 2-5). These were very similar to the ob servations in ot her MetAPs [8] [20] [21], but were significantly different from those reported by Zhang et al. [17], in which Co(II) was an activator, Mn(II) had no effect, and $\mathrm{Ni(II)}$ and Fe(II) showed inhibition instead of activation. The discrepancies likely resulted from the proteins used in the assays. The MtMetAP Ia characterized in our assay was in the apoform, while Zhang and colleagues used proteins with metal ions likely already incorporated. It is clear from the activation curves that high concentration of a metal ion often inhibited the enzyme activity; therefore inhibition could be observed for an activator when a metalated MetAP is used.

Since the His-tag could potentially affect metal binding, a small amount of untagged MtMetAP Ia was purified and tested to compare with that of HisMtMetAP Ia. After being treated by thrombin, the HisMtMetAP Ia was loaded onto a HiTrap His tag column to separate the untagged MtMetAP Ia (Figure 2-7A). Three peaks in total appeared during elution; peak 1 and peak 2 were eluted at low imidazole concentration while peak 3 was eluted at high imidazole concentration. All three fractions were identified by Western blotting using HRP-conjugated anti-His antibody. Only fractions in peak 2 were untagged MtMetAP Ia (Figure 2-7B).

This untagged MtMetAP Ia was used for metal activation and measurement of binding affinity indicated as an apparent $K_{d}$ in comparsion with HisMtMetAP Ia (Table 2-2). The result showed comparable metal activation curves. Fe(II) showed the tightest binding to both the tagged and untagged enzymes with smallest apparent $K_{d}$ values, followed by $\mathrm{Co}(\mathrm{II})$, and $\mathrm{Ni}$ (II). The apparent $K_{d}$ of Mn (II) indicated the weakest binding to the protein. 

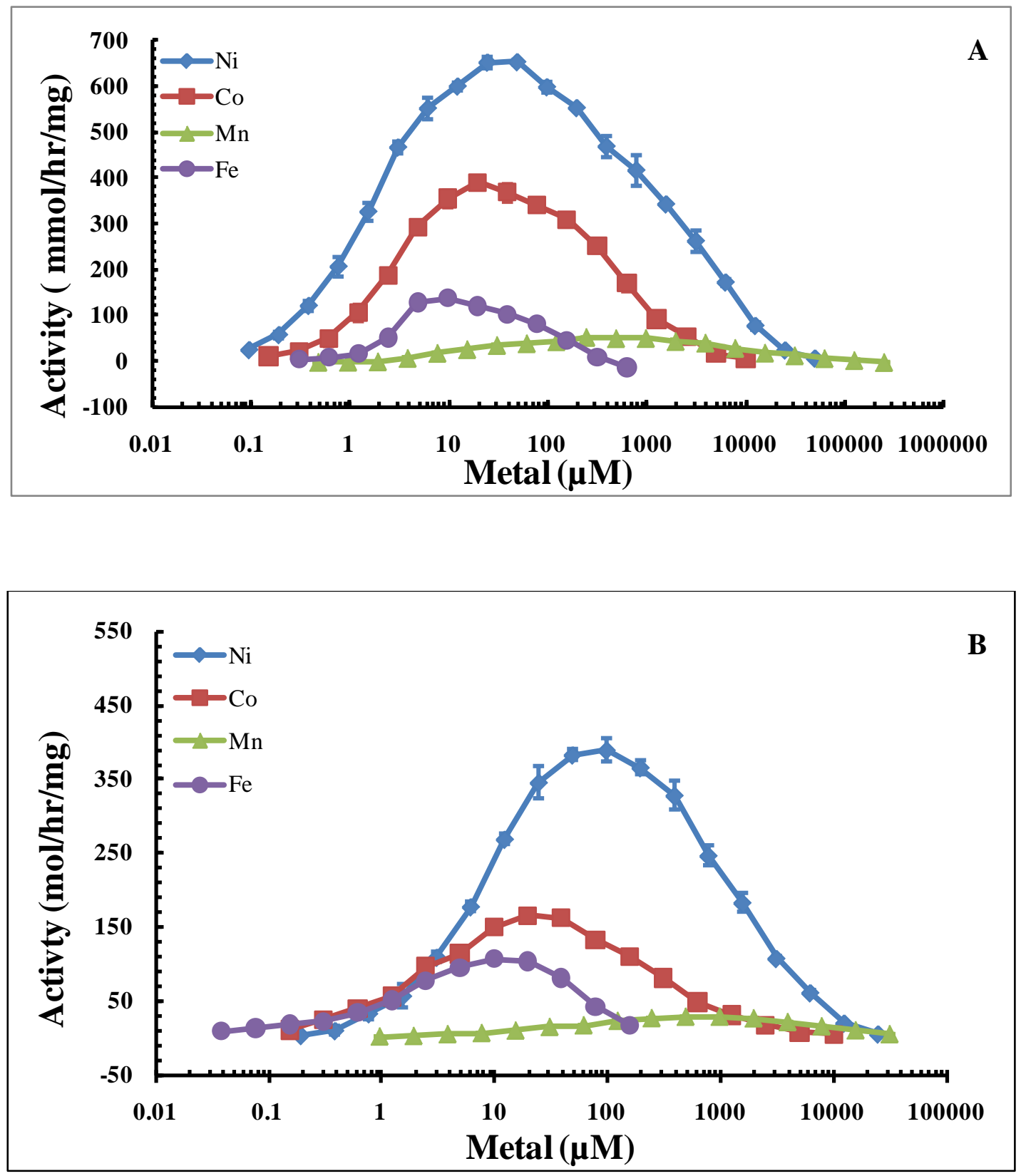

Figure 2-5 Metal activation of (A) HisMtMetAP Ia and (B) untagge d MtMetAP Ia 

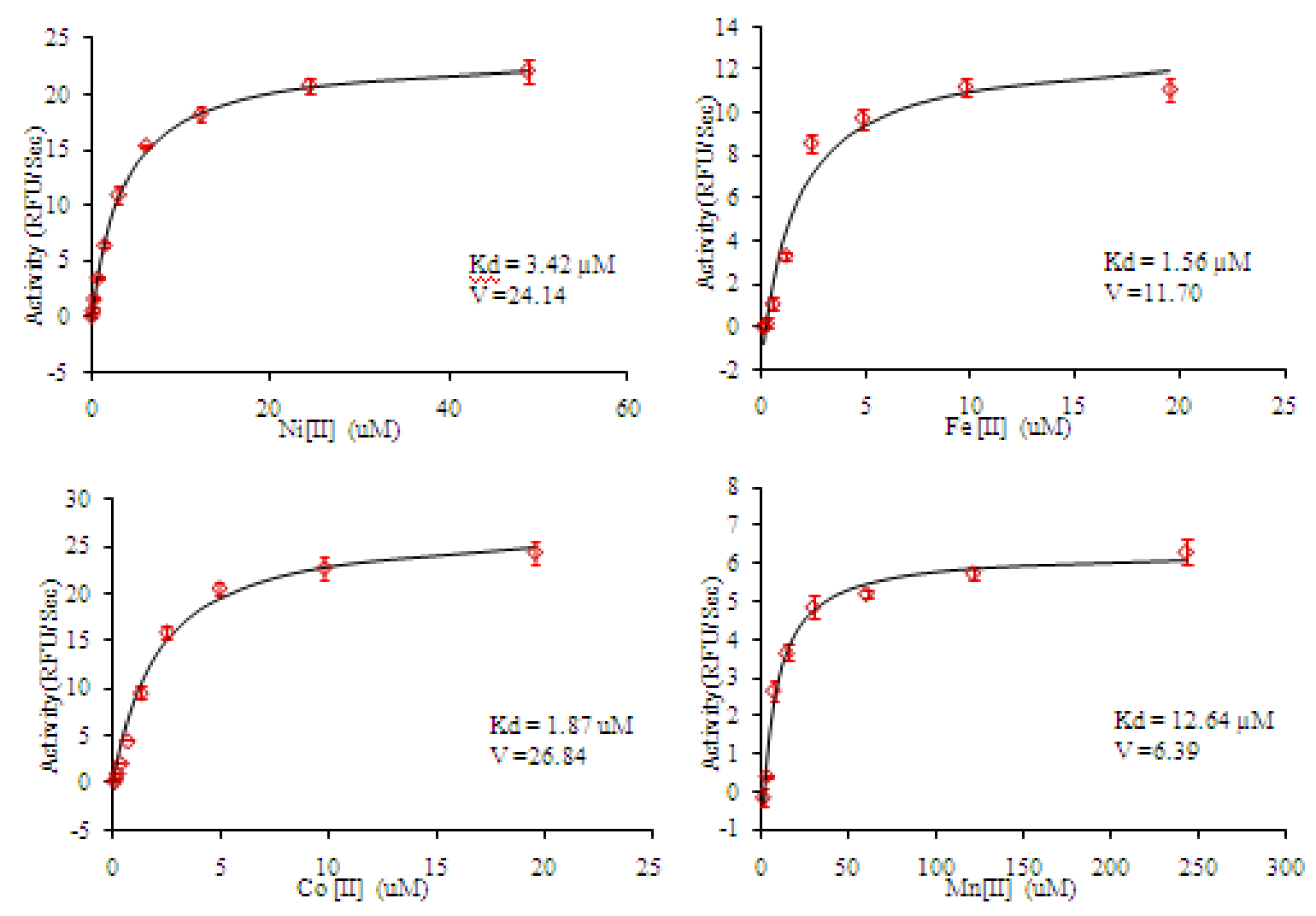

Figure 2-6 Calculation of the apparent $K_{d}$ of diffe rent metalloforms of MtMetAP Ia. Details were described in Method 2.3.3.

Table 2-3 Comparis on of metal activa tion of His MtMetAP Ia and MtMetAP Ia

\begin{tabular}{|c|c|c|c|c|}
\hline His MtMetAPa & $\mathrm{Fe}(\mathrm{II})$ & $\mathrm{Ni}(\mathrm{II})$ & $\mathrm{Co}(\mathrm{II})$ & $\mathrm{Mn}(\mathrm{II})$ \\
\hline$A p p K_{\mathrm{d}}, \mu \mathrm{M}$ & $1.56 \pm 0.03$ & $2.31 \pm 0.11$ & $1.87 \pm 0.10$ & $12.64 \pm 0.71$ \\
\hline Vmax (RFU/Sec) & $11.70 \pm 2.16$ & $24.14 \pm 2.55$ & $26.84 \pm 1.27$ & $6.39 \pm 0.83$ \\
\hline MtMetAP1a & $\mathrm{Fe}(\mathrm{II})$ & $\mathrm{Ni}(\mathrm{II})$ & $\mathrm{Co}(\mathrm{II})$ & $\mathrm{Mn}(\mathrm{II})$ \\
\hline$A p p K_{\mathrm{d}}, \mu \mathrm{M}$ & $1.59 \pm 0.11$ & $6.29 \pm 0.5$ & $2.33 \pm 0.37$ & $33.76 \pm 2.30$ \\
\hline Vmax (RFU/Sec) & $8.43 \pm 0.38$ & $14.57 \pm 0.51$ & $12.87 \pm 0.19$ & $4.04 \pm 0.23$ \\
\hline
\end{tabular}




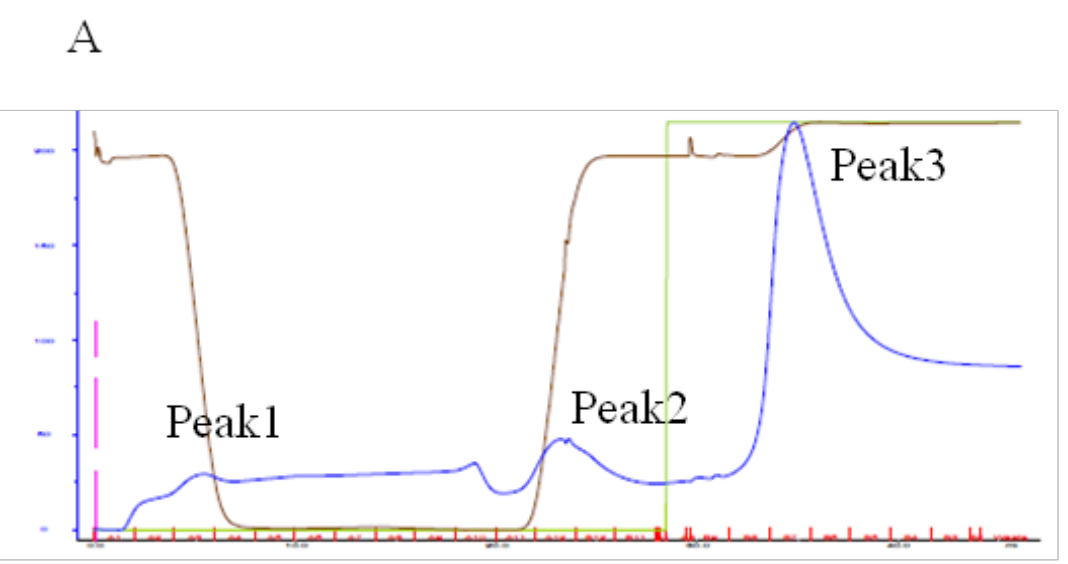

\section{B}

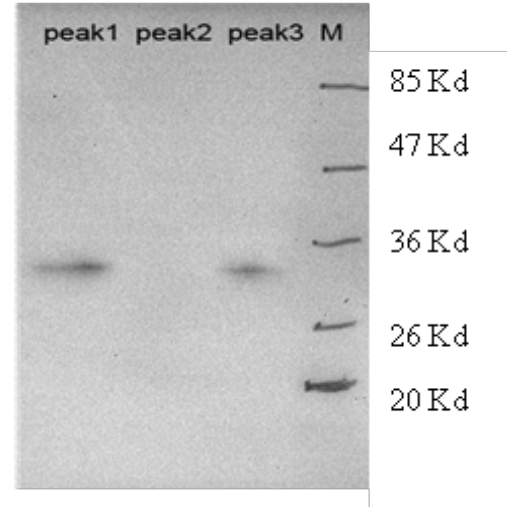

Figure 2-7 Removal of His-tag from HisMtMetAP Ia confirmed by Western blot

A: The HisMtMetAP Ia was loaded onto $5 \mathrm{~mL}$ HiTrap His column after thrombin treatment. There were three peaks during the elution: peaks 1-3.

B: Fractions from peaks 1-3 were identified by Western blotting using HRP-conjugated anti-His antibod $\mathrm{y}$. 
When the metal activation of HisMtMetAP Ia to the untagged MtMetAP Ia were compared, no significant difference in binding a ffinity among the metals was observed (Table 22, Figure 2-7). The apparent $K_{d}$ of Co(II) to HisMtMetAP Ia and untagged MtMetAP Ia were $1.87 \mu \mathrm{M}$ and $2.33 \mu \mathrm{M}$, respectively; and the apparent $K_{d}$ for Fe(II) binding to His MtMetAP Ia and untagged MtMetAP Ia were $1.56 \mu \mathrm{M}$ and $1.59 \mu \mathrm{M}$, respectively. The similar binding affinity of $\mathrm{Co}(\mathrm{II})$ and $\mathrm{Fe}(\mathrm{II})$ to MtMetAP Ia regardless of the His-tag was also coincident with the metal titration curves (Figure 2-5).

In the cases of $\mathrm{Ni}$ (II) and $\mathrm{Mn}$ (II), a smaller $K_{d}$ with untagged MtMetAP Ia than HisMtMetAP Ia was observed. The $K_{d}$ value of HisMtMetAP Ia and MtMetAP Ia for Ni (II) were $2.31 \mu \mathrm{M}$ and $6.29 \mu \mathrm{M}$, respectively. The $K_{d}$ values for Mn-substituted HisMtMetAP Ia and MtMetAP Ia were $12.64 \mu \mathrm{M}$ and $33.76 \mu \mathrm{M}$, respectively (Figure 2-6). Theoretically, the apparent $K_{d}$ measured from His-tagged protein should be bigger than the apparent $K_{d}$ measured from untagged protein if there is any interaction between the His-tag and the metal. The reason for the reverse observation could possibly be the loss of the enzyme activities (Table 2-3), so that the binding was not reflected by the AMC production.

In summary, the activation of all the metals showed similar order in both His-tagged and untagged MtMetAP Ia, which was Fe(II) $>\mathrm{Co}$ (II) $>\mathrm{Ni}$ (II) $>\mathrm{Mn}$ (II), with the binding affinity from high to low. The metal concentration for optimal enzyme activity were used for the following kinetic characterization.

\subsubsection{Kinetic measure ment of different metalloform HisMtMetAP Ia:}

For $\mathrm{Km}$ measurements, it is usual that the substrate concentration is significantly higher than the enzyme concentration. In the HisMtMetAP Ia case, the enzyme concentration was 

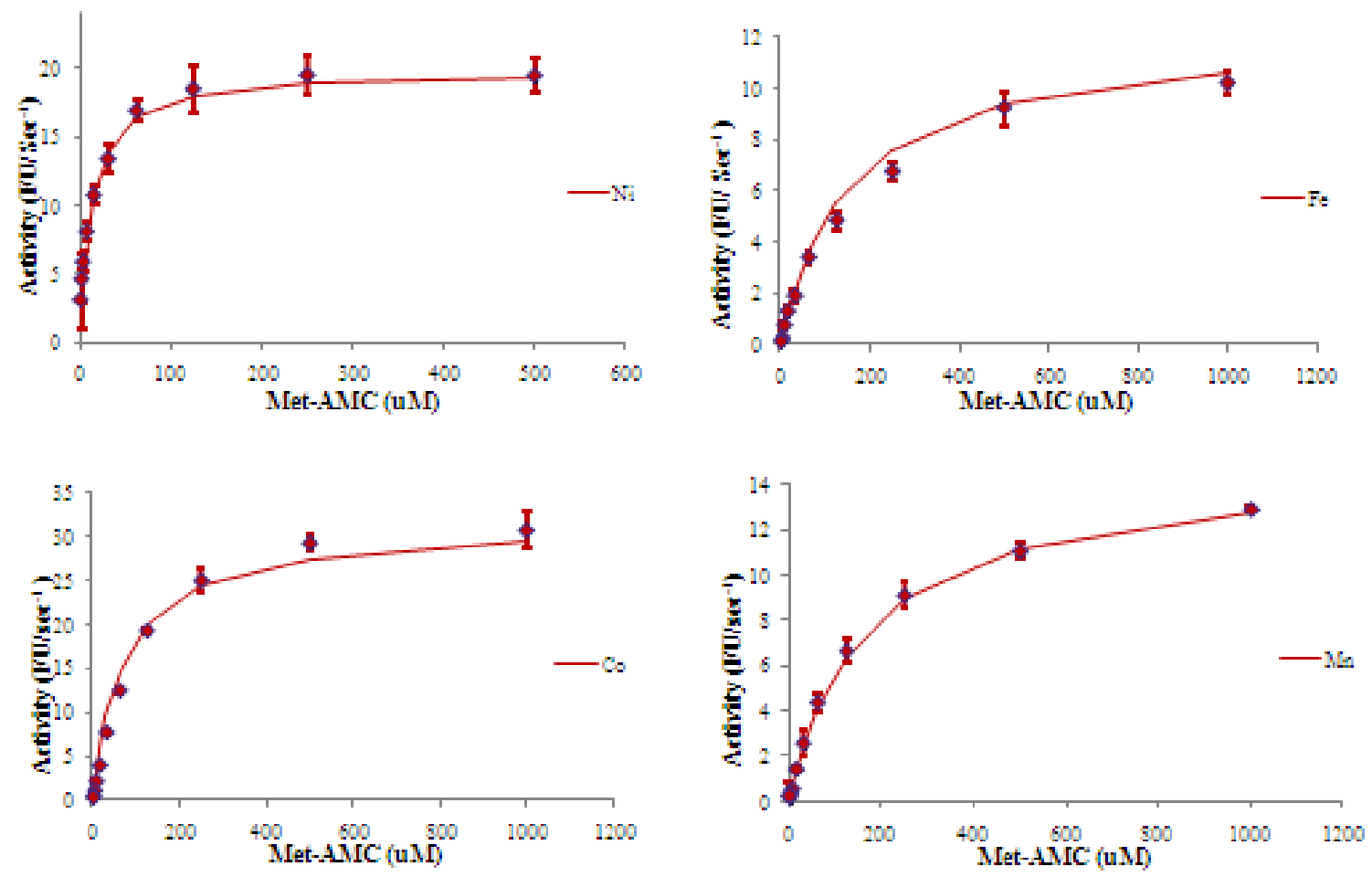

Figure 2-8 Calculation of the $K_{m}$ of different metalloforms of MtMetAP Ia by using no linear regression curve fitting based on Michaelis-Menten equation.

Table 2-4 Kinetic measurement of HisMtMetAP Ia

\begin{tabular}{ccccc}
\hline His MtMetAP Ia & $\mathrm{Fe}(\mathrm{II})$ & $\mathrm{Ni}(\mathrm{II})$ & $\mathrm{Co}(\mathrm{II})$ & $\mathrm{Mn}(\mathrm{II})$ \\
\hline$K_{\mathrm{m}}, \mu \mathrm{M}$ & $148.96 \pm 9.26$ & $13.13 \pm 2.62$ & $70.46 \pm 7.52$ & $169.92 \pm 10.29$ \\
$k_{\mathrm{cat}}, \mathrm{sec}^{-1}$ & $0.1429 \pm 0.0077$ & $0.4779 \pm 0.0068$ & $0.3719 \pm 0.018$ & $0.062 \pm 0.018$ \\
$k_{\mathrm{cat}} / K_{\mathrm{m}}, \mathrm{M}^{-1} \mathrm{sec}^{-1}$ & 959 & 35634 & 5277 & 364 \\
\hline
\end{tabular}

The Ni(II)-substituted HisMtMetAP Ia showed the highest affinity for substrate, followed by the Co(II)-substituted enzyme. Both Mn(II)-substituted and Fe(II)-substituted His MtMetAP Ia gave $K_{m}$ values that were about $11 \sim 13$ fold bigger than the $K_{m}$ of Ni(II)substituted HisMtMetAP Ia. 
around nM. Serially diluted substrates of Met-AMC from $2 \mathrm{mM}$ to $0.9 \mu \mathrm{M}$ were prepared and HisMtMetAP Ia with the optimal metal concentration used to initiate the hydrolysis of Met from Met-AMC. The increase in fluorescence at $460 \mathrm{~nm}\left(\lambda_{\mathrm{Ex}}=360 \mathrm{~nm}\right)$ was recorded and converted into $\mu \mathrm{M}$ AMC per min (Figure 2-8) (Table 2-3).

At the optimal activating metal concentrations for each metal $\left(10 \mu \mathrm{M} \mathrm{FeCl}_{2}, 20 \mu \mathrm{M}\right.$ $\mathrm{CoCl}_{2}, 200 \mu \mathrm{M} \mathrm{MnCl}$, or $20 \mu \mathrm{M} \mathrm{NiCl}$ ), Michaelis-Menten constants were calculated for substrate hydrolysis. Ni(II)-activated MtMetAP Ia was most efficient among the metallo forms tested in catalyzing the hydrolys is, with the lowest $K_{m}$ and the fastest $k_{\text {cat }}$, consistent with the metal titration curves (Figure. 2-5). Co(II) was the next, Fe(II) followed and Mn(II) was the least efficient. It is important to note that although this order of activation is similar for MtMetAP Ia and MtMetAP Ic. However MtMetAP Ia is a much more efficient enzyme.

\subsubsection{IC I $_{50}$ determination with different metalloform MtMetAP Ia:}

Assignment of the physiologically relevant metalloform has been difficult, and a novel approach was developed for the assignment using the metalloform-selective inhibitors that can distinguish different metals at the active site $[11,22]$. In our research on characterization of EcMetAP, a set of MetAP inhibitors were tested for the inhibition of different metalloforms [23] . For comparison, the same inhibitors for metalloform-selective inhibition were investigated with MtMetAP Ia (Table 2-4). From previous tests on EcMetAP; compound s 1 and 2 showed specific inhibition on Fe(II)-form enzyme [24], compounds 3 and 4 were Mn(II)-form selective [22], and compounds 5-7 were $\mathrm{Co}$ (II)- and $\mathrm{N}$ i(II)- for m selective [22-23].However, when they were tested on different metal-subs tituted MtMetAP Ia, compounds 1 and 2 showed potent inhibition in all four metalloforms, and their metalloform selectivity was lost (Table 2 -5). It was more surprising 
Table 2-5. Inhibition of enzymatic activities of purified MtMetAP Ia ${ }^{\text {a }}$

\begin{tabular}{ccccc} 
& \multicolumn{4}{c}{ MtMetAP Ia $^{\mathrm{b}}$} \\
\cline { 2 - 5 } Cmpd & $\mathrm{Fe}(\mathrm{II})$ & $\mathrm{Ni}(\mathrm{II})$ & $\mathrm{Co}(\mathrm{II})$ & $\mathrm{Mn}(\mathrm{II})$ \\
\hline 1 & 0.19 & 0.7 & 0.031 & 0.11 \\
2 & 0.07 & 2.3 & 0.53 & 0.1 \\
3 & $>250$ & $>250$ & $>250$ & 0.25 \\
4 & $>250$ & 172 & 20 & 104 \\
5 & $>250$ & $>250$ & $>250$ & $>250$ \\
6 & $>250$ & $>250$ & $>250$ & $>250$ \\
7 & $>250$ & $>250$ & $>250$ & $>250$ \\
8 & $>250$ & $>250$ & 205 & $>250$ \\
\hline
\end{tabular}

${ }^{\mathrm{a}}$ IC50 values are expressed in $\mu \mathrm{M} .{ }^{\mathrm{b}}$ Purified enzymes were reconstituted by activating the apoenzyme with different divalent cations [Fe(II), $10 \mu \mathrm{M}$; Co(II) and Ni(II), $20 \mu \mathrm{M}$; Mn(II), 200 $\mu \mathrm{M})]$. 
that compounds 3-8 showed almost no activity, even though they inhibited EcMetAP1 and MtMetAP Ic with metalloform selectivity as expected. MtMetAP Ia and MtMetAP Ic are highly homologous in sequence, and many active site residues are conserved (Figure. 2-9). The X-ray structure of MtMetAP Ia is not available, and conceivably a homology model can be built based on the structures of MtMetAP Ic [23, 25].

However, it will be difficult to explain the remarkable differences in inhibition of MtMetAP Ia by these inhibitors both in potency and metalloform selectivity unt il a structure of MtMetAP Ia is solved experimentally. The differences in inhibition foretell significant differences in structure, especially at the active site, between MtMetAP Ia and MtMetAP Ic.

\subsubsection{Co-crystallization of MtMetAP Ia with inhibitors}

In order to improve HisMtMetAP Ia solubility for purification, LB medium with different additives was tested (Figure 2-1, and Table 2-2). The HisMtMetAP Ia solubility did not improve by changing the culture medium and the protein was produced in LB and purified with lower yield (2 mg per liter culture). However, enough protein was purified that protein crystallization screens were performed as described in Table 2-5. In the first trial, CrystalScreen ${ }^{\mathrm{TM}}$, CrystalScreen $2^{\mathrm{TM}}$, Index ${ }^{\mathrm{TM}}$, S altR ${ }^{\mathrm{TM}}$ were tested with Mn-substituted His MtMetAP Ia. Even though HisMtMetAP Ia did not form crystals that were good enough for diffraction, the protein tended to form light precipitation, or needle clusters in the presence of polyethylene glycol (PEG). Staining by Izit Crystal Dye (Hampton Research, Aliso Viejo, C A) suggested these crystals were proteinaceous. Therefore, MtMetAP Ia $(5 \mathrm{mg} / \mathrm{mL})$ with inhibitory compounds were used to set up with PEG/ION kit ${ }^{\mathrm{TM}}$ and the protein concentration was reduced from $5 \mathrm{mg} / \mathrm{mL}$ to $3 \mathrm{mg} / \mathrm{mL}$ because precipitation occurred in most wells in the initial trials. The huge 'crystal' 
Table 2-6: Summary of MtMetAP Ia initial crystallization screens ( $\times$ : screen performed)

\begin{tabular}{|c|c|c|c|c|c|c|c|c|c|c|}
\hline Protein & Protein Buffer & Additives or other factor & \multicolumn{8}{|c|}{ ScreenBuffer } \\
\hline & & & 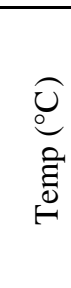 & 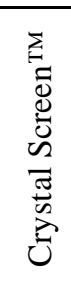 & 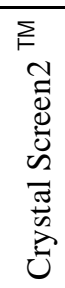 & & 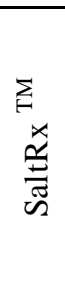 & 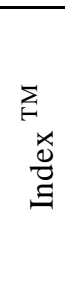 & 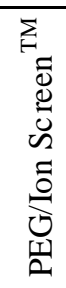 & 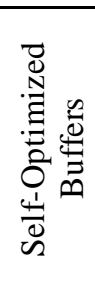 \\
\hline HisMtMetAP1a & $50 \mathrm{mM}$ MOPS pH 7.5 & $2 \mathrm{mM} \mathrm{MnCl}_{2}$ & RT & $x$ & $x$ & $x$ & & $x$ & & \\
\hline $5 \mathrm{mg} / \mathrm{mL}$ & $150 \mathrm{mM} \mathrm{NaCl}$ & 0.67 uM compound A54 & & & & & & & & \\
\hline HisMtMetAP1a & 50 mM MOPS pH 7.5 & $2 \mathrm{mM} \mathrm{MnCl}{ }_{2}$ & $\mathbf{R T}$ & $x$ & $x$ & $x$ & & $x$ & & \\
\hline $5 \mathrm{mg} / \mathrm{mL}$ & $150 \mathrm{mM} \mathrm{NaCl}$ & 0.67 uM compound A121 & & & & & & & & \\
\hline His MtMetAP1a & 50 mM MOPS pH 7.5 & $2 \mathrm{mM} \mathrm{MnCl} 2\left(\mathrm{NiCl}_{2}\right.$ or $\left.\mathrm{CoCl}_{2}\right)$ & RT & & & & & & & $x$ \\
\hline $2.7 \mathrm{mg} / \mathrm{mL}$ & $150 \mathrm{mM} \mathrm{NaCl}$ & 0.5 uM compound & & & & & & & & \\
\hline HisMtMetAP1a & 50 mM MOPS pH 7.5 & $2 \mathrm{mM} \mathrm{MnCl} 2$, or $\mathrm{NiCl}_{2}$ & RT & & & & & & $\mathbf{X}$ & \\
\hline $2 \mathrm{mg} / \mathrm{mL}$ & $150 \mathrm{mM} \mathrm{NaCl}$ & 0.5 uM compound & & & & & & & & \\
\hline MtMetAP1a & $50 \mathrm{mM}$ MOPS pH 7.5 & None & RT & & & & & & $x$ & \\
\hline $2.5 \mathrm{mg} / \mathrm{mL}$ & $150 \mathrm{mM} \mathrm{NaCl}$ & & & & & & & & & \\
\hline MtMetAP1 a & $50 \mathrm{mM}$ MOPS pH 7.5 & $2 \mathrm{mM} \mathrm{MnCl}_{2}$ & RT & & & & & & $x$ & \\
\hline $2.5 \mathrm{mg} / \mathrm{mL}$ & $150 \mathrm{mM} \mathrm{NaCl}$ & & & & & & & & & \\
\hline
\end{tabular}


formed in solution PEG/ION buffer 1 (0.2M sodium fluoride, 20\% PEG3350). However, o nly a few diffraction spots with strong intensity were obtained in the high resolution area when these crystals were exposed to synchrotron radiation, which suggested these crystals were likely salt crystals and the Izit Crystal dye identified them as salt.

\section{Discussion}

Of two MetAPs in M. tuberculosis, MtMetAP Ia was suggested to have higher expression level in M. tuberculosis at the log phase [17]. Knock-down experiment also suggested that MtMetAP Ia played a more important role than MtMetAP Ic in M. tuberculosis viability [26]. When the kinetic characterization of MtMetAP Ia was carried out, there was particular interest on its metal-selective inhibition and how the enzymes interact with the metal specific inhibitors in the presence of specific divalent metals.

Thus, the MtMetAP Ia was cloned, o ver-expressed and purified as an active enzyme. It showed a much lower solubility than EcMetAP and MtMetAP Ic when it was first expressed without a His-tag. The untagged protein with lower solubility posed difficulties for purifying a large amount of the proteins, and achieving highly concentrated protein samples for crystallization. To potentially improve solubility and purification, the mapA gene was cloned into a pET28a plasmid so that the protein was expressed with a His tag at the $\mathrm{N}$-terminus. In this system, larger portion of the protein was expressed as inclusion bodies with a small amount of soluble protein, which could be more efficiently purified through a nickel affinity column and used for kinetic characterization. The purified protein was treated with 1,10-phenathroline to 
remove metal ions following metal-affinity chromatography. The resulting apoenzyme showed no activity in hydrolyzing the fluorogenic substrate Met-AMC until metals were added.

MtMetAP Ia is shown to be a metallohydrolase and several divalent metals, including Fe (II) (in the presence of two-fold ascorbic acid), $\mathrm{Mn}(\mathrm{II}), \mathrm{Co}(\mathrm{II})$, and $\mathrm{Ni(II)}$ were tested for catalytic activity. Both His-tagged and untagged MtMetAP Ia were tested for the metal binding affinities for compa rison (Table 2-3). Metal activation profiles of HisMtMetAP Ia and MtMetAP Ia were very similar. The binding affinity of different covalent metals, from high to low, was listed as: Fe (II) $>\mathrm{Co}$ (II) $>\mathrm{Ni}$ (II) $>\mathrm{Mn}$ (II). Even though the apparent $K_{d}$ values of metals for binding to the untagged MtMetAP Ia were higher than the apparent $K_{d}$ values of metals binding to the Histagged MtMetAP Ia, the overall metal activation scenarios were similar.

The determination of kinetic characteristics was carried out with HisMtMetAP Ia (Table 2-3). $\mathrm{Ni}(\mathrm{II})$ was the most efficient metal to activate the enzyme, having the lowest $K_{\mathrm{m}}$ and the highest $k_{\text {cat. }}$. Co(II) with a $K_{m}$ of $70.46 \mu \mathrm{M}$ and a $K_{\text {cat }}$ of $0.37 \mathrm{sec}^{-1}$ was the next in efficiency, Fe(II) followed, and Mn(II) was the least efficient. Although the order of activation is similar between HisMtMetAP Ia and MtMetAP Ic [24]. HisMtMetAP Ia is a much more efficient enzyme, and the catalysis efficiency of Fe-substituted MtMetAP Ia was 22-fold higher than Fesubstituted MtMetAP Ic; 67 fold higher for Ni-substitued enzymes, 20-fold for Co-subs titued enzymes and 4 fold for Mn-substituted enzymes, respectively. It was surprising to see $\mathrm{Ni}$ (II) as the best activator for MtMetAP Ia in vitro. There are a limited number of enzymes utilizing $\mathrm{Ni}$ in vivo. It will be interesting to know if $\mathrm{Ni}$ is used by MtMetAP Ia in M. tuberculosis cells.

The ability of metal-selective compo unds was tested on HisMtMetAP Ia and IC $_{50}$ values were calculated. To our surprise, only the Fe (II)-selective enzyme showed inhibition. Yet, the 
metal-selectivity was although lost as they inhibited all the metallo forms of MtMetAP Ia. This raised the question as to why these compounds lost their inhibitions of MtMetAP Ia.

To address this question, we attempted to co-crystallize MtMetAP Ia with inhibitory compounds to elucidate the interaction between MtMetAP Ia and the compounds. However, We failed to crystallize MtMetAP Ia . The failure in obtaining crystals could be partly due to the low solubility of MtMetAP Ia. Even though the protein solubility of MtMetAP1 was predicted to be similar to those of EcMetAP and MtMetAP Ic, this was not the case. The achievable highest concentration for HisMtMetAP Ia was about $5 \mathrm{mg} / \mathrm{ml}$ in the presence of metals. The concentrated protein was easily precipitated. Later, a lower protein concentration $(2.7 \mathrm{mg} / \mathrm{ml})$ was employed to set up crystal trays. Less precipitation occurred while most crystal drops remained clear. Attempts to improve the solubility of HisMtMetAP Ia were unsuccessfully. The amino acid sequences of MtMetAP Ia, MtMetAP Ic and EcMetAP, were aligned (Figure 2-9). MtMetAP Ia shares a $36.4 \%$ identity of amino acid sequence to its homolog MtMetAP Ic in M. tuberculosis and a 36.9\% identity to EcMetAP. The conserved amino acid residues in metal binding site in EcMetAP were D97, D108, H171, E204 and E235, and D131, D142, H205, E238 and E269 in MtMetAP Ic. MtMetAP Ia had them all with different numbering, which were D106, D117, H186, E219 and E250 (Figure 2-9). Theoretically, proteins with conserved function cons ist of conserved residues, therefore, MtMetAP Ia would be expected to retain conserved enzymatic characteristics, and the binding mode for the inhibitors should remain similar to those of $E c$ MetAP and MtMetAP Ic.

The primary differences observed from the amino acid alignment are an extension of the $\mathrm{N}$-terminus and the length of a loop flanked by two $\alpha$-helices close to the C-terminus (Figure 29). However, the differences of the loops were not observed in the virtual structure of MtMetAP 


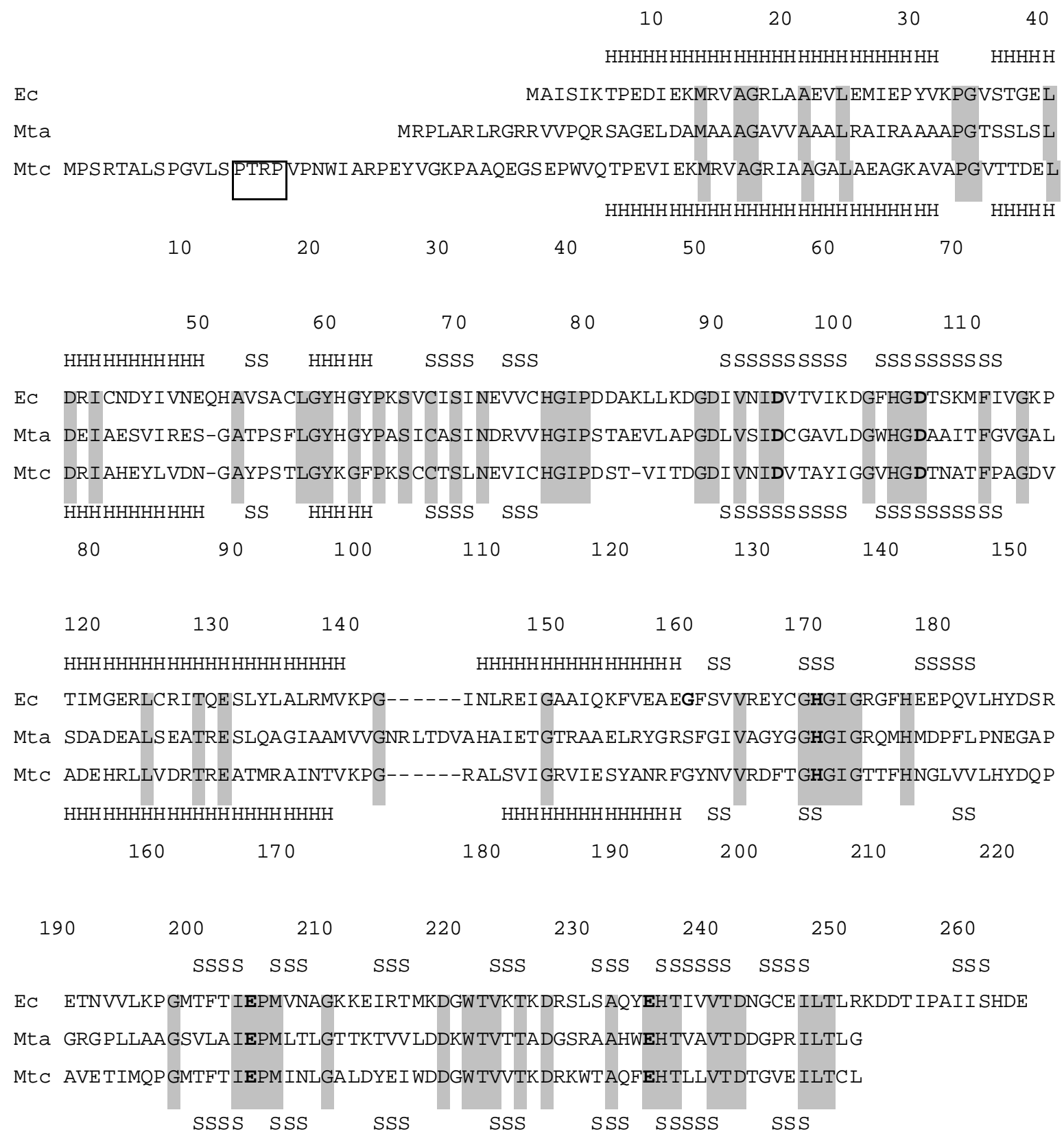

Figure 2-9. Structure-based sequence alignment of EcMetAP, MtMetAP Ia and MtMetAP Ic (labeled as Ec, Mta and Mtc, respectively). The numbering and secondary structures of $E c$ MetAP are above the sequences, and the numbering and the secondary structures for MtMetAP Ic are below the sequences. " $\mathrm{H}$ " stands for $\alpha$-helices and "S" stands for $\beta$-sheets. The secondary structures of EcMetAP and MtMetAP Ic are from the coordinates of 1XNZ and 3IU7, respectively. The identical residues among all three MetAPs are highlighted by shading in grey. The five conserved metal-ligating residues are shown in bold face. 

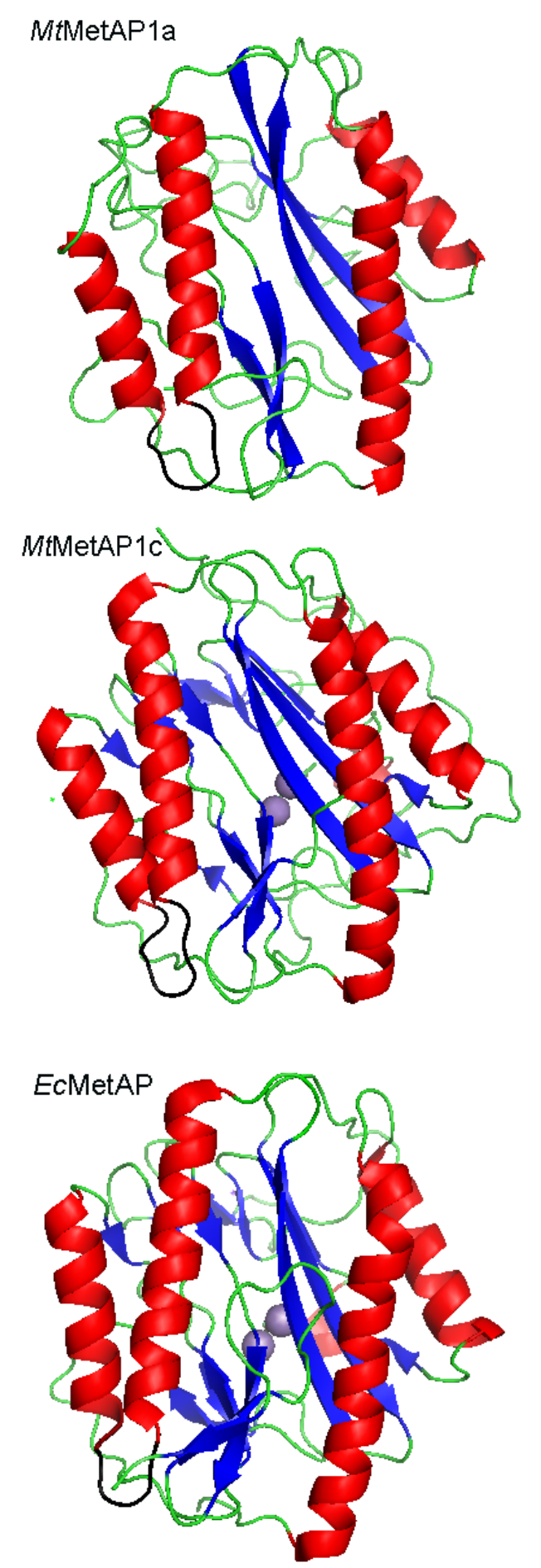

Figure 2-10. Ribbon drawing of the 'pita-bread' domain fold existing in EcMetAP, MtMetAP Ic, and homology model of MtMetAP Ia bas ed on MtMetAP Ic structure. Protein structure of MtMetAP Ia predicted by: 3D-JIGSAW. 
Ia, which was generated by molecular modeling (Figure 2-10). The common 'pita-bread' domain in the active site of MetAPs was clearly seen in MtMetAP Ia with the pseudo two-fold do main; one fold located in the $\mathrm{N}$-terminus and the other located in the C-terminus do main. Each of them consisted of two $\alpha$-helices and two anti-parallel $\beta$-sheets. The fact the inhibitors failed to access to the active site may be due to the side chains of the amino acids.MtMetAP Ia does not have an N-terminal extension. Neither does EcMetAP1. MtMetAP Ic has a 42-amino acid long loop at the $\mathrm{N}$-terminus, and it is clearly seen in the crystal structure that the loop wraps around the active site and forms sequence-specific contacts with other residues. Its function is proposed to bind MetAPs to the ribo some by a complex be tween a PxxP (amino acid residue of 14-17 in MtMetAP Ic) motif in MetAPs and an SH3 do main on the ribo some [25]. The presence/absence of this $\mathrm{N}$-terminal extension did not affect the enzyme activity as these compounds were tested in both MtMetAP Ic (chapter 3) and EcMetAP [20, 24], Similar inhibitory activity and metal selectivity were seen in both enzymes. Thus, the absence of $\mathrm{N}$-terminal extension in MtMetAP Ia did not correlate with the loss of the inhibition and metal selectivity. Crystal structure of EcMetAP suggested that the absence of the $\mathrm{N}$-terminal extension did not affect the formation of the active site. Neither should it affect enzyme inhibitions. The loss of inhibition and metal selectivity of these compounds cannot be explained neither by the absence of $\mathrm{N}$-terminal extension nor the different length of the inside loop. F urther study is needed to explain the loss of inhibition and metal selectivity of these compo unds on MtMetAP Ia.

In this project, about one hundred MetAPs inhibitors were tested with MtMetAP Ia, and it is possible that many potential MtMetAP Ia inhibitors were not included. Screening a compound library with structural diversity would hold the promise of discovering more effective inhibitors for MtMetAP Ia for use as leads for novel antitubercular drugs. 
Reference:

1. Gandhi, N.R., et al., Extensively drug-resistant tuberculosis as a cause of death in patients co-infected with tuberculosis and HIV in a rural area of South Africa. Lancet, 2006. 368(9547): p. 1575-80.

2. $\quad$ Organization, W.H., 2009 update TUBE RCULOSIS FACTS. 2010.

3. Giglione, C., A. Boularot, and T. Meinnel, Protein N-terminal methionine excision. Cell Mol Life Sci, 2004. 61(12): p. 1455-74.

4. Chang, S.Y., E.C. McGary, and S. Chang, Methionine aminopeptidase gene of Escherichia coli is essential for cell growth. J Bacteriol, 1989. 171(7): p. 4071-2.

5. Chen, X., et al., Inhibitors of Plasmodium falciparum methionine aminopeptidase $1 \mathrm{~b}$ possess antimalarial activity. Proc Natl Acad Sci U S A, 2006. 103(39): p. 14548-53.

6. Li, X. and Y.H. Chang, Amino-terminal protein processing in Saccharomyces cerevisiae is an essential function that requires two distinct methionine aminopeptidases. Proc Natl Acad Sci U S A, 1995. 92(26): p. 12357-61.

7. Lowther WT, Z.Y., Sampson PB, Honek JF, Matthews BW., Insights into the mechanism of Escherichia coli methionine aminopeptidase from the structural analys is of reaction products and phosphorus-based transition-state analogues. Biochemistry, 1999. 38(45): p. 14810-9.

8. Li, J.Y., et al., Specificity for inhibitors of metal-substituted methionine aminopeptidase. Biochem Biophys Res Commun, 2003. 307(1): p. 172-9.

9. D'Souza V, M. and R.C. Holz, The methionyl aminopeptidase from Escherichia coli can function as an iron(II) enzyme. Biochemistry, 1999. 38(34): p. 11079-85.

10. Lowther, W.T. and B.W. Matthews, Structure and function of the methionine aminopeptidases. Biochim Biophys Acta, 2000. 1477(1-2): p. 157-67.

11. Chai, S.C., W.L. Wang, and Q.Z. Ye, FE(II) is the native cofactor for Escherichia coli methionine aminopeptidase. J Biol Chem, 2008. 283(40): p. 26879-85.

12. Wang, J., et al., Physiologically relevant metal cofactor for methionine aminopeptidase-2 is manganese. Biochemistry, 2003. 42(17): p. 5035-42.

13. Leopoldini, M., N. Russo, and M. Toscano, Which one among Zn(II), Co(II), Mn(II), and $\mathrm{Fe}(\mathrm{II})$ is the most efficient ion for the methionine aminopeptidase catalyzed reaction? J Am Chem Soc, 2007. 129(25): p. 7776-84.

14. Schiffmann, R., et al., Metal ions as cofactors for the binding of inhibitors to methionine aminopeptidase: a critical view of the relevance of in vitro metalloenzyme assays. Angew Chem Int Ed Engl, 2005. 44(23): p. 3620-3.

15. Luo, Q.L., et al., Discovery and structural modification of inhibitors of methionine aminopeptidases from Escherichia coli and Saccharomyces cerevisiae. J Med Chem, 2003. 46(13): p. 2631-40.

16. Cole, S.T., et al., Deciphering the biology of Mycobacterium tuberculosis from the complete genome sequence. Nature, 1998. 393(6685): p. 537-44.

17. Zhang, X., et al., Expression and characterization of two functional methionine aminopeptidases from Mycobacterium tuberculosis H37Rv. Curr Microbiol, 2009. 59(5): p. 520-5.

18. Oganesyan, N., et al., Effect of osmotic stress and heat shock in recombinant protein overexpression and crystallization. Protein Expr Purif, 2007. 52(2): p. 280-5. 
19. Yang, G., et al., Steady-state kinetic characterization of substrates and metal-ion specificities of the full-length and $N$-terminally truncated recombinant human methionine aminopeptidases (type 2). Biochemistry, 2001. 40(35): p. 10645-54.

20. Huang, M., et al., Metal mediated inhibition of methionine aminopeptidase by quinolinyl sulfonamides. Biochem Biophys Res Commun, 2006. 339(2): p. 506-13.

21. Meng, L., et al., Overexpression and Divalent Metal Binding Properties of the Methionyl Aminopeptidase from Pyrococcus furiosust. Biochemistry, 2002. 41: p. 7199-7208.

22. Ye, Q.Z., et al., Metalloform-selective inhibitors of escherichia coli methionine aminopeptidase and $X$-ray structure of a Mn(II)-form enzyme complexed with an inhibitor. J Am Chem Soc, 2004. 126(43): p. 13940-1.

23. Lu, J.P., S.C. Chai, and Q.Z. Ye, Catalysis and inhibition of Mycobacterium tuberculosis methionine aminopeptidase. J Med Chem, 2010. 53(3): p. 1329-37.

24. Wang, W.L., et al., Discovery of inhibitors of Escherichia coli methionine aminopeptidase with the Fe(II)-form selectivity and antibacterial activity. J Med Chem, 2008. 51(19): p. 6110-20.

25. Addlagatta, A., et al., Identification of an SH3-binding motif in a new class of methionine aminopeptidases from Mycobacterium tuberculosis suggests a mode of interaction with the ribosome. Biochemistry, 2005. 44(19): p. 7166-74.

26. Olaleye, O., et al., Methionine aminopeptidases from Mycobacterium tuberculosis as novel antimycobacterial targets. Chem Biol, 2010. 17(1): p. 86-97. 


\section{CHAPTER 3}

\section{BIOCHEMICAL CHARACTERIAZATION OF METHIONINE AMINOPEPTIDASE 1C IN MYCOBACTERIA TUBERCULOSIS}

The work described in this chapter was published in the Journal of Medicinal Chemistry, entitled

"Catalysis and inhibition of Mycobacterium tuberculosis methionine aminopeptidase".

\subsection{Introduction}

Methionine aminopeptidase (MetAP) is a unique metallohydrolase. It removes the Nterminal initiator methioine from nascent polypeptides[1]. This $\mathrm{N}$-terminal modification occurs in majority of the proteins; indicating the important roles of MetAP in protein maturation, stability, function and de gradation. The essential function for MetAP has been demonstrated by the fact that deletion of MetAP from the geno mes of E.coli[2], Salmonella typhimurium[3], and Saccharomyces cerevisiae [4] is lethal. Therefore, inhibitors against MetAP offer hope for the treatment of microbial and fungal infections.

Tuberculosis (TB) caused by Mycobaterium tuberculosis is one of leading cause of mortality worldwide. Approximately one third of the world's population is infected by $M$. tuberculosis and about 1.8 million people die each year [5]. Due to the extreme survival capability of $M$. tuberculosis in the human host, current treatments of TB usually involve three to four antibiotics that are administrated at the same time. Additionaly, a prolonged period for drug treatment (six to nine months) is required to completely eliminate the causative agent in TB patients. With the presence of multidrug-resistant and extensively drug-resistant for ms of TB[6- 
7], and the prevalence of TB-HIV co-infection [8], the need for new and improved antibiotics with novel mechanisms of action to fight TB infections has increased

Recently, two MetAP genes (mapA and mapB ) from M. tuberculosis H37 Rv [9], were cloned, and two corresponding MtMetAPs were purified, and characterized. Their mRNA transcripts were also analyzed in log phase and stationary phase bacterial culture [10]. The MtMetAP Ia gene (mapA) is expressed more in log phase, while MtMetAP Ic gene (mapB) shows a higher level in stationary phase culture, suggesting that the two MetAPs play their roles in different grow th phases of $M$. tuberculosis. Olaleye et al introduced a plasmid pSCW35DsigF with mapA or mapB into M. tuberculosis and constructed MetAP knock-in strains. O verexpressed MtMetAP Ia and MtMetAP1 in these knock-in strains of M. tuberculosis conferred the resistance to the MetAP inhibitors [11], ind icating MetAP in M. tuberculosis may be a promising target for the development of antituberculosis agents.

In order to further characterize MetAP in M. tuberculosis, particular the metal activation, both MtMetAP Ia and MtMetAP Ic were cloned, purified and characterized in our laboratory. In this chapter, the characterization of MtMetAP Ic is described. The MtMetAP complemented the functional of inactive EcMetAP in the E.coli with amber mutant and enabled E. coli to grow in the non-permissive medium. A set of metal-selective inhibitors were tested towards the Fe(II)form, the $\mathrm{Mn}$ (II)-form, or the $\mathrm{Co}(\mathrm{II})$ - and $\mathrm{Ni}$ (II)-forms of the enzyme, and their metal-selective inhibition on MtMetAP Ic were consistent with what observed in EcMetAP. These metalloform selective inhibitors were then used to identify which metalloform of MtMetAP Ic was physiologically important. Only the Fe (II)-form selective inhibitors inhibited the cellular MtMetAP Ic activity and inhibited the MtMetAP Ic-complemented cell growth. The data suggested that Fe (II) is the native metal used by MtMetAP Ic in an E. coli cellular environment. 
X-ray structures of MtMetAP Ic in complex with metalloform-selective inhibitors were analyzed and showed different bind ing modes and different interactions between metal ions and active site residues. Understanding the catalytic mechanism and inhibition of the mycobacterial MetAP is essential to discovering and developing effective MetAP inhibitors as therapeutics.

\subsection{Materials and Methods}

\subsubsection{Cloning of MtMetAP Ic into pGEMEX-1 plas mid.}

The DNA encoding MtMetAP Ic (mapB, loc us_tag Rv2861c) was obtained by PCR using genomic DNA of M. tuberculosis H37 Rv as the template (a kind gift from Professor Scott G. Franzblau at the University of Illino is at Chicago). The forward primer was 5'-GGA TCA CCA GCT AGC ATG CCT AGT CGT ACC GCG, and the reverse primer was 5'-AGC ACT CGA

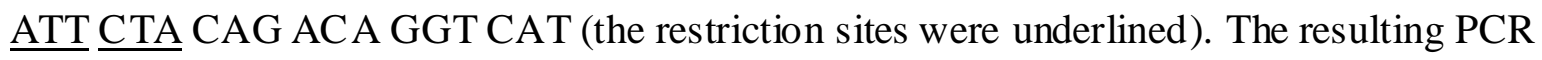
product of MtMetAP Ic was digested with EcoRI and NheI (New England Biolabs, Ispwich, MA), and cloned into an E. coli plasmid pGEMEX-1 (Promega, Madison, W isconsin) for overexpression under the control of a T7 promotor. The final recombinant protein MtMetAP Ic has three residues MAS added to its $\mathrm{N}$-terminus and were not removed. The sequence of the desired plasmid of pGEMEX1-MtMetAP Ic was confirmed by DNA sequence analys is, and transformed into E. coli BL21(DE3) (Invitrogen, Carlsbad, CA) for protein over-production.

\subsubsection{Over-expression and purification of MtMetAP Ic.}

E.coli BL21(DE3) harboring the plasmid MtMetAP Ic was grown in a $5 \mathrm{~mL}$ of LB medium with $50 \mathrm{ng} / \mathrm{mL}$ ampicillin at $37^{\circ} \mathrm{C}$ overnight. The culture was then used to inoculate 1 liter of LB containing $50 \mathrm{ng} / \mathrm{mL}$ of ampicillin the next day for protein expression. The cells 
were grown at $37{ }^{\circ} \mathrm{C}$ with shaking at $225 \mathrm{rpm}$ until the $\mathrm{OD}_{600}$ reached $0.6 \sim 0.8$ before $0.4 \mathrm{mM}$ IPTG was added to initiate protein expression. Thereafter, the induced E.coli cells were kept growing at $16{ }^{\circ} \mathrm{C}$ for 20 hours. The cells were harvested by centrifugation at $4400 \times \mathrm{g}$ for 5 minutes. A resuspension buffer (50 mM Tris- $\mathrm{HCl}$, pH 8.0, $150 \mathrm{mM} \mathrm{NaCl,} 5 \mathrm{mM}$ EDTA) was used to suspend cell pellets, and the cell suspension was stored at $-20{ }^{\circ} \mathrm{C}$.

Frozen cells after thawing were broken by three consecutive passes through a French Press (Thermo Fisher Scientific, Asheville, NC) at 20000 psi. The supernatant was collected from centrifugation at $47,810 \times \mathrm{g}$ for 30 minutes and loaded onto a $20 \mathrm{~mL}$ Q-Sepharose column pre-equilibrated with buffer A (50 mM Tris-HCl, pH 8.0). The proteins were eluted with a linear gradient of $\mathrm{NaCl}$ from 0 to $1 \mathrm{M}$. The MtMetAP Ic appeared in the flow-through fractions. Solid a mmonium sulfate was added to the combined fractions in a step-wise manner. The majority of MtMetAP Ic was precipitated when ammonium sulfate was $40 \%$ saturated. The pellet was resuspended in buffer A, and the mixture was loaded onto a 5-mL HiTrap desalting column (GE Healthcare Life Science, P iscataway, NJ) to remove ammonium sulfate. Chelex100 resin (BioRad, Hercules, CA) was added to the desalted fractions, and was shaken at $4{ }^{\circ} \mathrm{C}$ for $2 \mathrm{hr}$ to remove the metals. The sample was filtered to remove the resin, and loaded onto a desalting column. Buffer B (50 mM Tris-HCl, pH 8.0, 150 mM NaCl, which was pre-treated with Chelex-100 resin) was used to elute the protein.

The MtMetAP Ic in the apo-form was verified by hydrolysis of Met-AMC in the presence and absence of divalent metals. No activity was detected before metal was added.

\subsubsection{Metal activation of MtMetAP Ic.}


Several covalent metals $\left(\mathrm{NiCl}_{2}, \mathrm{CoCl}_{2}, \mathrm{MnCl}_{2}, \mathrm{ZnCl}_{2}\right.$ or $\mathrm{FeCl}_{2}$ with twice the concentration of ascorbic acid) were used to test the metal activation of apo-MtMetAP Ic. The measurement was carried out in 384-well plates and the total reaction volume was $80 \mu \mathrm{L}$. The well contained 50 mM MOPS-NaOH, pH 7.5, $100 \mu \mathrm{M}$ fluorogenic substrate Met-AMC (Bachem Bioscience, King of Prussia, PA), $0.5 \mu \mathrm{M}$ apoenzyme and increasing amounts of metal ions. The initial velocity values, which were measured changes in relative fluor escent intensity (Relative Fluorescence Unit), were converted to specific activity values and plotted against increasing concentrations of the metals.

An improved model of the multiple independent binding sites (MIBS) was used to accurately calculate the binding affinity ( apparent $K_{d}$ ) when the amount of functional enzyme was taken into consideration [12]. Briefly, the initial rate of hydrolys is was plotted against increasing concentrations of Co(II) at two MtMetAP Ic protein concentrations (20 $\mu \mathrm{M}$ and 0.5 $\mu \mathrm{M}$ ) and fit with the MIBS model [12] via an iterative process to obtain an accurate protein concentration. For apparent $K_{d}$ determination of the various divalent metals to MtMetAP Ic, the titration curves were generated using the calculated apoenzyme concentration of $0.54 \mu \mathrm{M}$ in 50 mM MOPS-NaOH, pH 7.5, $200 \mu \mathrm{M}$ Met-AMC and increasing concentrations of either $\mathrm{CoCl}_{2}$, $\mathrm{MnCl}_{2}, \mathrm{~N} \mathrm{iCl}_{2}$ or $\mathrm{FeCl}_{2}$. In the case of $\mathrm{FeCl}_{2}$, ascorbic acid was added at double the concentration of $\mathrm{FeCl}_{2}$. An iterative process was allowed to proceed until apparent $K_{d}$ and functional enzyme concentration values converged after a few cycles.

\subsubsection{Kinetic measure ment of different metalloforms of MtMetAP Ic.}

To obtain the $k_{\text {cat }}$ and $K_{m}$, reactions were carried out in $80 \mu \mathrm{L}$ assay mixture with $50 \mathrm{mM}$ MOPS-NaOH, pH 7.5, $0.5 \mu \mathrm{M}$ MtMetAP Ic and divalent metal ions (50 $\mu \mathrm{M} \mathrm{FeCl} \mathrm{F}_{2}$ with $100 \mu \mathrm{M}$ ascorbic acid, $10 \mu \mathrm{M} \mathrm{CoCl}_{2}, 20 \mu \mathrm{M} \mathrm{MnCl}_{2}$, or $20 \mu \mathrm{M} \mathrm{NiCl}_{2}$ ), and increasing concentrations of 
Met-AMC from $0.9 \mathrm{mM}$ to $2 \mathrm{mM}$. The $k_{c a t}$ and $K_{m}$ values of $M t$ MetAP Ic were derived from a nonlinear regression fitting of the curve in the plot of the initial rates vs the subs trate concentrations, using the Michaelis-Menton equation $\mathrm{V}=\mathrm{V}_{\max }[\mathrm{S}] /\left(K_{m}+[\mathrm{S}]\right)$.

\subsubsection{IC Ino $_{50}$ determination with different metalloform MtMetAP Ic.}

Serial dilution of the tested compounds was performed by Precision liquid handling system from BioTek (Winooski, VT). For $\mathrm{IC}_{50}$ determination, the hydrolysis of Met-AMC was monitored in the presence of the 3-fold diluted inhibitors, with concentrations varying from 1000 $\mu \mathrm{M}$ to $0.5 \mu \mathrm{M}$. In addition to the inhibitors, each well contained $50 \mathrm{mM}$ MOPS-NaOH, $\mathrm{pH}$ 7.5, $100 \mu \mathrm{M}$ Met-AMC, $0.5 \mu \mathrm{M}$ MtMetAP Ic, and the metal ion that gave the op timal activity of MtMetAP Ic (50 $\mu \mathrm{M} \mathrm{FeCl}_{2}$ with $100 \mu \mathrm{M}$ ascorbic acid, $10 \mu \mathrm{M} \mathrm{CoCl}_{2}, 20 \mu \mathrm{M} \mathrm{MnCl}_{2}$, or $20 \mu \mathrm{M}$ $\mathrm{NiCl}_{2}$ ). The $\mathrm{IC}_{50}$ values were calculated from non-linear regression curve fitting of percent inhibitions as a function of inhibitor concentrations.

\subsubsection{Comple mentation of the essential function of EcMetAP with MtMetAP Ic in E. coli.}

To evaluate the MtMetAP Ic function in the cellular environment, an E. coli strain with conditional expression of the endo ge nenous EcMetAP under the control of pBAD promoter, was used for complementation testing [13-14]. This E. coli strain with an amber mutantion is constructed by inserting a n amber stop codon (UAG) in the chromosomal EcMetAP gene, and has a plasmid pBAD/sup2 that encodes an amber-mutation-suppressor tRNA under the control on arabinose promoter. Since the EcMetAP gene is essential for cell viability, the insertion of this amber mutation in the EcMetAP gene causes a premature termination of protein translation thus leading to cell death. However, the lethal effect can be suppressed by expression of the 
A

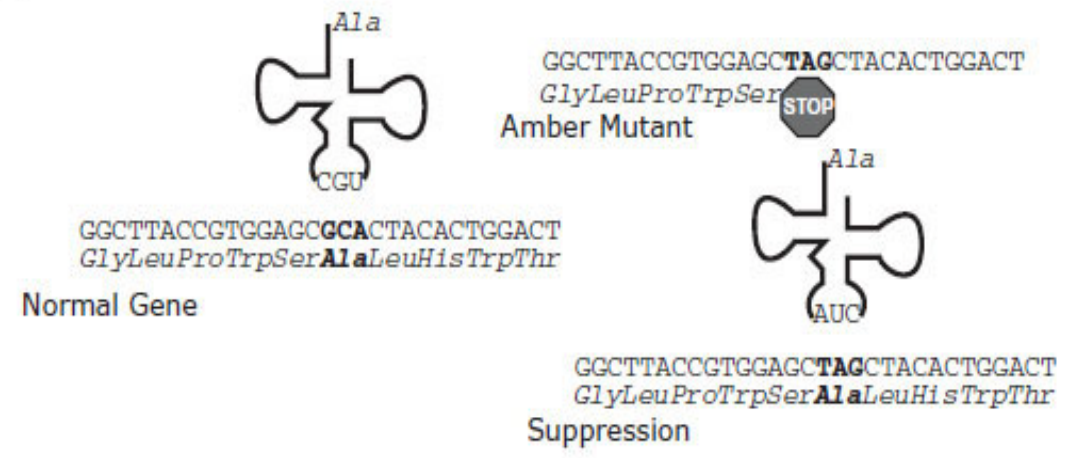

B

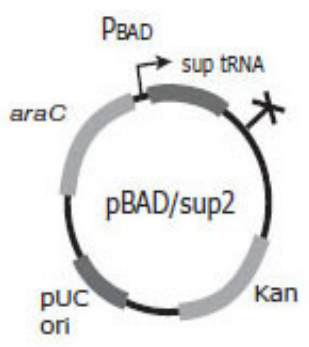

Figure 3-1 Conditional control of growth of $E$. coli. amber mutant.

A) In the normal gene, tRN A attaches an appropriate amino acid into the elongated peptide based on the three-base codon region in mRNA. In the amber mutant, the amber stop codon (TAG) in the gene will result in the termination of protein synthesis. In the amber suppression mutant, the suppressor tRNA, which is encoded by the pBAD plasmid and controlled by arabinose, can recognize the amber stop codon and insert an Ala to the elongation of the peptide. B) The map of pBAD/sup2 plasmid (from reference [13] with modification.) 
supp ressor tRNA, which has modification in its encoding DNA sequence that allows it to insert an amino acid at the UAG coden. Therefore, the trans lation continues regardless of the Amber mutation so that EcMetAP is fully translated and enable the E.coli to survive in the nonpermissive medium. By adjusting the amount of glucose or arabinose in the medium, the expression of suppressor tRNA can be tightly controlled (Figure 3-1).

Plasmid pFLAGC TC was used as the vector for complementation tests as the desired gene could be expressed under the control of an IPTG-inducible tac promoter. MtMetAP Ic gene was taken from plasmid p GEMEX1-MtMetAP Ic by digestion of NdeI and BamH I, a nd cloned into pF LAGCTC. Similarly, the EcMetAP gene was cloned into the pFLAGCTC plasmid as pFLAGCTC-EcMetAP. Both the parent plasmid pFLAGCTC and the plasmid pF LAGCTCEcMetAP were used as controls. These plasmids were all transformed into the E. coli amber mutant. The cells were cultured in a special MOPS-NaOH-based liquid medium (Teknova,Hollister, CA) or on agar plates prepared with the medium. The MOPS-based rich defined medium was used in combination with kanamycin, ampicillin, IPTG and L-arabinose, or D-glucose.

\subsubsection{Inhibition of cellular MtMetAP Ic ac tivity}

The abo ve-mentioned pF LAGCTC-MtMetAP Ic-transformed E. coli cells (MtMetAP Iccomplemented cells) were used to establish the cellular MtMetAP Ic activity assay. Bacterial cells were allowed to grow to the exponential phase, harvested and washed twice with water. The final cell pellet was resuspended in $10 \mathrm{mM} \mathrm{CaCl}_{2}, 100 \mathrm{mM}$ Tris-HCl, $\mathrm{pH} 7.5$ [15] and then an equal volume of glycerol was added. The cell suspension was kept at $-80{ }^{\circ} \mathrm{C}$ for storage. 
For the cellular MtMetAP Ic activity assay, the cell suspension was diluted with $10 \mathrm{mM}$ $\mathrm{CaCl}_{2}$, and $100 \mathrm{mM}$ Tris-HCl, $\mathrm{pH}$ 7.5. The cells, substrate Met-AMC, and inhibitors at 12 serially diluted concentrations were combined in wells of a 384-well plate. The final assay volume was $80 \mu \mathrm{l}$ with $150 \mu \mathrm{M}$ Met-AMC, $5 \mathrm{mM} \mathrm{CaCl}_{2}$, and $50 \mathrm{mM}$ Tris-HCl, $\mathrm{pH}$ 7.5. Increase of the fluorescent product was monitored via fluorescence $\left(\lambda_{\mathrm{ex}} 360 \mathrm{~nm}, \lambda_{\mathrm{em}} 460 \mathrm{~nm}\right)$ at room temperature every 2 min for $6-8 \mathrm{hr}$. The $\mathrm{IC}_{50}$ values were calculated from the rate of substrate hydrolysis.

\subsubsection{Inhibition of MtMetAP Ic-complemented $E$. coli cell growth}

Inhibition of bacterial growth was carried out using the MtMetAP Ic-complemented $E$. coli cells. The experiments were performed in a similar way as previously reported with minor modifications[15]. The assay was carried out on 384-well opaque plates containing 12 serially diluted concentrations for each inhibitor ( $40 \mu \mathrm{L}$ per well) with the highest final concentration of $1 \mathrm{mM}$ in the assay. A suspension of bacterial cells was prepared from agar plates containing rich defined media with $0.2 \%$ glucose, $50 \mu \mathrm{g} / \mathrm{mL}$ kanamycin and $100 \mu \mathrm{g} / \mathrm{mL}$ ampicillin grown to the exponential phase, which was used to inoculate a second culture batch. This ensured that the survival of the cells was due to MtMetAP Ic complementation rather than residual endo genous EcMetAP. The suspension was adjusted to 0.5 McFarland optical density [16] and then further diluted by 1000 fold in the same medium containing $100 \mathrm{mM}$ Tris-HCl, $\mathrm{pH}$ 7.5, and $225 \mu \mathrm{M}$ resazurin. Cells were dispensed into the microplate ( $40 \mu \mathrm{L}$ per well) by a Multidrop Combi reagent dispenser (Thermo Scientific, Waltham, MA). The conversion from resazurin to resofurin was monitored kinetically by fluorescence at $\lambda_{\text {em }} 590 \mathrm{~nm}$ with $\lambda_{\text {ex }} 530 \mathrm{~nm}$ using a SpectraMax Gemini XPS plate reader. Fluorescence kinetic experiments were carried out for 10 
hours at $37^{\circ} \mathrm{C}$, with readings taken every 5 min. Signal intensities at time points along the exponential phase of the growth curve corresponding to $50-85 \%$ of total intensity of an uninhibited sample were averaged and converted to percent inhibition to calculate $\mathrm{IC}_{50}$ values by non-linear regression curve fitting.

\subsubsection{Crystallization and data collection}

Crystals of the enzyme-inhibitor complexes were obtained independently by using a hanging-drop vapor-diffusion method at room temperature. The MtMetAP Ic crystal was first grown in buffer 3 (0.1M Bis-Tris-HCl pH 5.5, 2.0 M ammonium sulfate) and buffer 4 (0.1M BisTris-HCl pH 6.5, 2.0 M ammonium sulfate) in Index ${ }^{\mathrm{TM}}$ kit (Hampton Research, Aliso Viejo, $\mathrm{CA}$ ). The well solutions were optimized by changing the ammonium sulfate concentration, $\mathrm{pH}$ buffer and addition of additives, such as glycerol and PEG400. Each of the inhibitors (100 mM or $50 \mathrm{mM}$ in DMSO) was added to high concentration of metalated enzyme (10 mg/mL, 0.32 $\mathrm{mM}$ protein; $2 \mathrm{mM}$ metal) in $50 \mathrm{mM}$ Tris- $\mathrm{HCl}, \mathrm{pH} 8.0,150 \mathrm{mM} \mathrm{NaCl}$ and the molar ratio of inhibitor to MtMetAP Ic was 5:1 or 10:1. The enzyme/inhibitor mixture was mixed with the reservoir buffer in a 1:1 ratio. The reservoir buffer was $100 \mathrm{mM}$ Bis-Tris-HCl, pH 5.5, 1.1 M 1.4 $\mathrm{M} \mathrm{NH}_{4} \mathrm{SO}_{4}, 5 \%$ - 15\% glycerol or PEG400. Diffraction data were collected at the Advanced Photon Source, Argonne National Laboratory (beamline 19BM) and processed with HKL3000 [17]. All of the crystals belong to space group $P 6_{3}$. One molecule is in the asymmetric unit.

\subsubsection{Structural solution and refine ment}

The structures were solved by molecular replacement with MolRep [18] in CCP4 [19] with CCP4i interface [20], using the previously published MtMetAP Ic structure (PDB code 
1YJ3) [21] as the search model. The structure was refined with REFMAC5 [22] with iterative model building using WinCoot [23]. The refinement was monitored with $5 \%$ of the reflections set aside for $R_{\text {free }}$ factor analys is throughout the whole refinement process. Electron density was clear for all residues except a few residues at the $\mathrm{N}$-terminus, and residues from the second (P2) in the native protein to the end (L285) were modeled. Comparison of structures and generation of structural drawings were carried out by using PyMOL [24]. Statistic parameters in data collection and structural refinement are shown in Table 3-3. Atomic coordinates and structure factors for the three structures were deposited in the Protein Data Bank.

\subsubsection{Identification of quaternary structure of MtMetAP Ic using size exclusion chromatography}

As the crystal structure of MtMetAP Ic showed a trimeric form, it is suspect whether it also exhibited as a trimer in solution. Therefore, size exclusion chromatography was employed to identify the quaternary structure of MtMetAP Ic in solution. Protein molecular weight standards from Gel Filtration Calibration Kits (GE Healthcare Life Science, Piscataway, NJ) including blue dextran (2000 Kd), aldolase (153 Kd), bovine serum albumin (67 Kd), ovalbumin (43 kD) and ribo nuclease $(13.7 \mathrm{kD})$ were dissolved into water to make $10 \mathrm{mg} / \mathrm{mL}$ stock solution. In order to make the protein standard, one hundred microliter samples were taken from each stock and mixed to make a $500-\mu \mathrm{L}$ protein standard. The protein standard was applied to a size-exclusion column, Superdex 75 10/300 GL, (GE Healthcare Life Science, Piscataway, NJ) and eluted with $50 \mathrm{mM}$ MOPS- $\mathrm{NaOH} \mathrm{pH} 7.5$ and $150 \mathrm{mM} \mathrm{NaCl}$ at a rate of $0.5 \mathrm{~mL} / \mathrm{min}$ until all the proteins

were eluted from the Superdex 75 10/300 GL column. Two hundred and fifty microliter of purified MtMetAP Ic (5 mg/mL) was applied to Superdex column and washed with $50 \mathrm{mM}$ 
MOPS-NaOH pH 7.5 and $150 \mathrm{~mL} \mathrm{NaCl}$. The elution volume was recorded and compared to that of protein standard to determine the size of MtMetAP Ic in solution.

\subsection{Results}

\subsubsection{Expression and purification of MtMetAP Ic.}

The MtMetAP Ic protein was expressed in E.coli as a soluble protein and was purified using anion exchange chromatography followed by ammonium sulfate precipitation. The purified MtMetAP Ic was 99\% homologous as determined by SDS-PAGE (Figure 3-2) with a yield of 20-30 mg per liter of cells. Three amino acid residues MAS were added to the Nterminus of the protein for cloning purposes. No attempt was made to remove the extra sequence, although the terminal methionine is often processed cotranslationally by MetAP in E. coli cells. The apoenzyme showed no activity when tested by the fluorogenic substrate Met-AMC and could be immediately activated by adding divalent metals ions.

\subsubsection{Metal binding and activation of MtMetAP Ic}

A metalloenzyme usually can be activated by several different metal ions because the similar sizes of these metal ions make this isomorphous replacement possible. The MtMetAP Ic was tested for activation by divalent metals, including $\mathrm{Co}(\mathrm{II}), \mathrm{Ni}(\mathrm{II}), \mathrm{Mn}(\mathrm{II}), \mathrm{Fe}(\mathrm{II})$ and $\mathrm{Zn}$ (II) (Figure 3-3). Bell-shaped metal activation curves were observed, similar to these observed previously with EcMetAP. The apoform of MtMetAP Ic did not show activity in the absence of metal ions or when the metal concentrations were lower. As the metal concentrations increased, the metallated MtMetAP Ic could hydrolyze the substrate Met-AMC, as indicated by the increase of fluorescence detected at $\lambda_{\mathrm{em}} 460 \mathrm{~nm}\left(\lambda_{\text {ex }} 360 \mathrm{~nm}\right)$. High concentrations of a metal often inhibit 


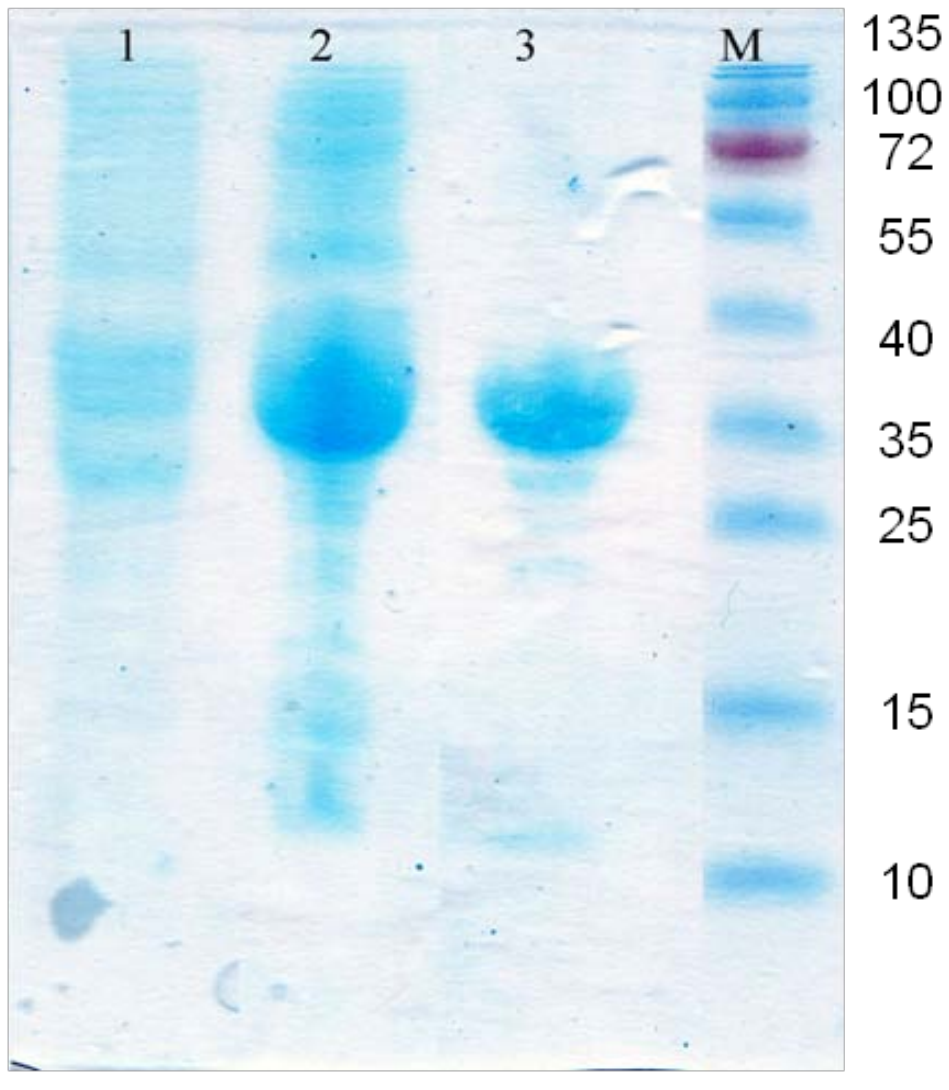

Figure 3-2 : The purification of MtMetAP Ic

Lane 1: Cell lysate of BL21(DE3)-pGEMEX1-MtMetAP Ic before IPTG-induction Lane 2: Cell lysate of BL21(DE3)-pGEMEX1-MtMetAP Ic after IPTG-induction Lane 3: Purified MtMetAP Ic

Lane 4: pre-stained protein ladders from Fermantas 


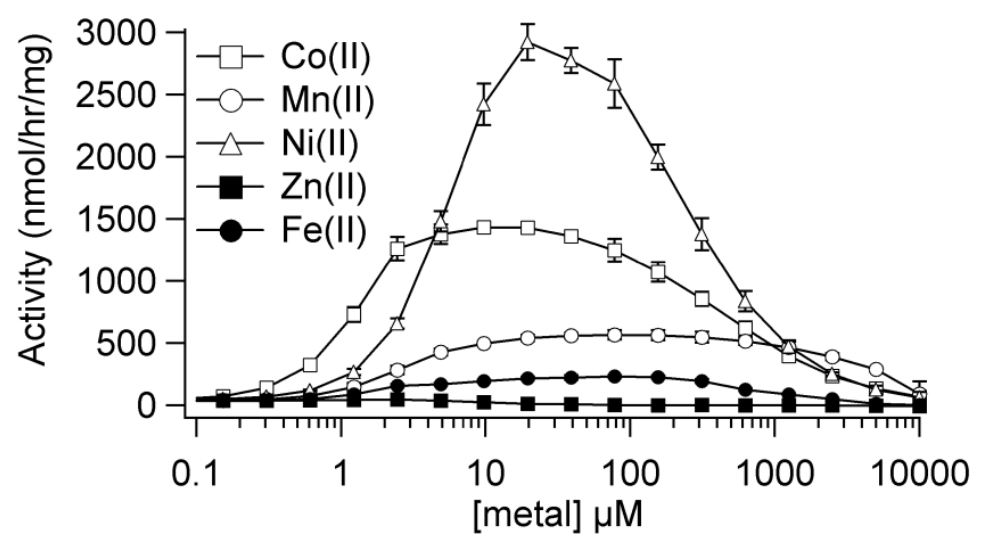

Figure 3-3. Activation of MtMetAP Ic apoenzy me by divalent metals. 
MetAP enzymatic activity [25-26], which was observed in all the metals tested on MtMetAP Ic. Co(II) activated MtMetAP Ic effectively, starting at a low concentration less than $1 \mu \mathrm{M}$, consistent with its activation for many MetAPs. Mn(II) and Fe(II) also showed activation, a nd the starting concentrations were around $1 \mu \mathrm{M}$, while no activation was observed for $\mathrm{Zn}(\mathrm{II})$. What is unique and surprising was the observed strong activation of MtMetAP Ic by Ni(II), starting around $1 \mu \mathrm{M}$. This has not been observed in EcMetAP or other MetAPs, and raises the question whether $\mathrm{Ni}(\mathrm{II})$ is the native cofactor for MtMetAP Ic. To further understand the metal binding a nd activation of MtMetAP Ic, a detailed kinetic study was carried out with the activating metal ions. The hydrolysis of Met-AMC can be conveniently monitored by fluorescence from the released aminomethylcoumarin. The affinity (apparent $K_{\mathrm{d}}$ ) for each of the activating metals was measured by fitting a model of multiple independent binding sites (MIBS), taking into consideration the amount of functional enzyme [12]. It is apparent that $\mathrm{Co}$ (II) bound to $M t$ MetAP Ic the tightest with the lowest apparent $K_{\mathrm{d}}$ values, followed by $\mathrm{Fe}(\mathrm{II})$ and $\mathrm{Mn}$ (II) (Table 3-1). Ni(II) was shown to have the weakest affinity, which is abo ut 4-fold weaker than Co(II).

\subsubsection{Kinetic characte rization of purified MtMetAP Ic.}

For $\mathrm{Km}$ measurements of an enzyme, it is used that the subs trate concentration is higher tha n the enzyme concentration. In this case, the concentration of MtMetAP Ic was fixed at 0.5 $\mu \mathrm{M}$, which was much lower than the concentrations of Met-AMC, ranging from $1 \mu \mathrm{M}$ to $2 \mathrm{mM}$. The increase in fluorescence at $\lambda_{\mathrm{em}} 460 \mathrm{~nm}\left(\lambda_{\mathrm{ex}} 360 \mathrm{~nm}\right)$ was recorded and converted into $\mu \mathrm{M}$ product per min at the op timal metal concentrations, Michaelis-Menten constants were calculated (Table 3-2). Interestingly, $\mathrm{N}$ i(II)-activated MtMetAP Ic was the most efficient among 

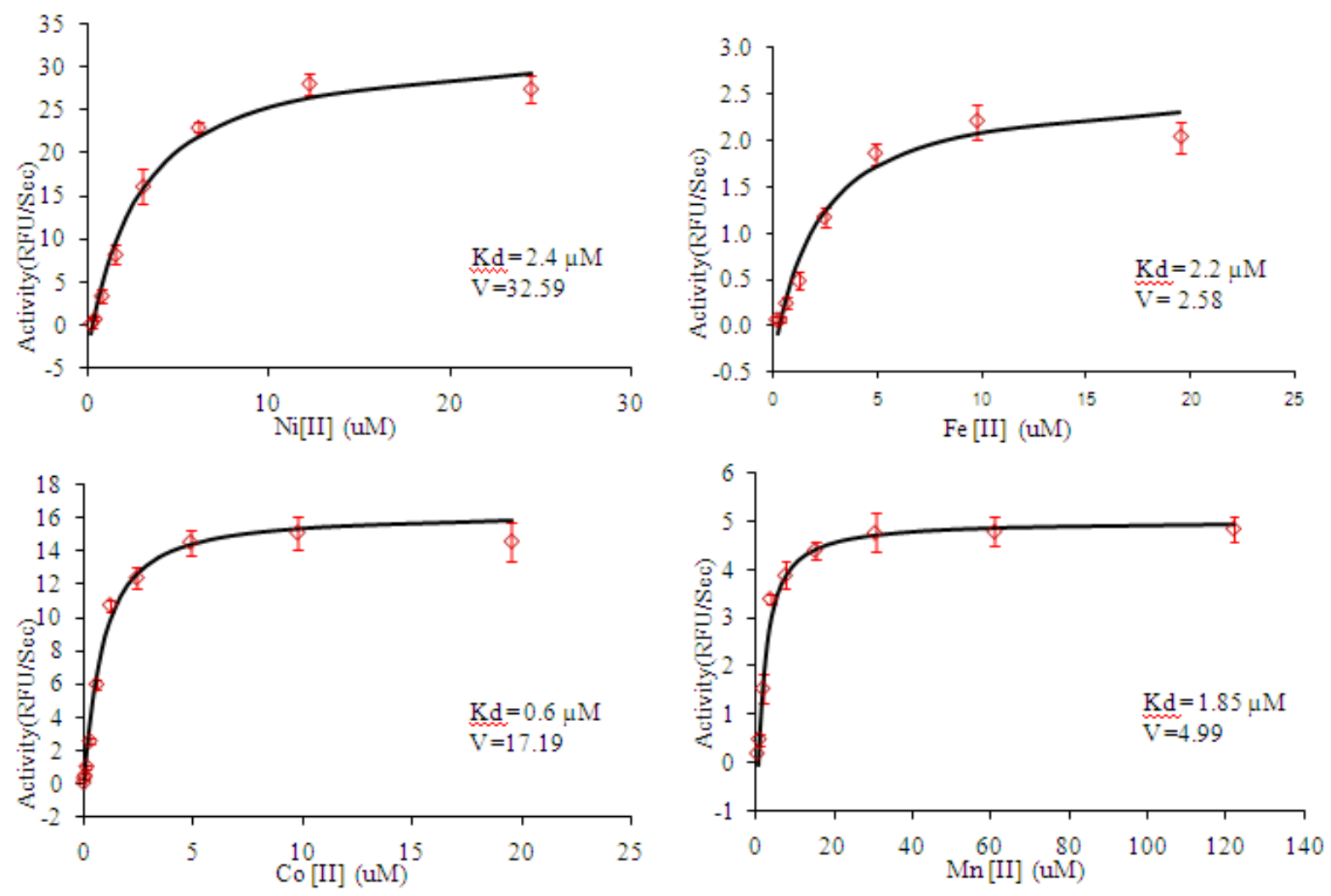

Figure 3-4 Calculation of the apparent $K_{d}$ of different metallo forms of MtMetAP Ic by using a MIBS model [12]

Table 3-1 Activation of MtMetAP Ic by different metals ${ }^{\text {a }}$

\begin{tabular}{ccccc}
\hline MtMetAP Ic & $\mathrm{Fe}(\mathrm{II})$ & $\mathrm{Ni}(\mathrm{II})$ & $\mathrm{Co}(\mathrm{II})$ & $\mathrm{Mn}(\mathrm{II})$ \\
\hline$A p p K_{\mathrm{d}}, \mu \mathrm{M}$ & $2.2 \pm 0.1$ & $2.4 \pm 0.2$ & $0.6 \pm 0.1$ & $2.1 \pm 0.2$ \\
\hline
\end{tabular}

${ }^{\text {a }}$ App $K_{\mathrm{d}}$ is apparent $K_{d}$, which represents the metal concentration when apoform MtMetAP Ia achieves 50\% activation. The constants were obtained with $0.5 \mu \mathrm{M}$ apoenzyme, $100 \mu \mathrm{M}$ substrate Met-AMC in $50 \mu \mathrm{M}$ MOPS-NaOH. The apparent $K_{d}$ was obtained from three separate tests and it is represented as the mean and the standard deviation (s.d.) of three experiments. 
3.3.4. Functional complementation of EcMetAP I in E.coli growth by MtMetAP Ic
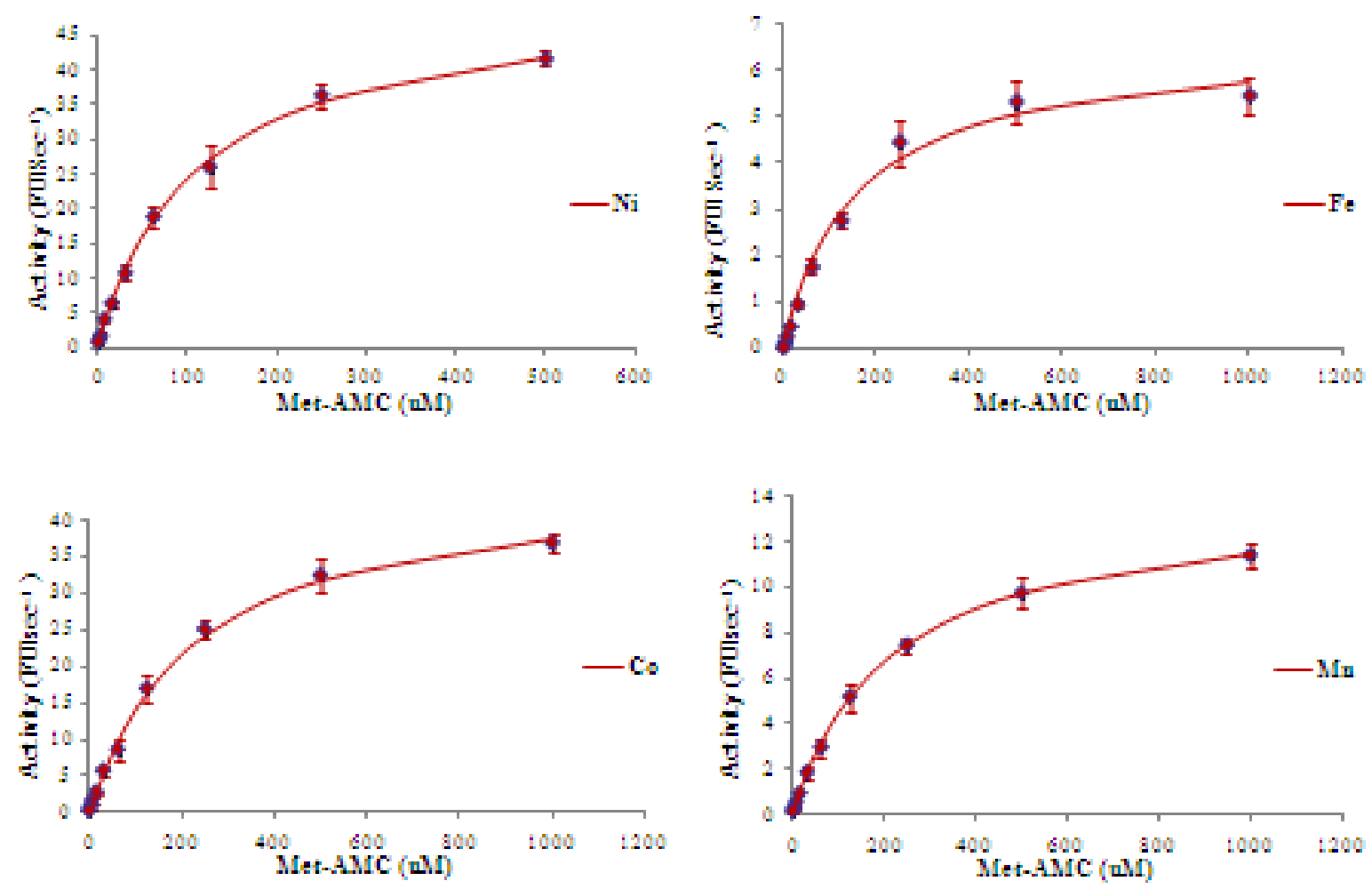

Figure 3-5 Calculation of $K_{m}$ value of different metalloform of MtMetAP Ic

Table 3-2 Kinetic measurement of MtMetAP Ic

\begin{tabular}{lcccc}
\hline & $\mathrm{Fe}(\mathrm{II})$ & $\mathrm{Ni}(\mathrm{II})$ & $\mathrm{Co}(\mathrm{II})$ & $\mathrm{Mn}(\mathrm{II})$ \\
\hline$K_{\mathrm{m}}, \mu \mathrm{M}$ & $160.7 \pm 6.0$ & $96.3 \pm 9.8$ & $221.1 \pm 13.2$ & $227.3 \pm 8.8$ \\
& & & & \\
$k_{\text {cat }}, \mathrm{sec}^{-1}$ & $0.0039 \pm 0.0002$ & $0.029 \pm 0.002$ & $0.027 \pm 0.0004$ & $0.0082 \pm 0.00033$ \\
$k_{\text {cat }} / K_{\mathrm{m}}, \mathrm{M}^{-1} \mathrm{sec}^{-1}$ & 24.3 & 301.1 & 122.1 & 36.1 \\
\hline
\end{tabular}

$K_{m}$ and $K_{c a t}$ are the Michaelis-Menten constants and they were obt ained with Fe(II) at $50 \mu \mathrm{M}$, $\mathrm{Ni(II)}$ and $\mathrm{Mn}(\mathrm{II})$ at $20 \mu \mathrm{M}$, and $\mathrm{Co}(\mathrm{II})$ at $10 \mu \mathrm{M}$. 
the metalloforms tested in catalyzing the hydrolysis of the substrate, with the lowest $K_{\mathrm{m}}$ and the highest $k_{\text {cat }}$, consistent with the metal titration curve (Table 3-2).

A functional MetAP enzyme is essential for E. coli growth [2] and the EcMetAP gene cannot be deleted. However, an E. coli strain with an amber mutation at its chromosomal EcMetAP gene and a plasmid with a pBAD-regulated amber suppressor tRNA gene suppresses the lethal effect of the amber mutation and provides a perfect tool to evaluate the function of MtMetAP Ic in the E.coli environment [14]. When the E. coli cells grow in the presence of arabinose, because expr ession of the tRN A induced, which suppresses the lethal effect of the amber mutation, functional EcMetAP is produced. On the other hand, the cells cannot grow in the presence of glucose, because no such tRNA is expressed and the translation of Ec MetAP is prematurely terminated due to the amber mutation in the EcMetAP gene. The hypothesis for this experiment is that function of the chromosomally expressed EcMetAP can be complemented with a functional MetAP expressed from a plasmid. In order to test whether MtMetAP Ic can function in an E. coli cellular environment, the MtMetAP Ic gene was inserted into pFLAGCTC and transformed into the E.coli amber mutant. The parent plasmid pFLAGCTC without any MetAP gene, and the plasmid pF LAGCTC-EcMetAP with EcMetAP gene, were used as controls and were transformed into E.coli amber mutant as well. On agar plates, cells transformed with parent plasmid pFLAGCTC grew in the presence of arabinose and did not grow in the presence of glucose (Figure. 3-6A). This confirmed that a functional MetAP is required for cell growth. The cells with either pFLAGCTC-EcMetAP or pF LAGCTC- MtMetAP Ic grew on the agar plate in the absence of arabinose and presence of glucose (Figure 3-6A), which suggests that EcMetAP or MtMetAP Ic expressed from the plasmids was functional and complemented the function of chromosomally expressed EcMetAP to support the growth. 

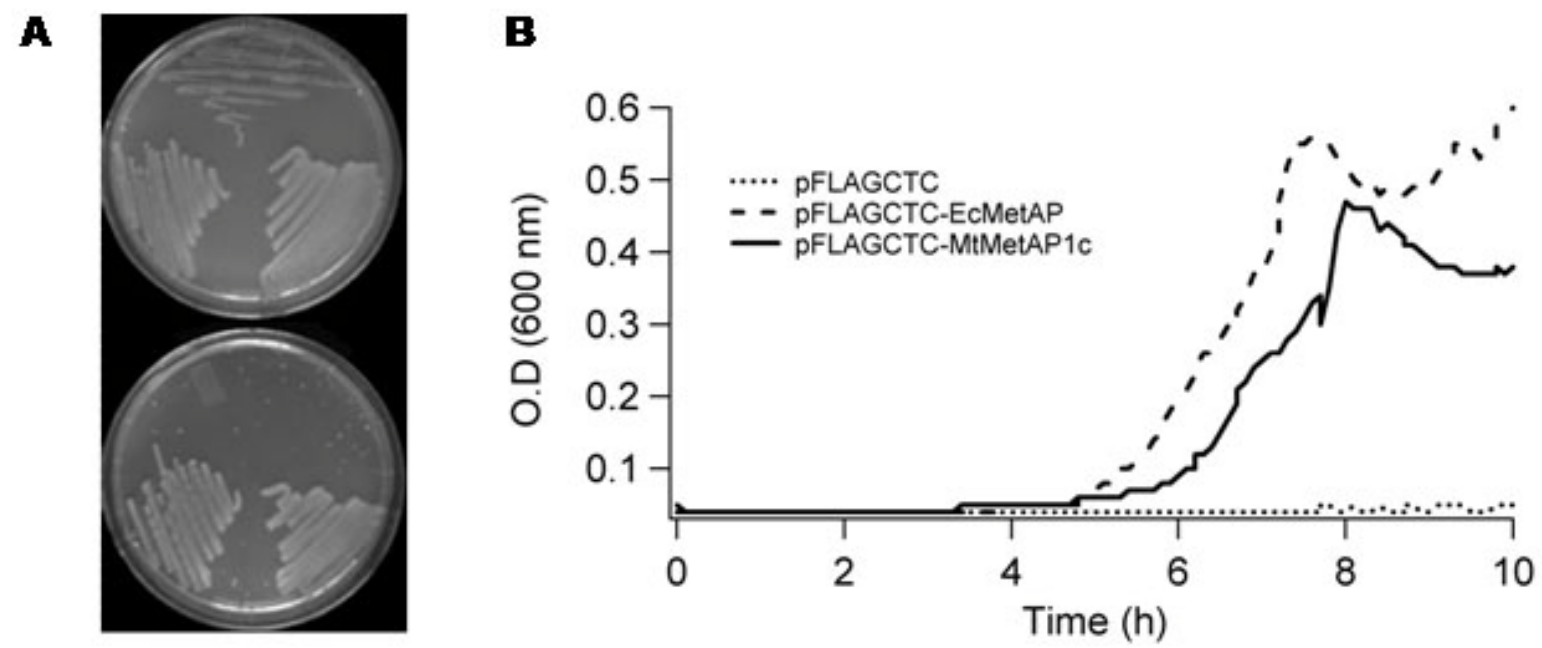

Figure 3-6. Complementation of EcMetAP I function by MtMetAP Ic.

A. E. coli cells carrying an amber mutation in chromosomal EcMetAP gene were streaked on agar plates with glucose (bottom plate) or with arabinose (top plate). Each plate displays cells containing pFLAGCTC (top), pFLAGCTC-MtMetAP Ic (bottom left) or pFLAGCTC-EcMetAP (bottom right). B. Growth of the E. coli cells in liquid medium supplemented with glucose. 
The growth of the transformed E. coli strains was also tested in a liquid medium supplemented with glucose and without arabinose. The cells with either pFLAGCTC-EcMetAP or pFLAGC TC-MtMetMetAP Ic showed robust growth, while the E. coli cells with the parent plasmid pFLAGCTC did not grow under the same conditions (Figure. 3-6B). These results confirm that MtMetAP Ic expressed from a plasmid in E. coli was a functional enzyme and supported the growth of $E$. coli cells when EcMetAP was absent.

\subsubsection{Metalloform-selective inhibition of purified MtMetAP Ic and the enzyme in an $E$. coli cellular environment}

Assignment of the physiologically relevant metalloform has been difficult, and a new approach was developed in our lab for the assignment using metalloform-selective inhibitors that can distinguish different metals at the active site [15, 27]. A set of inhibitors (Table 3-3) with known metalloform-selectivity for EcMetAP were used to evaluate inhibition of purified MtMetAP Ic enzyme and the same enzyme in an E. coli cellular environment, to provide clues for the metal cofactor used by MtMetAP Ic in cells. The catechol compounds $\mathbf{1}$ and $\mathbf{2}$ inhibited selectively the Fe(II) form of EcMetAP [28], while compound $\mathbf{3}$ and $\mathbf{4}$ were shown to be highly selective inhibitors for the $\mathrm{Mn}(\mathrm{II})$ form [27]. Triazole inhibitors were shown to interact directly with the catalytic metal ions through nitrogen atoms [29], and it was hypothesized that they may inhibit the $\mathrm{Co}(\mathrm{II})$ and $\mathrm{Ni(II)}$ forms of MetAP because of their chelation through nitrogen atoms [30]. Four such triazole compounds, 5-8, were selected for this study. All of the eight MetAP inhibitors were first tested with purified MtMetAP Ic apoenzyme activated by $\mathrm{Co}(\mathrm{II}), \mathrm{Ni}$ (II), $\mathrm{Mn}(\mathrm{II})$ or $\mathrm{Fe}(\mathrm{II})$. Indeed, all of these inhibitors showed potent and metalloform-selective inhibition at low micromolar or submicromolar concentrations (Table 3-3). Compounds 1 and 2 
were selective for the $\mathrm{Fe}(\mathrm{II})$ form, compounds $\mathbf{3}$ and $\mathbf{4}$ were selective for the $\mathrm{Mn}$ (II) form, and compounds 5-8 were selective for the $\mathrm{Ni(II)}$ and $\mathrm{Co}(\mathrm{II})$ forms.

\subsubsection{Growth inhibition of MtMetAP Ic-comple mented E. coli cells.}

Subsequently, the ability of compounds 1-8 to inhibit the cellular enzymatic activity of MtMetAP Ic in permeabilized E. coli cells was tested. Inclusion of Ca(II) at $5 \mathrm{mM}$ made these cells permeable to substrates and inhibitors, and $\mathrm{Ca}(\mathrm{II})$ had no effect on MetAP activity[15]. Clearly, the highest inhibition of the cellular MtMetAP Ic activity was achieved by the two Fe(II)-form selective inhibitors 1 and 2 (Table 3-3), suggesting that MtMetAP Ic present in the live E. coli cells used $\mathrm{Fe}(\mathrm{II})$, not $\mathrm{Ni}$ (II) or $\mathrm{Co}(\mathrm{II})$, as the cofactor for catalysis.

The excision of $\mathrm{N}$-terminal methionine is an important co-translational process, and a lethal phenotype is observed when the single gene coded for EcMetAP was deleted in E. coli [2], demonstrating that it is essential for bacterial survival. In our construct, it was obs erved that the MtMetAP Ic complemented the essential function of EcMetAP in E. coli cells. Therefore, effective inhibition of cellular MtMetAP Ic would conceivably inhibit the growth of the E. coli cells. Therefore, some of the metalloform-selective inhibitors were also tested on the E. coli cells with MtMetAP Ic complementation and we observed that only the Fe(II)-form selective inhibitors 1 and 2 arrested bacterial cell growth (Table 3-3). In contrast, inhibitors 3, 5 and 6 showed no inhibition at the highest concentration $(1 \mathrm{mM})$ tested. Although there are many reasons a compound may not work in whole cells, including lack of cell penetration, the observed inhibition by $\mathbf{1}$ and $\mathbf{2}$ is consistent with the conclusion that the functional metalloform of cellular MtMetAP Ic exists as the Fe(II)-form in E.coli. 
Table 3-3. Inhibition of enzymatic activities of purified and cellular MtMetAP Ic and inhibition of cell growth of MtMetAP Ic-complemeted $E$. coli by metalloform-selective inhibitors ${ }^{a}$

\begin{tabular}{|c|c|c|c|c|c|c|}
\hline \multirow{2}{*}{ Cmpd } & \multicolumn{4}{|c|}{ Purified Enzyme ${ }^{b}$} & \multirow{2}{*}{ Cellular Enzyme ${ }^{c}$} & \multirow{2}{*}{ Bacterial Growth ${ }^{\mathrm{d}}$} \\
\hline & Fe(II) & $\mathrm{Ni(II)}$ & $\mathrm{Co}(\mathrm{II})$ & $\mathrm{Mn}(\mathrm{II})$ & & \\
\hline 1 & 3.6 & 104 & 76 & 37 & 20 & 208 \\
\hline 2 & 1.4 & 60 & 38 & 14 & 35 & 89.5 \\
\hline 3 & $>500$ & $>500$ & $>500$ & 14 & 623 & $>1000$ \\
\hline 4 & $>500$ & $>500$ & $>500$ & 16 & N.D. ${ }^{\mathrm{e}}$ & N.D. \\
\hline 5 & $>500$ & 1.3 & 0.74 & 18 & 121 & $>1000$ \\
\hline 6 & $>500$ & 2.5 & 0.69 & 26 & 281 & $>1000$ \\
\hline 7 & $>500$ & 0.58 & 2.0 & 143 & N.D. & N.D. \\
\hline 8 & 40 & 0.24 & 0.26 & 2.0 & N.D. & N.D. \\
\hline
\end{tabular}




\subsubsection{Co-crystallization of MtMetAP Ic with inhibitors}

Structural information for mycobacterial MetAPs is lacking, and only two X-ray structures of MtMetAP Ic either as an apoenzyme or in complex with product methionine were reported [21]. With the confirmed inhibition of MtMetAP Ic by the metalloform selective inhibitors, crystallization and structural analysis were utilized to elucidate their binding mode at the active site of MtMetAP Ic. Three structures of such enzyme-inhibitor complexes with $\mathbf{4}$, $\mathbf{7}$, or 8 were determined independently. All of the structures were folded in the "pita-bread" shape commonly seen in previous MetAP structures [31]. Electron density for two $\mathrm{Mn}(\mathrm{II})$ or $\mathrm{Ni(II)}$ ions was clearly observed at the dinuclear metal site, and fluorescence spectrum scan was used to conf irm the divalent metal ion existed in the crystals based on the excitation energy. All there inhibitors bound in the shallow and mostly hydrophobic active site pocket.

All MtMetAP Ic-inhibitor complex crystals belonged to the space group $P 6_{3}$ with unit cell dimension a $=106.4 \AA, \mathrm{b}=106.4 \AA, \mathrm{c}=50.5 \AA$. Data collection statistics are listed in Table 3-4.

The structure was solved with a resolution of $1.4 \AA$, and two molecules of inhibitor 4 were fitted to the structure. One of the inhibitor molecules occupied the active site, and the other took a position on the opposite side of the protein molecule, $10.9 \AA$ away from the active site inhibitor. The structure of EcMetAP in complex with the same inhibitor was solved before (pdb code 1XNZ), and only one inhibitor molecule was identified [32]. When these two structures were overlaid, the active site inhibitor showed the same binding mode with a non-coplanar conformation between its two aromatic rings (Fig. 3-7B). Occupation of 4 at the active site is likely sufficient for MetAP inhibition, because the second molecule of $\mathbf{4}$ was not observed in the EcMetAP structure, and 4 inhibited both MtMetAP Ic and EcMetAP potently at $16 \mu \mathrm{M}$ and 0.24 
Table 3-4 X-ray data collection and refinement statistics

\begin{tabular}{|c|c|c|c|}
\hline Inhibitor & 4 & 7 & 8 \\
\hline Inhibitor code & FCD & T03 & T07 \\
\hline PDB code & 3IU7 & 3IU8 & 3IU9 \\
\hline Metal ion & $2 \mathrm{Mn}(\mathrm{II})$ & $3 \mathrm{Ni}(\mathrm{II})$ & $2 \mathrm{Ni}(\mathrm{II})$ \\
\hline \multicolumn{4}{|l|}{ Cell Parameters } \\
\hline space group & $P 6_{3}$ & $P 6_{3}$ & $P 6_{3}$ \\
\hline$a(\AA)$ & 106.4 & 105.7 & 106.2 \\
\hline$b(\AA)$ & 106.4 & 105.7 & 106.2 \\
\hline$c(\AA)$ & 50.4 & 50.4 & 50.8 \\
\hline$\alpha($ deg) & 90 & 90 & 90 \\
\hline$\beta$ (deg) & 90 & 90 & 90 \\
\hline$\gamma($ deg $)$ & 120 & 120 & 120 \\
\hline \multicolumn{4}{|l|}{ X-ray Data Collection } \\
\hline Resolution range $(\AA)^{\mathrm{a}}$ & $50-1.40(1.42-1.40)$ & $50-1.85$ (1.88-1.85) & $50-1.75(1.78-1.75)$ \\
\hline Collected reflections & 642,578 & 304,665 & 301,490 \\
\hline Unique reflections & 64,180 & 27,549 & 32,971 \\
\hline Completeness (\%) ${ }^{\mathrm{a}}$ & $99.9(100)$ & $99.5(90.5)$ & $99.5(92.2)$ \\
\hline$I / \sigma(I)^{\mathrm{a}}$ & $43.8(9.4)$ & $23.3(3.8)$ & $59.8(15.7)$ \\
\hline$R_{\text {merge }}(\%)^{\mathrm{a}}$ & $4.5(21.5)$ & $15.6(71.4)$ & $7.8(17.5)$ \\
\hline \multicolumn{4}{|l|}{ Refinement Statistics } \\
\hline$R(\%)$ & 17.1 & 16.5 & 16.4 \\
\hline$R_{\text {free }}(\%)$ & 19 & 20 & 19.5 \\
\hline R.m.s.d. bonds $(\AA)$ & 0.031 & 0.028 & 0.028 \\
\hline R.m.s.d. angles $\left({ }^{\circ}\right)$ & 2.52 & 1.97 & 2.31 \\
\hline $\begin{array}{l}\text { No. of solvent } \\
\text { molecules }\end{array}$ & 249 & 162 & 193 \\
\hline$<$ B> protein $\left(\AA^{2}\right)$ & 11 & 14.4 & 14.1 \\
\hline$<\mathrm{B}>$ inhibitor $\left(\AA^{2}\right)$ & 9.5 & 21.4 & 12.5 \\
\hline$<$ B $>$ water $\left(\AA^{2}\right)$ & 18.6 & 19.2 & 19.7 \\
\hline
\end{tabular}

${ }^{\mathrm{a}}$ Values given in parentheses correspond to the outer shell of data. 

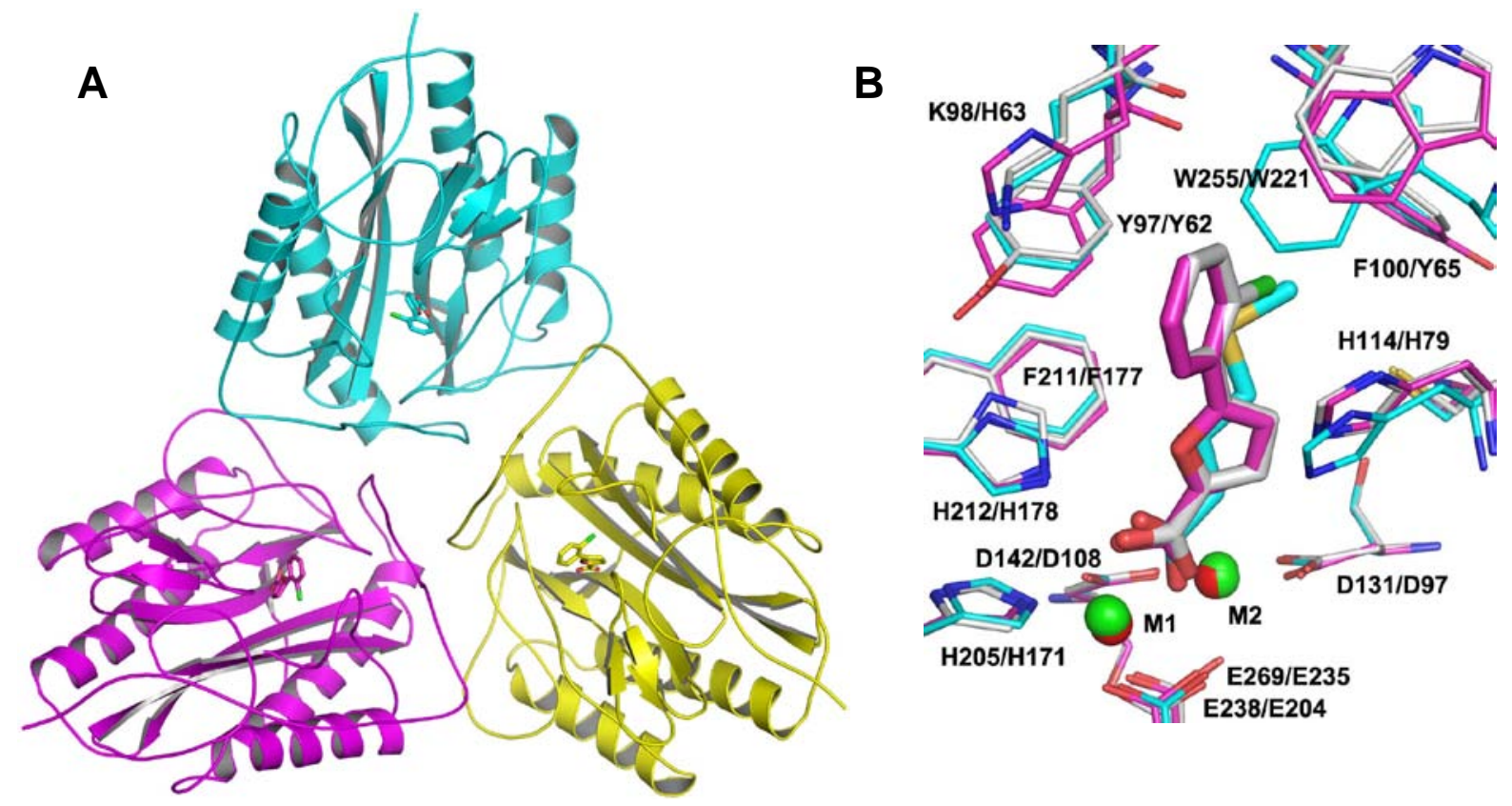

Figure 3-7. Structure of MtMetAP Ic in the Mn(II)-form in complex with the Mn(II)-form selective inhibitor 4. A. the trimeric arrangement of MtMetAP Ic in the crystal. Inhibitor $\mathbf{4}$ at the active site is shown as sticks. The three molecules of MtMetAP Ic were colored cyan, magenta and yellow, respectively. B. Overlay of this structure with EcMetAP in complex with the same inhibitor (carbon magenta, pdb 1XNZ) and with the same protein in complex with methionine (carbon cyan, pdb 1YJ3). Only residues (thin sticks) surrounding the ligands (thick sticks) at the active site are shown. Non-carbon atoms are colored: red, oxygen; blue, nitrogen; yellow, sulfur; and green, chlorine. $\mathrm{Mn}(\mathrm{II})$ (green) and $\mathrm{Co}(\mathrm{II})$ (red) ions are shown as spheres. For residue labeling, the first is for MtMetAP Ic and the second for EcMetAP. 
$\mu \mathrm{M}$ [27], respectively. Ec MetAP has a longer C-terminus, and the binding of a second $\mathbf{4}$ is spatially incompatible with residues R251, D253 and D254 in EcMetAP.

The previous MtMetAP Ic structure (pdb code 1YJ3) is in the Co(II) form, and the ligand used is also different. However, superimposing the two structures by aligning all main chain atoms from residue R4 to the end residue L285 gave a rmsd of $0.301 \AA$, indicating very similar structures. Due to different ligands, the active site residues showed movements to accommodate the different sizes of the ligands. The most significant movements were H114, which moved by $1.4 \AA$ and is a conserved residue in EcMetAP that plays an important role in catalys is, ${ }^{37}$ and W255, which moved the most by $2.2 \AA$.

Triazoles were reported as potent inhibitors of the Co(II)-form of Staphylococcus aureus MetAP ( $\left.\mathrm{IC}_{50}, 43.7 \mathrm{nM}\right)$ [29] and X-ray structures of enzyme-inhibitor complexes were reported. Here we described the inhibition of MtMetAP Ic by similar triazole compounds with high potency at submicromolar concentrations and selectivity for the $\mathrm{Co}(\mathrm{II})$ and $\mathrm{Ni}$ (II)-form. We crystallized two of the triazole inhibitors (7 and 8) with MtMetAP Ic in a uni que Ni(II)-form and solved the complexes to $1.85 \AA$ and $1.75 \AA$ resolution, respectively. Although both inhibitors have the same triazole moiety, they bound differently at the active site. While inhibitor $\mathbf{8}$ bound at the active site as a dimetalated structure (Figure 3-8 B), inhibitor 7 acquired an additional $\mathrm{Ni(II)}$ ion to form a trimetalated structure (Figure 3-8A). The extra ion was tetra coordinated with ligation to the conserved H144 mentioned before and to a water molecule and a chlorine ion as the third and fourth coordination points. Trimetalated MetAP enzymes in complex with other types of inhibitors have been observed before [30, 33-34] and their formation requires specific spatial arrangement of coordinating heteroatoms. However, it is interesting to note that inhibitor $\mathbf{7}$ formed a trimetalated structure, while inhibitor $\mathbf{8}$ for med a dimetalated structure with small 

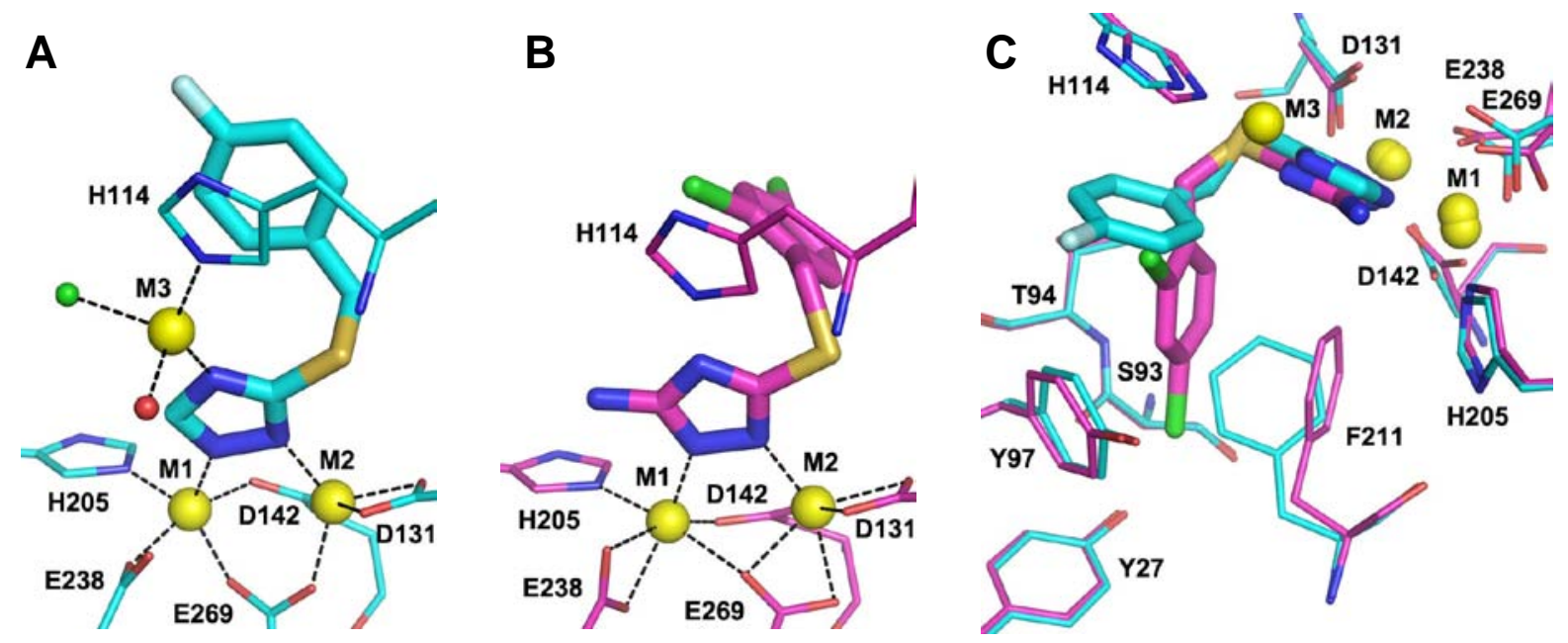

Figure 3-8. Structures of MtMetAP Ic in the Ni(II)-form in complex with the Co(II)- and Ni(II)-form selective inhibitors 7 and 8. A. Trimetalated active site with inhibitor 7 bound. Inhibitor is shown as thick sticks and the protein residues as thin sticks (carbon, cyan; oxygen ,red; nitrogen, blue; sulfur, yellow; and fluorine, pale). $\mathrm{Ni(II)}$ ions (yellow) are shown as large spheres, and water (red) and chlorine ion (green) are shown as small spheres. Metal coordination is shown as dashed lines. B. Dimetalated active site with inhibitor 8 bound. The same color scheme as in A is used, except carbon is colored magenta and chlorine is colored green. C. Comparison of the bound conformations of $\mathbf{7}$ and $\mathbf{8}$. For clarity, only selected protein residues are shown. 
structural differences. These two structures also differ significantly at the dinuclear metal site. M1 and M2 were both pentacoordinated in the complex with inhibitor 7, and they became hexacoordinated in the complex with inhibitor 8. The distances from M1 to the two oxygen atoms of E238 are $2.0 \AA$ and $3.2 \AA$ in the complex with 7, therefore, E238 provided only one oxygen atom for coordination. In contrast, the distances are $2.1 \AA$ and $2.2 \AA$ in the other complex, and both oxygen atoms coordinated with M1. For M2 coordination, one of the oxygen atoms of E269 shifted from a monodentate mode to M1 in complex with inhibitor 7 to a bridging bidentate mode to both M1 and M2 in complex with inbhitor 8, providing the additional coordination point for M2.

A unique structural feature of the complex with inhibitor 8 is the bound conformation of the inhibitor. Although both inhibitors $\mathbf{7}$ and $\mathbf{8}$ have the core benzylthiotriazole structure, inhibitor 8 adapted a bound conformation, with its benzyl group turning into a pocket formed by rotation of F211 by $90^{\circ}$ (Figure 3-8C). This binding pocket identified by this structure has not been seen in any other MetAP structures and provides additional interactions for MetAP inhibitor design.

\subsubsection{Identification of the quaternary structure of MtMetAP Ic using size exclusion chromatography}

It is interesting that all of the three structures showed $P 6_{3}$ space group in the crystal packing, instead of the common $P 2_{1}$ space group seen in other MetAPs. This symmetry indicates a trimeric arrangement in the crystals (Figure 3-7A), and indeed, the calculation on the PISA server (http://www.ebi.ac.uk/msd-srv/prot_int/pistart.html, Protein Interface Surfaces and 
Assemblies service) showed that there are large contact surfaces between the protein molecules, and a trimetric form is energetically favored.

A similar analysis for the previous MtMetAP Ic structures (PDB codes $1 \mathrm{Y} 1 \mathrm{~N}$ and $1 \mathrm{YJ}$, with $P 2_{1}$ space group) yielded no specific interactions between protein molecules, and a monomeric solution structure was predicted. The previously reported MtMetAP Ic has a longer N-terminus with a His-tag present [21], and it is not known whether the extra sequence, although not visible in the X-ray structures, prevented its packing within the crystals as a trimer. The Histag has identified not locate near the contact surfaces. One question is whether MtMetAP Ic is trimeric in solution. We eluted our MtMetAP Ic (31 kDa predicted molecular weight) in $50 \mathrm{mM}$ Tris-HCl pH 7.5 with $150 \mathrm{mM} \mathrm{NaCl}$ through a Superdex 75 size-exclus ion column, with blue dextran (2000 kDa), aldolase (153 kDa), bovine serum albumin (67 kDa), ovalbumin (43 kDa), and ribonuclease (13.7 kDa) as molecular weight standards (Figure 3-9A). MtMetAP Ic was eluted between ovalbumin and ribonuclease and its calculated $\mathrm{Mw}$ was $33 \mathrm{kDa}$, suggesting a monomeric state in the solution condition (Figure 3-9C). Disagreement in oligomer states between crystal packing and solution has been noted [35], and it is possible that MtMetAP Ic exists in a trimeric form in some crystals, while it is monomeric in solution.

\subsection{Discussion}

Although the majority of bacteria have only one MetAP gene, two or more MetAP genes have been identified in a small number of bacteria, but most of them have not been characterized enzymatically. Two homologous type 1 MetAP isozymes in Bacillus subtilis were isolated and investigated. Although both showed enzymatic activity, only one of them was essential for 


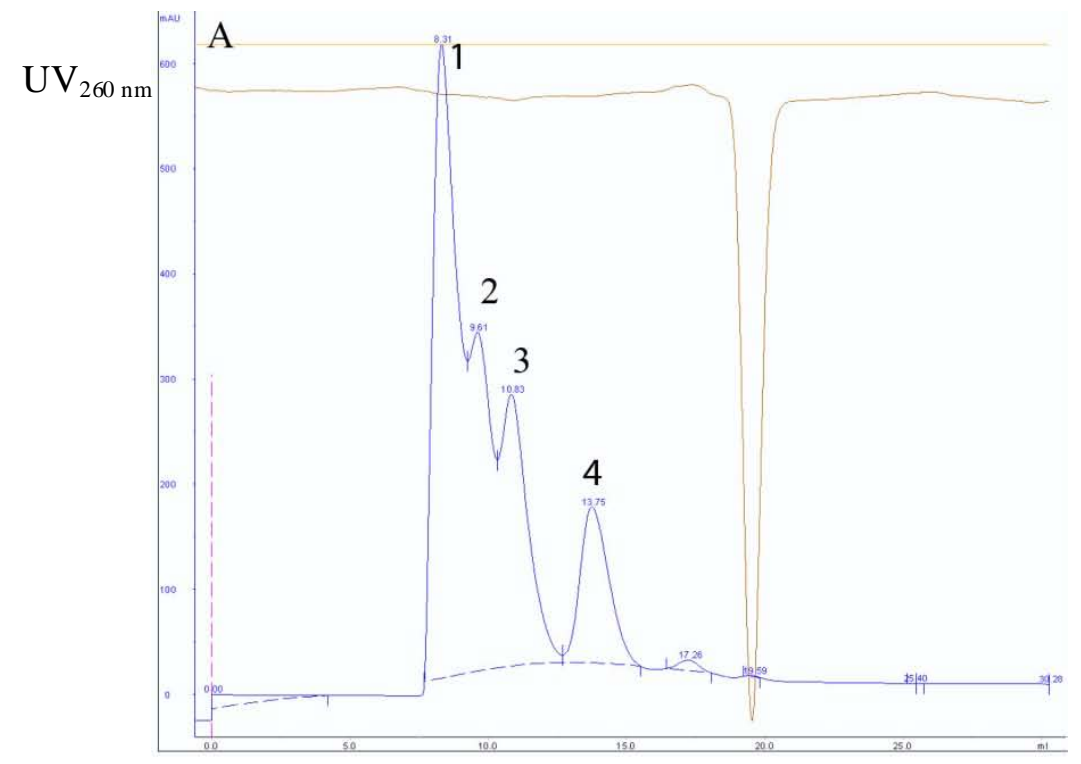

Elution volume (mL)

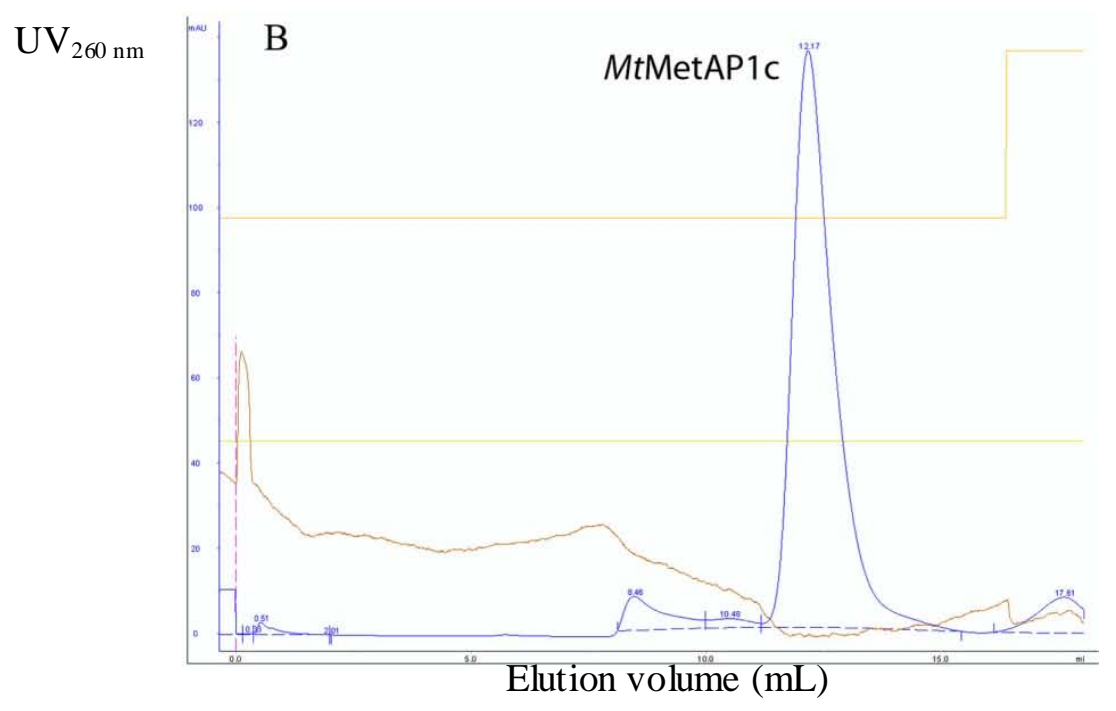

Figure 3-9 Identification of quaternary s tructure of MtMetAP Ic using Supe rdex 75.

A) The elution curve of protein standard. Peaks were 1) blue dextran and Aldolase; 2) bovine serum albumin, 3) ovalbumin; 4) ribonuclease

B) The elut ion curve of MtMetAP Ic 


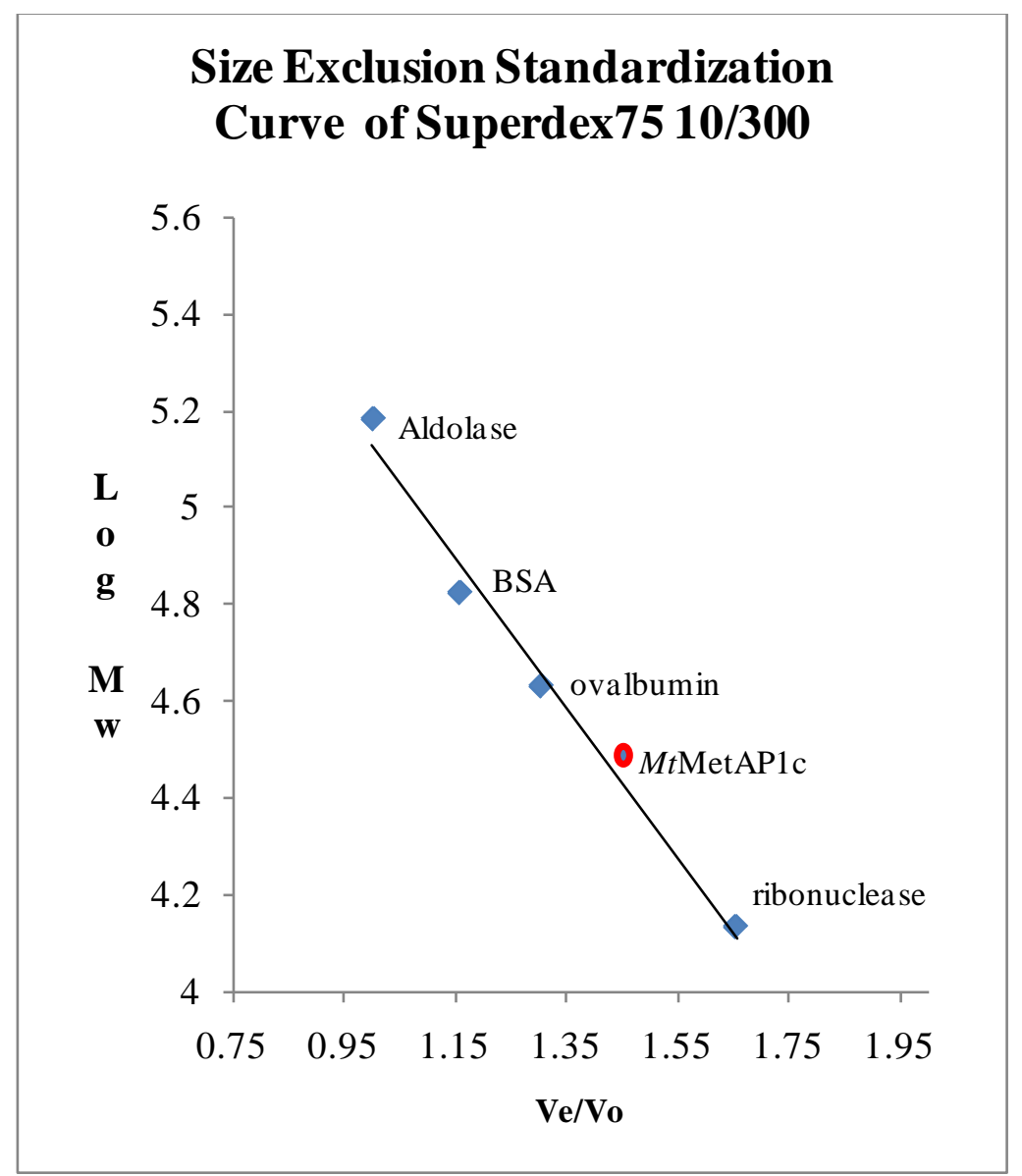

Figure 3-9 Identification of quaternary s tructure of MtMetAP Ic using Supe rdex 75.

C) The standardization curve of Superdex 75 10/300. The eluted MtMetAP Ic (illustrated as a red dot) was between ribonuclease and ovalbumin, consisting with a molecular weight of $30.9 \mathrm{Kd}$, which indicated it was a monomer. 
growth, a nd the other was concluded to be non-essential due to low expression [36]. Two MetAP genes were also ide ntified in Acinetobacter baumannii, but none of them has been demonstrated as a functional enzyme. The protozoa n parasite Plasmodium falciparum has four MetAP sequences, and inhibitors discovered and characterized on one of the four showed antimalarial activity [3]. Deletion of the single MetAP gene from E. coli [30] or Sa lmonella typhimurium [37] is lethal. For those organisms that have two copies of MetAP enzymes, one type 1 and one type 2, such as Saccharomyces cerevisiae, deletion one of MetAP showed a slow growth phenotype, and deletion of both was proved [4].

There are two MetAP enzymes in M. tuberculosis, MtMetAP Ia and MtMetAP Ic. Both belong to type I MetAP, and an alignment of their protein sequences showed 36\% identity to each other [38]. Because MtMetAP Ia and MtMetAP Ic are homologous enzymes, it is likely that the function of one can be complemented by the other, and inhibitors of one will inhibit the other as well. Therefore, both MtMetAP Ia and MtMetAP Ic are potential drug targets, and inhibition of one or both is likely required to show antimycobacterial activity. The mRNA transcript analys is of these two MetAPs in M. tuberculosis showed different mRNA levels in the log phase and the stationary phase [10]. The expression of MtMetAP Ia ge ne (mapA) expressed more in the log phase, while the expression of MtMetAP Ic gene $(\operatorname{mapB})$ showed a higher level in the stationary phase, suggesting that the two MetAPs may perform important functions in different growth phases of $M$. tuberculosis [10]. The special characteristics of the mycobacterial life cycle may require more than one MetAP enzyme to carry out this important cotranslational modification.

We purified MtMetAP Ic to homogeneity as an apoenzyme and demonstrated its enzymatic function not only as a purified enzyme but also in live E. coli cells. Divalent metals 
Co(II), Mn(II), Ni(II), and Fe(II) all showed immediate activation of the purified apoenzyme. Co(II) and Fe(II) had a higher affinity, while Ni(II) bound more weakly but showed the highest catalytic efficiency. Zhang et al [10] described Fe(II) and Ni(II) as inhibitors of MtMetAP Ic activity, partially contradicting our results. However, their enzyme showed high activities before the metal ions were added, indicating that a metalated enzyme was already present. Considering that the enzyme was purified as a His-tagged protein, and no procedure was described for metal removal, their observed inhibitory effect of $\mathrm{Fe}(\mathrm{II})$ or $\mathrm{Ni}$ (II) was probably due to competition of the metal added with the active site metal already in place. Another possibility is that higher metal concentrations (in addition to the metal already in place) were used in their experiments, as our metal activation profiles (Figure 3-3) showed that a metal can also inhibit MetAP activity at high concentrations. It is interesting to note that a MetAP enzyme was purified from Mycobacterium smegmatis $\mathrm{mc}^{2} 155$ strain, and its enzymatic activity was enhanced by $\operatorname{Mg}(\mathrm{II})$ and $\mathrm{Co}(\mathrm{II})$ and inhibited by $\mathrm{Fe}(\mathrm{II})$ and $\mathrm{Cu}(\mathrm{II})[39]$. However, the enzyme was purified by following the hydrolysis of a MetAP substrate, and its identity as a mycobacterial MetAP was not confirmed by sequencing.

Many dinuclear metallohydrolases [40] play key roles in physiological and pathological processes and often are targets for therapeutics. For instance, MetAP in protein cotranslational modification, dicer in RNA interference [41], HIV reverse transcriptase in AIDS [42], and protein phosphatase-1 in cell cycle reguhtion [43]. Assignment of their physiologically relevant metalloform is often difficult and confusing, but it is critically important for the discovery and development of inhibitors that are effective against cellular enzymes. Initially from highthroughput screening, we discovered several classes of unique MetAP inhibitors that can distinguish different metal ions at the enzyme active site [27-28] . These metalloform-selective 
inhibitors are valuable research tools for the assignment, and here we presented an example of their application to clarification of the native metalloform of MtMetAP Ic in an E. coli cellular environment. With confirmed inhibitory potency and selectivity on the metalloforms of the purified MtMetAP Ic, we characterized these inhibitors for inhibition of MetAP activity from the recombinant MtMetAP Ic in live E. coli cells. Only the Fe(II)-form selective inhibitors inhibited the cellular MtMetAP Ic activity and inhibited the growth of MtMetAP Ic-complemented E. coli cells, leading to the conclusion that MtMetAP Ic is in the Fe(II)-form in an E. coli cellular environment. It is intriguing why MtMetAP Ic utilizes Fe(II) for catalysis when Ni(II) offers higher catalytic efficiency. One possible explanation is that the higher binding affinity and easier availability of $\mathrm{Fe}(\mathrm{II})$ results in its preferential use. It was de monstrated that $E$. coli peptide deformylase utilized Fe(II) as the native metal cofactor, but the Borrelia burgdorferi used Zn(II) after heterologous expression in E. coli [44]. Therefore, expression of MtMetAP Ic in E. coli probably does not swap the intracellular type of metal utilized by MtMetAP Ic in $M$. tuberculosis. Nevertheless, the native metalloform of MtMetAP Ic in M. tuberculosis remains to be confirmed. Our approach of using MtMetAP Ic in E. coli cells is an attractive alternative to the direct manipulation of pathogenic organisms for drug discovery in that the conventional approach would not be readily accessible due to the dangers they pose.

The first group of small molecule inhibitors for a mycobacterial MetAP enzyme was presented and elucidated their binding characteristics at the enzyme active site. They showed not only potency but also selectivity for different metalloforms and were initial lead compounds for the development of inhibitors of mycobacterial MetAPs as novel anti-TB drugs. Although metalloform selectivity may not be required for effective inhibition of cellular MetAPs, selective inhibition of different metalloforms may be advantageous. Fe(II) is likely the metal used by 
MetAPs in bacteria such as E. coli and Bacillus [15]. On the contrary, human type 2 MetAP uses $\mathrm{Mn}(\mathrm{II})$ as its physiologically relevant metal cofactor [45] . It is unknown which metal the human type 1 MetAP uses for its catalysis, but it is possibly not Fe(II) because free $\mathrm{Fe}(\mathrm{II})$ concentration in mammalian cells is low and sequestering iron is a defense mechanism against bacterial infection [46-47]. Metalloform-selectivity may provide a viable strategy for selective inhibition of bacterial MetAP enzymes. 


\section{References:}

1. Bradshaw, R.A., W.W. Brickey, and K.W. Walker, $N$-terminal processing: the methionine aminopeptidase and $N$ alpha-acetyl transferase families. Trends Biochem Sci, 1998. 23(7): p. 263-7.

2. Chang, S.Y., E.C. McGary, and S. Chang, Methionine aminopeptidase gene of Escherichia coli is essential for cell growth. J Bacteriol, 1989. 171(7): p. 4071-2.

3. Chen, X., et al, Inhibitors of Plasmodium falciparum methionine aminopeptidase $1 b$ possess antimalarial activity. Proc Natl Acad Sci U S A, 2006. 103(39): p. 14548-53.

4. $\mathrm{Li}, \mathrm{X}$. and Y.H. Chang, Amino-terminal protein processing in Saccharomyces cerevisiae is an essential function that requires two distinct methionine aminopeptidases. Proc Natl Acad Sci U S A, 1995. 92(26): p. 12357-61.

5. $\quad$ Organization, W.H., 2009 update TUBERCULOSIS FACTS. 2010.

6. Fauci, A.S., Multidrug-resistant and extensively drug-resistant tuberculosis: the National Institute of Allergy and Infectious Diseases Research agenda and recommendations for priority research. The Journal of Infectious Disease 2008. 197: p. 1493-8.

7. Gandhi, N.R., et al., Extensively drug-resistant tuberculosis as a cause of death in patients co-infected with tuberculosis and HIV in a rural area of South Africa. Lancet, 2006. 368(9547): p. 1575-80.

8. Corbett, E.L., et al., The growing burden of tuberculosis: global trends and interactions with the HIV epidemic. Arch Intern Med, 2003. 163(9): p. 1009-21.

9. Cole, S.T., et al, Deciphering the biology of Mycobacterium tuberculosis from the complete genome sequence. Nature, 1998. 393(6685): p. 537-44.

10. Zhang, X., et al., Expression and characterization of two functional methionine aminopeptidases from Mycobacterium tuberculosis H37Rv. Curr Microbiol, 2009. 59(5): p. 520-5.

11. Olaleye, O., et al., Methionine aminopeptidases from Mycobacterium tuberculosis as novel antimycobacterial targets. Chem Biol, 2010. 17(1): p. 86-97.

12. Chai, S.C., J.P. Lu, and Q.Z. Ye, Determination of binding affinity of metal cofactor to the active site of methionine aminopeptidase based on quantitation of functional enzyme. Anal Biochem, 2009. 395(2): p. 263-4.

13. Herring, C.D. and F.R. Blattner, Conditional lethal amber mutations in essential Escherichia coli genes. J Bacteriol, 2004. 186(9): p. 2673-81.

14. Herring, C.D., Introduction of conditional lethal amber mutations in Escherichia coli. Methods Mol Biol, 2008. 416: p. 323-34.

15. Chai, S.C., W.L. Wang, and Q.Z. Ye, FE(II) Is the Native Cofactor for Escherichia coli Methionine Aminopeptidase. J Biol Chem, 2008. 283(40): p. 26879-85.

16. Stand ards, N.C.f.C.L., Methods for dilution antimicrobial susceptibility tests for bacteria that grow aerobically, Approved standard 2000, N ational Committee for Clinical Laboratory Standards: Wayne, PA.

17. Minor, W., et al., HKL-3000: the integration of data reduction and structure solution-from diffraction images to an initial model in minutes. Acta Crystallogr D Biol Crystallogr, 2006. 62(Pt 8): p. 859-66.

18. Vagin, A. and A. Teplyakov, Molecular replacement with MOLREP. Acta Crystallogr D Biol Crystallogr, 2010. 66(Pt 1): p. 22-5. 
19. Collaborative Computational Project, N., The CCP4 suite: programs for protein crystallography. Acta Crystallogr D Biol Crystallogr, 1994. 50(Pt 5): p. 760-3.

20. Potterton, E., et al., A graphical user interface to the CCP4 program suite. Acta Crystallogr D Biol Crystallogr, 2003. 59(Pt 7): p. 1131-7.

21. Addlagatta, A., et al., Identification of an SH3-binding motif in a new class of methionine aminopeptidases from Mycobacterium tuberculosis suggests a mode of interaction with the ribosome. Biochemistry, 2005. 44(19): p. 7166-74.

22. Murshudov, G.N., A.A. Vagin, and E.J. Dodson, Refinement of macromolecular structures by the maximum-likelihood method. Acta Crystallogr D Biol Crystallogr, 1997. 53(Pt 3): p. 240-55.

23. Emsley, P. and K. Cowtan, Coot: model-building tools for molecular graphics. Acta Crystallogr D Biol Crystallogr, 2004. 60(Pt 12 Pt 1): p. 2126-32.

24. DeLano, W.L. The PyMOL Molecular Graphics System. 2000.

25. Li, J.Y., et al., Specificity for inhibitors of metal-substituted methionine aminopeptidase. Biochem Biophys Res Commun, 2003. 307(1): p. 172-9.

26. Meng, L., et al., Overexpression and Divalent Metal Binding Properties of the Methionyl Aminopeptidase from Pyrococcus furiosust. Biochemistry, 2002. 41: p. 7199-7208.

27. Ye, Q.Z., et al., Metalloform-selective inhibitors of escherichia coli methionine aminopeptidase and X-ray structure of a Mn(II)-form enzyme complexed with an inhibitor. J Am Chem Soc, 2004. 126(43): p. 13940-1.

28. Wang, W.L., et al., Discovery of inhibitors of Escherichia coli methionine aminopeptidase with the Fe(II)-form selectivity and antibacterial activity. J Med Chem, 2008. 51(19): p. 6110-20.

29. Oefner, C., et al., The 1.15A crystal structure of the Staphylococcus aureus methionylaminopeptidase and complexes with triazole based inhibitors. J Mol Biol, 2003. 332(1): p. 13-21.

30. Xie, S.X., et al., Structural analysis of metalloform-selective inhibition of methionine aminopeptidase. Acta Crystallogr D Biol Crystallogr, 2006. 62(Pt 4): p. 425-32.

31. Lowther, W.T. and B.W. Matthews, Structure and function of the methionine aminopeptidases. Biochim Biophys Acta, 2000. 1477(1-2): p. 157-67.

32. Roderick, S.L. and B.W. Matthews, Structure of the cobalt-dependent methionine aminopeptidase from Escherichia coli: a new type of proteolytic enzyme. Biochemistry, 1993. 32(15): p. 3907-12.

33. Huang, M., et al., Metal mediated inhibition of methionine aminopeptidase by quinolinyl sulfonamides. Biochem Biophys Res Commun, 2006. 339(2): p. 506-13.

34. Douangamath, A., et al., Crystal structures of Staphylococcusaureus methionine aminopeptidase complexed with keto heterocycle and aminoketone inhibitors reveal the formation of a tetrahedral intermediate. J Med Chem, 2004. 47(6): p. 1325-8.

35. Krissinel, E., Crystal contacts as nature's docking solutions. J Comput Chem, 2010. 31(1): p. 133-43.

36. You, C., et al., The two authentic methionine aminopeptidase genes are differentially expressed in Bacillus subtilis. BMC Microbiol, 2005. 5: p. 57.

37. Miller, C.G., et al., pepM is an essential gene in Salmonella typhimurium. J Bacteriol, 1989. 171(9): p. 5215-7. 
38. Needleman, S.B. and C.D. Wunsch, A general method applicable to the search for similarities in the amino acid sequence of two proteins. J Mol Biol, 1970. 48(3): p. 44353.

39. Narayanan, S.S., et al., Purification and biochemical characterization of methionine aminopeptidase (MetAP) from Mycobacterium smegmatis mc2155. Appl Biochem Biotechnol, 2008. 151(2-3): p. 512-21.

40. Wilcox, D.E., Binuclear Metallohydrolases. Chem Rev, 1996. 96(7): p. 2435-2458.

41. Macrae, I.J., et al., Structural basis for double-stranded RNA processing by Dicer. Science, 2006. 311(5758): p. 195-8.

42. Davies, J.F., 2nd, et al., Crystal structure of the ribonuclease H domain of HIV-1 reverse transcriptase. Science, 1991. 252(5002): p. 88-95.

43. Maynes, J.T., et al., Crystal structure of the tumor-promoter okadaic acid bound to protein phosphatase-1. J Biol Chem, 2001. 276(47): p. 44078-82.

44. Nguyen, K.T., et al., Zinc is the metal cofactor of Borrelia burgdorferi peptide deformylase. Arch Biochem Biophys, 2007. 468(2): p. 217-25.

45. Wang, J., et al., Physiologically relevant metal cofactor for methionine aminopeptidase-2 is manganese. Biochemistry, 2003. 42(17): p. 5035-42.

46. Wooldridge, K.G. and P.H. Williams, Iron uptake mechanisms of pathogenic bacteria. FEMS Microbiol Rev, 1993. 12(4): p. 325-48.

47. Payne, S.M., Iron acquisition in microbial pathogenesis. Trends Microbiol, 1993. 1(2): p. 66-9. 


\section{CHAPTER 4}

\section{CONCLUSIONS AND FUTURE PLANS}

In this project, two methionine aminopeptidase (MetAP) enzymes from Mycobacterium tuberculosis were purified and characterized. Both MetAPs were active and could be activated by $\mathrm{Ni}(\mathrm{II}), \mathrm{Co}(\mathrm{II}), \mathrm{Mn}$ (II) and Fe(II). The plasmid-expressed MtMetAP Ic rescued an EcMetAP amber mutant in E.coli, which was otherwise lethal [1] [2]. A set of compounds with specific inhibitory activities against different metal-substituted MetAP were identified and tested in a cellular assay. Only Fe(II)-selective inhibitors show inhibition in this cellular MtMetAP Ic assay and the growth of E. coli, indicating that Fe(II) was most likely the metal used by MtMetAP Ic when it is expressed in E.coli. Both MtMetAPs were co-crystallized with inhibitors. Only crystal structures of different metalloforms MtMetAP Ic in complex with inhibitors were solved. The structural information of MtMetAP Ic with inibitors has provided awareness for development of anti-TB agents.

A number of questions regarding to the physiological functions of MetAP enzyme remain unsolved and further investigation is needed to address them. Compounds that inhibit MtMetAP Ia activity are still of great interest and needed for: 1) Testing their inhibition on different metalated MtMetAP Ia; 2) Testing their inhibitory activity on cellular growth; 3) Illuminating the interaction between the active sites of MtMetAP Ia and the inhibitory compounds; and 4) Identifying the role of MtMetAP Ia in M. tuberculosis pathogenesis.

MtMetAP Ia and MtMetAP Ic share approximately 36.9\% sequence identity. In addition, a homology model of MtMetAP Ia has an active site consisting of amino acid residues of Glu, 
His, and Asp, which is similar to that of MtMetAP Ic [3]. MtMetAP Ia, however, showed different enzymatic characteristic from MtMetAP Ic in our study. The metal binding a ffinities to MtMetAP Ia, from the highest to lowest, are showed as following; $\mathrm{Fe}(\mathrm{I} \ngtr \mathrm{Co}(\mathrm{II})>\mathrm{Ni}$ (II) $>$ $\mathrm{Mn}(\mathrm{II})$. In contrast, in $M t$ MetAP Ic, the affinities are $\mathrm{Co}(\mathrm{II})>\mathrm{Mn}(\mathrm{II}) \geq \mathrm{Fe}(\mathrm{II})>\mathrm{Ni}(\mathrm{II})$.

While both MtMetAP can hydrolyze the fluorogentic substrate Met-AMC, MtMetAP Ia is a more efficient enzyme than MtMetAP Ic as indicated by the larger $K_{c a t} / K_{m}$ value (Table 4-1). In testing inhibition, most MetAP inhibitors of EcMetAP Ia, HsMetAP Ia and MtMetAP Ic did not inhibit MtMetAP Ia. The only exceptions were the Fe(II)-selective inhibitors. However, these Fe(II)-selective inhibitors lose their metal specificity for MtMetAP Ia. These in vitro kinetic differences between MtMetAP Ia and MtMetAP Ic may contribute to their different functions as observed in the E. coli grow th complementary experiment.

In the experiment, the E. coli with an amber mutation in the map gene could be rescued from death by the plasmid-expressed MtMetAP Ic, which complementated of the function of the mutated $E c$ MetAP. However, $M t$ MetAP Ia gave an inconsistent result. MtMetAP Ia could supp ress the lethal effect of amber mutation in E.coli but it gave a much weaker complementation when compared with EcMetAP and MtMetAP Ic and it was not reproducible. Figure 4-1 shows the culture plates comparing relative growth of cells harboring plasmids of pFLAG-MtMetAP Ia, pF LAG-MtMetAP Ic, pF LAG-EcMetAP and pFLAG. In the plates, cells with MtMetAP Ia grew much slower than the others. Even after several days, the colonies were smaller than the other cells. It would be of significance to clarify the function of MtMetAP Ia in the pathogenesis of TB. 
Table $4-1^{\text {a }}$ comparison of Kinetic meas ure ment of His MtMetA Ia and MtMetAP Ic

\begin{tabular}{ccccc}
\hline MtMetAP Ia & $\mathrm{Fe}(\mathrm{II})$ & $\mathrm{Ni}(\mathrm{II})$ & $\mathrm{Co}(\mathrm{II})$ & $\mathrm{Mn}(\mathrm{II})$ \\
\hline \hline$k_{\mathrm{cat}}, \mathrm{sec}^{-1}$ & 0.1429 & $0.4779 \pm$ & $0.3719 \pm 0.018$ & $0.062 \pm 0.018$ \\
$k_{\text {cat }} / K_{\mathrm{m}}, \mathrm{M}^{-1} \mathrm{sec}^{-1}$ & \pm 0.0077 & 0.0068 & 5277 & 364 \\
\hline \multicolumn{5}{c}{} \\
959 & 35634 & & \\
\hline MtMetAP Ic & $\mathrm{Fe}(\mathrm{II})$ & $\mathrm{Ni}(\mathrm{II})$ & $\mathrm{Co}(\mathrm{II})$ & $\mathrm{Mn}(\mathrm{II})$ \\
\hline \hline$k_{\text {cat }}, \mathrm{sec}^{-1}$ & $0.0039 \pm$ & $0.029 \pm 0.002$ & $0.027 \pm 0.0004$ & $0.0082 \pm$ \\
$k_{\text {cat }} / K_{\mathrm{m}}, \mathrm{M}^{-1} \mathrm{sec}^{-1}$ & 0.0002 & 301.1 & 122.1 & 0.00033 \\
\hline
\end{tabular}

a Data taken from Table 2-4 in Chapter 2 and Table 3-1 in Chapter 3.
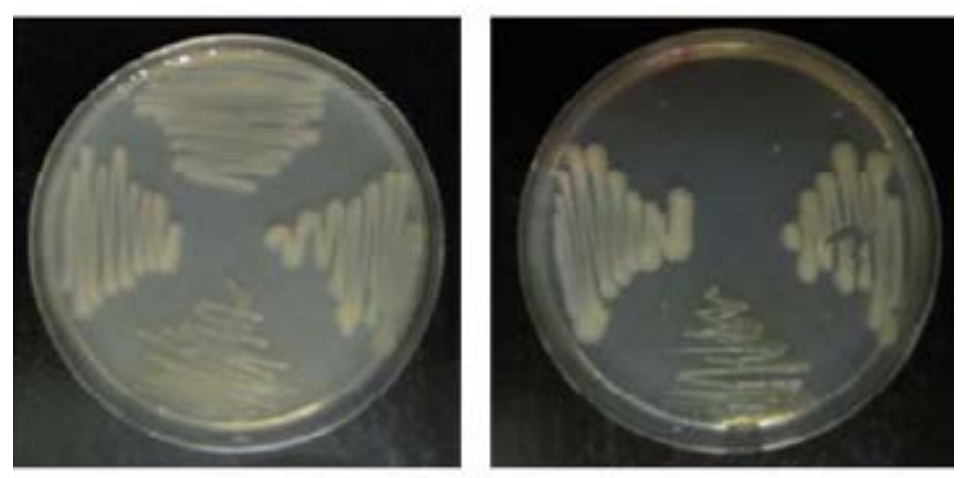

Figure 4-1. Complementation of EcMetAP function by MtMetAP1a.

A. E. coli cells carrying an amber mutation in the chromosomal EcMetAP gene were streaked on agar plates with arabinose (the left plate) or glucose (the right plate). Each plate displays cells containing pFLAGCTC (top), pFLAGCTC-MtMetAP1a (bottom), pFLAGCTC-EcMetAP (left) and pF LAGCTC-MtMetAP1c (right). 
Differences between MtMetAP Ia and MtMetAP Ic have also ben reported in other studies. Zhang et al. investigated the mRNA expression levels of MtMetAP Ia and MtMetAP Ic in the 14-day-old and the 60-day-old cultures of M. tuberculosis H37 Rv [4]. The mapA gene showed a two-fold decrease in the 60-day-old culture compared with the 14-day-old culture; the mapB gene showed a 1.5-fold higher expression in the 60-day-old culture than in the 14-day-old culture. The various transcription levels of the map gene indicate the important functions that MtMetAP Ia and MtMetAP Ic perform in different growth stages. Olaleye et al made a $M$. tuberculosis strains with knocked-down copies of the mapA or mapB ge nes by introducing a plasmid containing either the anti-mapA gene or the anti-mapB gene [5]. Inhibitors from a highthroughput screening of MtMetAP Ic were tested in these knock-down M. tuberculosis strains and compared to a control, in which neither the mapA nor map $B$ genes were down-regulated. The M. tuberculosis with the knock-down of MtMetAP 1a showed decreased cell viability to 76\%. The knock-down of MtMetAP Ic only caused a marginal effect on cell viability. The result suggested that MtMetAP Ia is likely the essential enzyme in cell viability and the observed inhibition on M. tuberculosis growth caused by the inhibitors is through the function of MtMetAP Ia, not MtMetAP Ic. All of these results indicate the essential role that MtMetAP Ia plays in pathogenesis of M. tuberculosis.

The inhibitors that selectively suppress the MtMetAP Ia enzyme in M. tuberculosis would be a help ful tool to achieve our goal of elucidating the role of MtMetAP Ia in tuberculosis pathogenesis. So far, there are no such compounds reported. The inhibitors used in the study of Olaleye et al. were from a high-throughput screening against Co-metalated MtMetAP Ic. They have not identified their inhibitory activities on MtMetAP Ia even though the knock-down experiment indicated the possible inhibition of MtMetAP Ia. The reason may be the relatively 
low yield of MtMetAP Ia and thus the difficulty in obtaining sufficient amount of MtMetAP Ia [4] [5]. Another reason maybe the lack of the knowledge abo ut the func tion of MtMetAP Ia in $M$. tuberculosis when these two studies were carried out. In conclusion, identifying the inhibitors that specifically target MtMetAP Ia, or/and MtMetAP Ic, would facilitate our understanding of the rules of MetAP in M. tuberculosis pa thogenesis in add ition to identifying new pathway for development of ant i-TB agents. 


\section{References}

1. Herring, C.D., Introduction of conditional lethal amber mutations in Escherichia coli. Methods Mol Biol, 2008. 416: p. 323-34.

2. Lu, J.P., S.C. Chai, and Q.Z. Ye, Catalysis and inhibition of Mycobacterium tuberculosis methionine aminopeptidase. J Med Chem, 2010. 53(3): p. 1329-37.

3. Addlagatta, A., et al., Identification of an SH3-binding motif in a new class of methionine aminopeptidases from Mycobacterium tuberculosis suggests a mode of interaction with the ribosome. Biochemistry, 2005. 44(19): p. 7166-74.

4. Zhang, X., et al., Expression and characterization of two functional methionine aminopeptidases from Mycobacterium tuberculosis H37Rv. Curr Microbiol, 2009. 59(5): p. 520-5.

5. Olaleye, O., et al., Methionine aminopeptidases from Mycobacterium tuberculosis as novel antimycobacterial targets. Chem Biol, 2010. 17(1): p. 86-97. 